NBSIR 77-1316

\title{
Performance Criteria Resource Document for Innovative Construction
}

Housing Technology Programs

Office of Housing \& Building Technology

Center for Building Technology

National Bureau of Standards

Washington, D.C. 20234

November 1977

\section{Prepared for}

Department of Housing and Urban Development

Division of Energy, Building Technology \& Standards

Office of Policy Development and Research

Washington, D.C. 20410 



\section{PERFORMANCE CRITERIA RESOURCE \\ DOCUMENT FOR INNOVATIVE CONSTRUCTION}

Housing Technology Programs

Office of Housing \& Building Technology

Center for Building Technology, IAT

National Bureau of Standards

Washington, D.C. 20234

November 1977

Prepared for

Department of Housing and Urban Development

Division of Energy, Building Technology \& Standards

Office of Policy Development and Research

Washington, D.C. 20410

The research and studies forming the basis of this report were conducted under Inter-Agency Agreement No. H-37-72, Task 190, sponsored by the Department of Housing and Urban Development (HUD). The statements and conclusions contained herein are those of the National Bureau of Standards and do not necessarily reflect the technical view or policies of HUD.

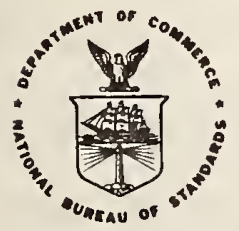

U.S. DEPARTMENT OF COMMERCE, Juanita M. Kreps, Secretary

Dr. Sidney Harman, Under Secretary

Jordan J. Baruch, Assistant Secretary for Science and Technology

NATIONAL BUREAU OF STANDARDS, Ernest Ambler, Acting Director 



\section{ACKNOWLEDGMENT}

The preparation of this resource report, under the direction of the Office of Housing and Building Technology -- Housing Technology Programs, has been a joint effort of members of the National Bureau of Standards' Center for Building Technology and Center for Fire Research - Team members include:

Office of Housing and Building Technology

Thomas K. Faison, Editor

Philip Cramp

Harvey W. Berger

William G. Street

Office of Building Standards and Code Service

Jim Harris

Structures Section

Bruce Ellingwood

Robert Crist

Felix Yokel

Materials and Composites Section

Robert Mathey

Arthur Hockman

Thermal Engineering Section

Thomas Watson

Building Service Section

Robert Wyly

Sensory Environment Section

Thomas Pierce

Program for Fire Control Construction (Center for Fire Research)

Daniel Gross 
Typing, Editing and Preparation by

Susan Ba1derson

Linda Sacchet

Linda Covel1

Vicki Reider

Valuable guidance was given by the professional staff of HUD's Office of Policy Development and Research and through in-depth reviews provided by HUD's Architectural and Engineering Division, Office of Housing. 
Acknowledgment

Abstract

vii

Purpose

Performance Approach

Organization of Materials

13.1.3 Enclosed Spaces - Acoustic Environment 8

13.1.3.1 Control of Noise Levels in Interior Spaces 8

13.2.2 Structure - Fire (Protection and Safety) 9

13.2.2.1 Limited-Combustible Innovative Construction 9 Components

13.2.4 Structure - Strength and Stiffness 10

13.2.4.1 Structural Safety - Resistance to Ultimate Load 10

13.2.4.2 Resistance to Repeated Loads 24

13.2.4.3 Structural Serviceability - Deflections 26

13.2.4.4 Structural Serviceability - Lateral Drift 30

13.2.4.5 Structural Serviceability - Vibrations 33

13.2.4.6 Structural Serviceability - Service Environment 37

13.2.4.7 Serviceability of Floor Surfaces 39

13.2.4.8 Serviceability of Walls 41

13.3.2 Exterior Enclosure - Fire (Protection and Safety) 44

13.3.2.1 Balconies and Porches 44

13.3.2.2 Limited-Combustible Exterior Enclosures 44

13.3.5 Exterior Enclosure - Atmospheric Environment 45

13.3.5.1 Condensation In or On Walls, Roofs, Floors, Windows 45 and Doors

13.3.5.2 Vapor Barrier Roof Decks 46

13.3.6 Exterior Enclosure - Durability/Maintainability $\quad 47$

Joint Sealants

$\begin{array}{lll}13.3 .6 .1 & \text { Hardness } & 47\end{array}$

$\begin{array}{lll}13.3 .6 .2 & \text { Color Change } & 48\end{array}$

13.3.6.3 Rheological Properties 48

13.3.6.4 Hardness After Heat Aging 49 
13.3.6.5 Application Life

13.3.6.6 Weight Loss, Cracking and Chalking Due to Heat

13.3.6.7 Tack Free Time

13.3.6.8 Staining of Substrate by Sealant

13.3.6.9 Joint Sealant Back-up Material Stain and Discoloration 51

13.3.6.10 Peel Adhesion Strength

13.3.6.11 Bond and Cohesion Properties

13.3.6.12 Bubble Formation

13.3.6.13 Tenacity

13.3.6.14 Shrinkage

Roofing Systems - Built-Up Membranes

13.3.6.15 Tensile Strength

13.3.6.16 Thermal Expansion

13.3.6.17 Thermal Movement (Shock Resistance) 56

13.3.6.18 Impact Resistance 56

13.3.6.19 Wind Resistance $\quad 57$

13.3.6.20 Punching Shear Strength 58

13.3.6.21 Flexural Strength 59

13.3.6.22 Permeability 59

13.3.6.23 Tensile Fatigue Strength 60

13.3.6.24 Flexural Strength 60

13.3.6.25 Load Strain Modulus 61

Roofing Systems - Mechanically Fastened

13.3.6.26 Impact Resistance

61

13.3.6.27 Wind Resistance $\quad 62$

Roofing Systems - Elastomeric Membranes

13.3.6.28 Tensile Strength 63

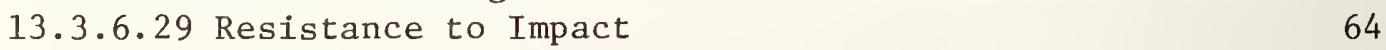

13.3.6.30 Wind Resistance $\quad 64$

13.3.6.31 Deformation Recovery $\quad 65$

13.3.6.32 Adhesion Durability 66

$\begin{array}{ll}\text { 13.3.6.33 Appearance Change : } & 67\end{array}$

13.3.6.34 Curing Time for Liquid Applied Membranes 68

Protective \& Decorative Coatings

$13.3 \cdot 6.35$ Color Change

13.3.6.36 Gloss Change

13.3.6.37 Washability

13.3.6.38 Adhesion Resistance

13.3.6.39 Adhesion

13.3.6.40 Salt Spray Resistance

13.3.6.41 Moisture Resistance

13.3.6.42 Impact Resistance 
TABLE OF CONTENTS (continued)

13.4.2 Interior Enclosure - Fire (Protection and Safety)

$\frac{\text { PAGE }}{74}$

13.4.2.1 Limited-Combustible Components of the Interior

74

Enclosure

13.4.3 Interior Enclosure - Acoustic Environment

13.4.3.1 Acoustic Properties of Interdwelling Walls and 75 Partitions

13.4.3.2 Acoustic Properties of Interdwelling Floor-Ceiling 77

13.4.3.3 Acoustic Properties of Walls and Partitions Within 78 a Living Unit

13.4.3.4 Acoustic Properties of Floor-Ceiling Assemblies Within a Living Unit

13.6.2 Plumbing - Fire (Protection and Safety)

13.6.2.1 Fire Spread

13.6.6 Plumbing - Durability/Maintainability

13.6.6.1 Life Expectancy Design

13.6.6.2 Maintenance of Hydraulic Function by Design 88

13.6.6.3 Long-Term Stability of Dimensions and Strength of 93 Piping

13.6.6.4 Resistance to Sustained Pressure

13.6.6.5 Resistance to Shock Pressure (water hammer)

13.6.6.6 Evaporation Protection in Seldom-Used Traps

13.6.6.7 Freeze Protection

13.6.7 Plumbing - Functional Operation

13.6.7.1 Leak Resistance

13.6.7.2 Adequacy of Flow Rates at Water Outlets 113

13.6.7.3 Hydraulic Capacity of Rainwater Drainage Subsystems 117

13.6.7.4 Hydraulic and Pneumatic Perfömance - DWV Branch 122 Assembly

13.6.7.5 Hydraulic and Pneumatic Performance - DWV Stack and 123 Building Drain Assembly

13.6.7.6 Lateral Deflection and Ring Distortion of Piping 133

13.6.7.7 Noise Reduction Between Spaces Within a Living Unit, 136 Through Walls and Partitions Containing Piping

13.6.7.8 Noise Reduction Between Spaces Within a Living Unit, 137 Through Floor-Ceiling Containing Piping.

13.6.7.9 Noise Level in Interior Spaces During Operation of 138 Plumbing Systems

13.6.7.10 Elution of Toxic Substances 
13.7.1.1 Safety of Eelctrical Components, Designs and Installation

13.7.6 Electrical - Durability/Maintainability

13.7.6.1 Resistance to Deterioration

13.8.6 Hardware and Specialities - Durability/Maintainability

13.8.6.1 Functional Life of Hardware

13.8.7 Hardware and Specialities - Functional Operation

13.8.7.1 Functiona1 Capatibility

13.9.7 Appliances - Functional Operation

13.9.7.1 Performance of Appliances 
ABSTRACT

Performance criteria for innovative construction are presented in this resource report in order to assist in the broad technical acceptance of new building products and materials. The levels of performance stated are intended to be equivalent to the Minimum Property Standards (MPS) which reflects acceptable performance of conventional building materials and designs for programs sponsored by the Department of Housing and Urban Development. The report is structured so that new performance criteria can be added in the future as additional technical data and evaluation methods become available.

Key Words: acoustics; appliances; atmospheric environment; durability; electrical; housing technology; HVAC; maintainability; materials; minimum property standards; performance criteria; performance evaluation; plumbing safety; innovative construction; structures; test methods. 

This resource report is intended to provide guidance to the Department of Housing and Urban Development in developing performance criteria which may be used to supplement the Minimum Property Standards (MPS) in the acceptance of new building technologies.

This document recommends performance criteria and methods of evaluation. A commentary relates to the intent, derivation and application of the criteria and methods of evaluation. A sound basis must be established for making the judgment relative to acceptable performance of new and innovative products or systems. The levels of performance recommended in this document are intended to be comparable to the requirements of the Minimum Property Standards for conventional construction.

This document for the most part presents what is currently considered to be the best guidance for performance evaluation based on available technology. However, because of the need for comparability with the Minimum Property Standards, the most advanced technology may at times not be reflected in these guidelines.

These criteria should be considered supplemental to the MPS since the performance requirements which have already been established in the MPS are not duplicated herein. Therefore, these criteria should not be used alone when considering total system performance. In addition, the current state of technology does not yet permit establishing performance criteria for all aspects of building construction, products and systems. 
The ideal in presenting performance criteria is to state the performance necessary to achieve the intended function without stating the material composition or physical construction. Relevant attributes for the building system, or subsystem, have been identified and requirements, in the form of design criteria, have been presented in performance language along with the recommended levels of performance.

For each building subsystem/attribute the order of performance presentation is Criterion, Method of Evaluation and, where appropriate, Commentary. The Criterion states a precise measure used to judge whether a performance requirement (attribute) has been satisfied and recommends the level of performance deemed acceptable for compliance. The Method of Evaluation states the methodology by which the subsystem will be evaluated for demonstrating that the criterion has been satisfied. Where appropriate a Commentary is included to assist in clarifying the intent, methodology or implementation of either the Criterion or Method of Evaluation.

The current state of knowledge for application of the performance concept is not sufficient for complete coverage of all aspects of housing construction. Traditionally, performance levels are implicit in prescriptive specifications which describe acceptable materials and designs. In this document a number of criteria are still prescriptive, yet the basis for the stated limits for prescriptive criteria have been derived from actual user requirements. There are other areas where little research has been done and the information at hand is so materials oriented that performance criteria, flexible enough to allow new materials, 
have not yet been generated. In areas where the state-of-the-art does not allow realistic presentation of performance criteria, reliance is placed on existing standards. These, then, are not considered complete, and as the state-of-the-art of the performance concept advances, modifications or additions to these criteria will need to be made. 


\section{ORGANIZATION OF MATERIAL}

To assure that coverage is given to the major building elements, a matrix is used which identifies the various subsystems of the total building system along with the various attributes required for acceptable performance of the subsystems. The user can identify specific subsystem(s) and attribute(s) and locate the intercept within which are presented supplemental performance criteria. The text of the document is organized into nine Parts: 13.1-13.9, one Part for each of the primary SUBSYSTEMS. Each of the Parts has sections which correspond to the ATTRIBUTES. The designation (13) was used to identify with Division 13 of the MPS. The SUBSYSTEMS and ATTRIBUTES are listed and defined below as follows:

\section{SUBSYSTEMS}

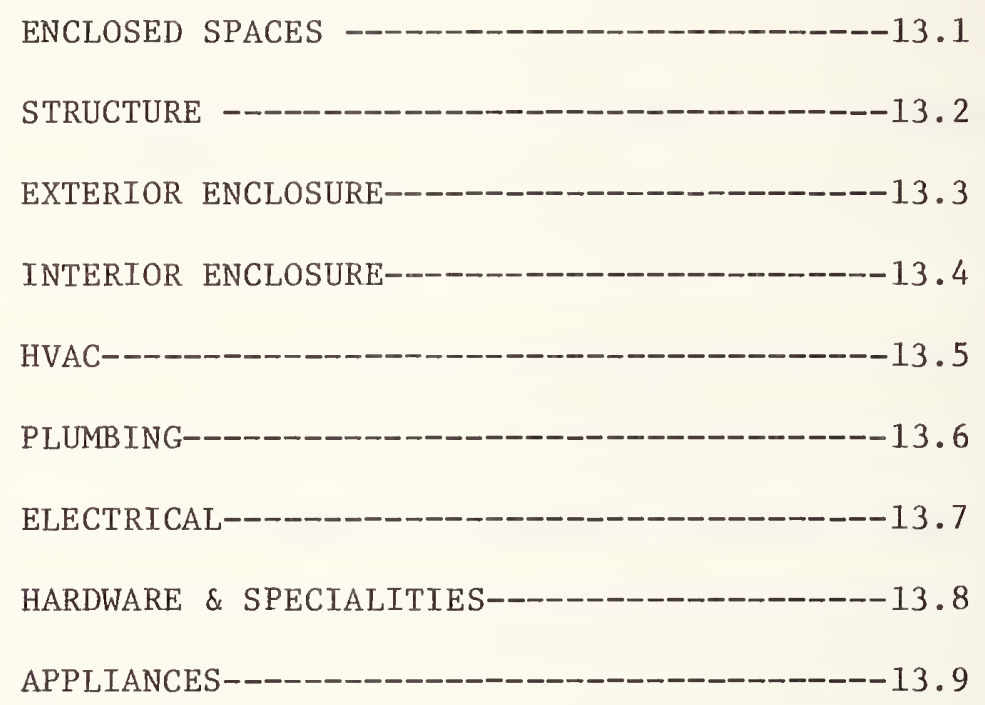

\subsection{ENCLOSED SPACES}

Those spaces created as a result of arranging the living unit into discrete areas by the user of interior enclosures. 


\subsection{STRUCTURE}

Those portions of the building system which support loads from other parts of the building and any other elements that because of their position, mass, or other property might be a safety hazard if failure occurs.

\subsection{EXTERIOR ENCLOSURE}

That portion of the building system which separates the interior space from the exterior environment.

\subsection{INTERIOR ENCLOSURE}

That portion of the building system not exposed to the exterior environment which separates the spaces within the living unit.

\subsection{HVAC}

The system and equipment for providing the required environmental conditions within the living unit with respect to temperature, humidity, air movement and air quality.

\subsection{PLUMBING}

The system and equipment for the supply of domestic water or gas and the removal of liquid-borne waste products.

\subsection{ELECTRICAL}

The system and equipment for the supply and distribution of electrical energy throughout the living unit.

\subsection{HARDWARE AND SPECIALITIES}

Those products and equipment which are incorporated into the building system, such as locks, hinges, communication, equipment, trash removal, etc. 


\subsection{APPLIANCES}

Those preassembled manufactured products which support human

activity, such as cooking, food preparation and storage, laundering, food waste disposal, etc.

\section{ATTRIBUTES}

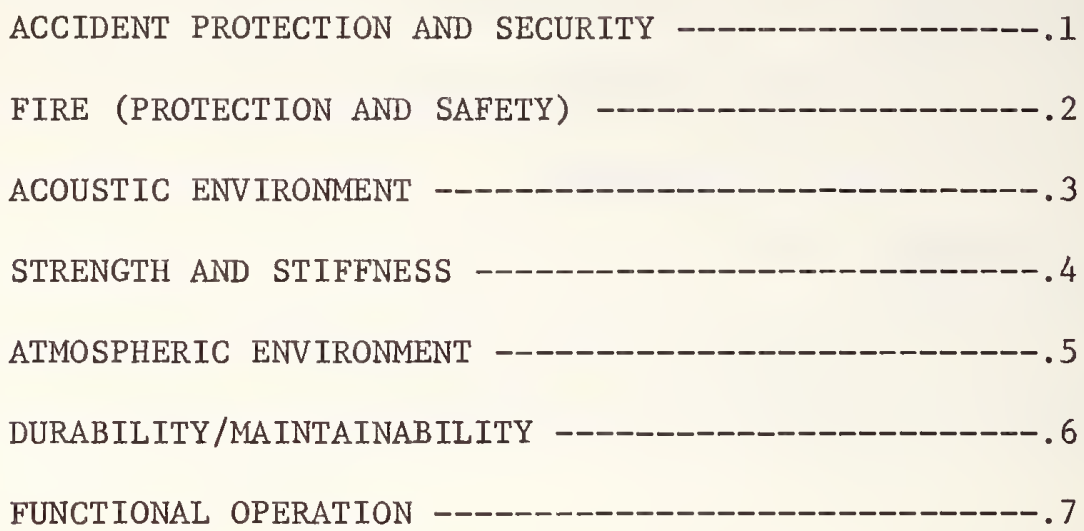

\section{.1 ACCIDENT PROTECTION AND SECURITY}

The prevention of household accidents as a result of normal occupant activities and protection from criminal acts through attention to design.

.2 FIRE (PROTECTION AND SAFETY)

The provisions for protection of the occupants and the building system from unwanted fire and combustion products.

\section{.3 ACOUSTIC ENVIRONMENT}

The levels of sound transmitted either through air or through the building system to the occupant.

.4 STRENGTH AND STIFFNESS

The ability of the building system to support and/or transmit the design loads without excessive deformation, vibration or collapse. 


\section{.5 ATMOSPHERIC ENVIRONMENT}

The conditioning of spaces bounded by the exterior enclosure for their intended use.

.6 DURABILITY/MAINTAINABILITY

The useful life of materials and assemblies when exposed to the environment, or characteristics which permit access for routine maintenance and/or servicing.

.7 FUNCTIONAL OPERATION

The ability of the particular subsystem to provide an acceptable level of performance for its' intended operation.

\section{EXAMPLE FOR USE OF THIS DOCUMENT:}

If one is interested in the performance criteria for "limited-combustible structural components" the procedure would be:
1) Structure - 13.2 See Page 9
2) Fire (Protection \& Safety) - 13.2.2 - - - See Page 9
3) Limited-Combustible - 13.2.2.1 - - 9 


\subsection{ENCLOSED SPACES}

\section{.3 ACOUSTIC ENVIRONMENT}

\subsubsection{Criterion: Control of Noise Levels in Interior Spaces}

Noise in interior spaces shall not exceed an A-weighted level of $45 \mathrm{~dB}$ resulting from interior sources such as heating, plumbing, and air conditioning.

Noise levels in interior spaces shall be kept below levels which will cause discomfort or annoyance to the occupants. Each subsystem shall perform its intended function without excessive noise generation or degradation of the acoustical performance of other subsystems. Required exterior-shell attenuation will be dependent upon ambient noise characteristics of specific cases.

\section{Method of Evaluation for 13.1.3.1}

Measurements sha11 be in accordance with ANSI S1.13-1971, "Standard Methods for the Measurement of Sound Pressure Levels." (Sound levels resulting from interior building sources shall be read on a meter with a fast-response characteristic and weighted on the A-scale as defined for Sound Level Meters). 


\subsection{STRUCTURE}

\section{.2 FIRE (PROTECTION AND SAFETY)}

\subsubsection{Criterion: Limited-Combustible Innovative Construction Components}

Structural components, defined as limited-combustible, shall have a potential heat no greater than $3500 \mathrm{Btu} / 1 \mathrm{~b}$. This is in addition to flame spread and fire resistance ratings of MPS Section 405, Fire Protection.

Method of Evaluation for 13.2.2.1

The potential heat test method described in NFPA 259 "Standard Test Method for Potential Heat of Building Materials 1976" will be used. These components shall also meet the requirements of NFPA 220-1975, for materials defined as limited-combustible. 


\subsection{STRUCTURE}

\section{.4 STRENGTH AND STIFFNESS}

The following criteria are presented to assure the safety and serviceability of building structures. The performance of structures is most clearly defined in terms of limit states; at such states, the behavior of the structure causes loss of safety or serviceability. The first two criteria deal with ultimate limit states, that is, the loss of safety from collapse of the structure under two different loading environments: the maximum load reasonably expected during the lifetime of the structure and the loads which are expected to be repeated many times during the life of the structure. Note that the word structure is taken to mean all portions of a building that support loads from other parts of the building and any other elements that because of their position, mass, or other property might be a safety hazard if they failed.

The next four criteria deal with functional limit states, that is, the serviceability of building structures under normal usage. Serviceability is a concept which includes maintainability and durability as well as preserving the comfort and confidence of human occupants.

The last two criteria deal with the serviceability of floor and wall surfaces. They are presented to measure the ability of floors and walls made from innovative materials to withstand normal loadings from occupants and interior furnishings.

\subsubsection{Criterion: Structural Safety - Resistance to Ultimate Load}

The factored ultimate strength $\mathrm{R}^{*}$ of all structural members and connections shall exceed the factored ultimate load $\mathrm{U}^{*} . \mathrm{R}^{*}$ and $\mathrm{U}^{*}$ shall 


\subsection{STRUCTURE}

\section{.4 STRENGTH AND STIFFNESS}

\subsubsection{1 (Continued)}

be determined according to the Method of Evaluation below.

\section{Method of Evaluation for 13.2.4.1}

a) Additive Loads - When the load effects are additive, U* shall be evaluated as:

$$
\mathrm{U}^{*}=1.1 \overline{\mathrm{D}}+1.45\left[\overline{\mathrm{Q}}+\sum \Psi_{i} \overline{\mathrm{F}}_{i}\right]
$$

in which

$$
\overline{\mathrm{D}}=\text { Dead load, as determined in MPS 601-3. }
$$$$
\bar{Q}=\text { mean (see definition of mean below) maximum variable load, }
$$
evaluated as described below.

$\Psi_{i} \bar{F}_{i}=$ mean transient load(s) acting simultaneously with $\bar{Q}$, as described below.

Definition of Mean (or expected value):

The mean of a random variable describes its central tendency and is often the value about which scatter occurs when repeated observations of the variable are made.

$\bar{Q}$ shall be any one of the following and $\bar{F}_{i}$ shall be each of the remaining, as appropriate:

$1.25 \mathrm{~L}$ where $\mathrm{L}$ is the live load from MPS $601-4$ or the railing load from MPS 601-7

$1.2 \mathrm{~S}$ where $\mathrm{S}$ is the snow load from MPS 601-5

$1.0 \mathrm{H}$ where $\mathrm{H}$ are the soil and hydrostatic pressure loads from MPS $601-8$ 


\subsection{STRUCTURE}

\section{.4 STRENGTH AND STIFFNESS}

\subsubsection{1 (Continued)}

$0.85 \mathrm{~W}$ where $\mathrm{W}$ is the wind load from MPS 601-6

$1.4 \mathrm{E}$ where $\mathrm{E}$ is the earthquake load from MPS 601-9

1.0 $\mathrm{T}$ where $\mathrm{T}$ is the constraint load arising from differential settlements of foundations and from restrained volume change due to temperature changes, shrinkage, creep, and similar effects. Also see paragraph 13.2.4.1(d).

$\Psi_{i}$ shall be determined from the following table:

\begin{tabular}{|c|c|c|c|c|c|c|}
\hline$F_{i}$ & $L$ & $S$ & $H$ & $W$ & $E$ & $T$ \\
\hline$\Psi_{i}$ & 0.65 & 0.25 & 1.0 & 0 & 0 & 1.0 \\
\hline
\end{tabular}

b) Counteracting Loads

Where the effect of a maximum variable load is counteracted by other loads, U* shall be evaluated as,

$$
\mathrm{U}^{*}=1.55 \overline{\mathrm{Q}}-\left(0.8 \overline{\mathrm{D}}+0.4 \sum \Psi_{i} \overline{\mathrm{F}}_{i}\right)
$$

where $\bar{D}, \bar{Q}, \bar{F}_{i}$ and $\Psi_{i}$ are as in $13.2 .4 .1(\mathrm{a})$

c) Load Effects

The load effects on individual members and connections shall be determined by standard means of structural analysis, taking equilibrium, geometric compatibility, and both short and long term material properties into account. Members made of materials which tend to accumulate residual deflections under repeated loads shall be analyzed with the added eccentricities expected to occur during the life of the structure. 


\subsection{STRUCTURE}

\section{.4 STRENGTH AND STIFFNESS}

\subsubsection{1 (Continued)}

d) Foundation Settlements

Foundation settlements shall be explicity allowed for by considering a differential foundation settlement of $11 / 2$ inches in any horizontal distance of 50 feet in determining $\overline{\mathrm{T}}$, except that in cases where a particular foundation is specifically designed to control differential settlements, the differential settlements used for $\mathrm{T}$ should be those consistent with the specified design.

\section{e) Factored Resistance}

The factored ultimate resistance $\mathrm{R}^{*}$ shall be evaluated as

$$
\mathrm{R}^{*}=\phi \overline{\mathrm{R}}
$$

in which

$$
\begin{aligned}
\overline{\mathrm{R}}= & \text { mean, or best estimate, of the resistance of the structure } \\
& \text { or its components in service. } \\
\phi= & \text { resistance factor which depends on the coefficient of variation } \\
& (\mathrm{c.o.v.}) \text { in } \mathrm{R}, \mathrm{V}_{\mathrm{R}} \text {, and the ductility, } \mu \text {, as follows: }
\end{aligned}
$$

Design Resistance Factor,

\begin{tabular}{c|c|c}
\hline$V_{R}$ & 2 or less & 5 or more \\
\hline 0.10 & 0.70 & 0.78 \\
0.20 & 0.50 & 0.63 \\
0.30 & 0.35 & 0.48
\end{tabular}

For intermediate values of $V_{R}$ and $\mu, \phi$ may be obtained by linear interpolation. The coefficient of variation of a random variable is its 


\subsection{STRUCTURE}

\section{.4 STRENGTH AND STIFFNESS}

\subsubsection{1 (Continued)}

standard deviation divided by its mean; the standard deviation is a measure of the scatter exhibited by repeated observations of the variable.

$\bar{R}, V_{R}$, and $\mu$ shall be determined as indicated in paragraphs 13.2.4.1(f) through $13 \cdot 2 \cdot 4 \cdot 1(\mathrm{~h})$.

\section{f) Mean Resistance}

Where adequate test data on the various material properties comprising the system are available, evaluation of the resistance will be performed using engineering analysis. Where adequate test data are unavailable, system elements and subassemblies will be evaluated in the laboratory using simulated static load levels consistent with the specified load combinations. Test conditions shall simulate those aspects of the service environment that might adversely affect the behavior of the structure.

g) Variability in Resistance

$\mathrm{V}_{\mathrm{R}}$ shall be determined as

$$
V_{R}=\left[V_{M}^{2}+V_{F}^{2}+V_{P}^{2}\right]^{1 / 2} \geqq 0.10
$$

Where

$V_{M}$ is the c.o.v. in material strength relevant to the limit state of the component considered (i.e., yield or tensile strength, compression strength, etc.)

$V_{F}$ is the c.o.v. attributable to fabrication, arising from dimensional variations in components and tolerances in the assembly of those components. $V_{F}$ shall not be taken less than 0.05 . 


\subsection{STRUCTURE}

\section{.4 STRENGTH AND STIFFNESS}

\subsubsection{1 (Continued)}

$\mathrm{V}_{\mathrm{P}}$ is the c.o.v. associated with the ability to predict the component capacity when all variables in the corresponding analytical model are precisely known. $V_{P}$ shall not be taken less than 0.05 .

Coefficients of variation shall be determined in accordance with standard methods of statistical analysis using existing test data on materials comprising the system and laboratory tests conducted during the development and acceptance stages for innovative structural elements and subassemblies.

\section{h) Ductility}

The ductility is defined as the ratio of maximum obtainable deflection to yield deflection for structures with load-deformation relations (not stress-strain relations) that exhibit a relatively definite yield point. For structures that do not have such relations, $\mu$ is calculated from an effective function (Figure 1) consisting of two straight lines. The first line is drawn through the origin and a point on the actual function at which the resistance is 60 percent of its maximum load value $\left(P_{u}\right)$. The second line is a horizontal line ending at the ultimate deflection $\left(\mathrm{d}_{\mathrm{u}}\right)$, which shall not exceed the value where the resistance function falls below 95 percent of its maximum load value. The horizontal line is located so that the area under the two lines forming the effective function is equal to the area under the actual function up to the point of ultimate deflection. Effective yield deflection ( $\mathrm{d}_{\mathrm{ye}}$ ) shall be taken as the deflection at the point of intersection of the two lines, which is at a 


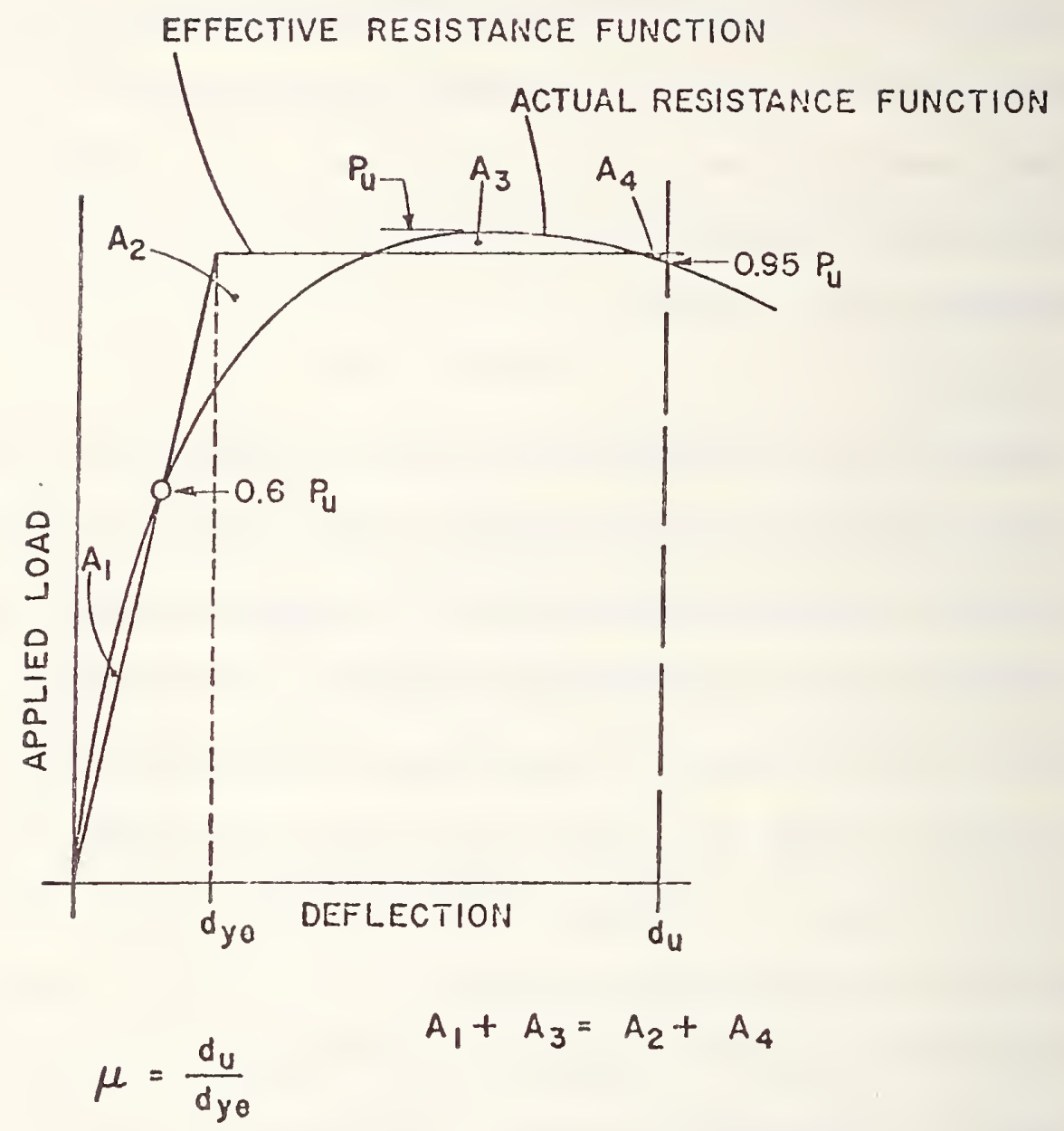

FIGURE 1 DETERMINATION OF TIE DUCTILITY FACTOR 


\subsection{STRUCTURE}

\section{.4 STRENGTH AND STIFFNESS}

\subsubsection{1 (Continued)}

resistance level termed "effective yield resistance." The ductility factor is based on the effective resistance ratio: $\mu=d_{u} / d_{y e}$.

Commentary for 13.2 .4 .1

This criterion is intended to apply to all portions of a building that serve a structural function. This includes a11 elements and connections that support loads from other parts of the building, and any other elements that because of their own position, mass, or other property might be a safety hazard if they failed. Thus items like parapets are included because of the consequence of their failure, and items like hangers and inserts are included because they support other loads. This criterion is not intended to guard against damage or failure arising from gross human errors or flagrant abuse.

Criteria governing the performance of a structure can be clearly defined in terms of its various limit states. Ultimate limit states are those corresponding to the maximum load-carrying capacity of the structure, and include loss of equilibrium of a portion of the structure, gross inelastic deformation of critical sections and instability failures, and it is to avoid these limit states that Criterion 13.2.4.1 is given.

Decisions regarding structural safety are invariably made in the presence of uncertainties which arise from basic randomness in many of the resistance and load parameters as well as imperfect modeling and information. Indeed, it is these uncertainties which motivate and neces- 


\subsection{STRUCTURE}

\section{.4 STRENGTH AND STIFFNESS}

\subsubsection{1 (Continued)}

sitate the use of safety factors in design. In the past, such factors have been arrived at subjectively. However, the recent trend to use probabilistically derived resistance and load factors in structural design represents an attempt to proportion members and connections so that the probability of attaining any limit state is acceptably sma11.

The basic idea is the following. A mathematical model is derived which describes the limit state of interest. In general, this model may be described as a function of load and resistance random variables $\underset{\sim}{\mathrm{X}}$, say $g(X)$, and the condition of structural safety is given as $g(\underset{N}{X})>0$. The measure of reliability is measured by the probability of not achieving the limit state. An alternative but equivalent measure of reliability is given by $[1] *$

$$
\bar{g}(X)-\beta \sigma_{g(X)}>0
$$

where $\bar{g}$ and $\sigma_{g}$ are mean and standard deviation of $g$, and $\beta$ is termed the safety index. Intuitively, as $\beta$ increases the level of reliability increases. It may be shown that $\bar{g}$ and $\sigma_{g}$ may be evaluated, to first order, using the means and coefficients of variation of $\underset{\sim}{X}$ (Coefficients of variation provide a convenient dimensionless measure of uncertainty.) Moreover, an appropriate factor $\beta$ for design may be determined by calibration with existing design criteria; studies have shown that for ultimate limit states, $\beta \simeq 3$ for ductile steel [2] and concrete [3] structures. With this information, load and resistance factors can be derived which are functions of the level of safety and the uncertainty in the resistance *See reference list at end of each section 


\subsection{STRUCTURE}

.4 STRENGTH AND STIFFNESS

\subsubsection{1 (Continued)}

(or load) parameters and in which a level of reliability is achieved in the ultimate limit states which is basically consistent with that currently obtained with design using conventional materials and construction methods. However the factor assigned to each variable is directly related to the uncertainty associated with it and the total factor of safety is correctly apportioned to the various terms in the design equation. Since the load and resistance factors are weakly coupled, one set of material independent load factors has been derived for use herein.

The analysis of uncertainties clearly plays an important role in this development. As these depend on imponderables which may affect design safety, they would include not only inherent statistical variability but also sources due to imperfect or incomplete modeling and information [4]. Thus, an examination of the mathematical models describing resistance and a comparison of predicted and observed values, in addition to the usual material strength tests, is generally required in order to evaluate $V_{R}$. (A similar analysis has already been performed in order to evaluate the uncertainties in load terms, which are assumed to be material-independent.) Thus, there is a clear economic motivation to reduce $V_{R}$ through additional analysis and data acquisition, since the $\phi$ factor can then be increased according1y .

When physical testing is done to establish values for the resistance, care should be taken to assure that all significant interactions with other positions of buildings and environmental effects are properly accounted for. 


\subsection{STRUCTURE}

\section{.4 STRENGTH AND STIFFNESS}

\subsubsection{1 (Continued)}

For example, when testing single stories of high rise buildings, the effect of lateral drift above the story in question should be added to the loads. Possible environmental factors that may be important include temperature, moisture, ultraviolet light and atmospheric pollution. The resistance to long term sustained loads and to repeated loads are frequently important, and fatigue is covered in another criterion in this document.

The seriousness of attaining a limit state in terms of either danger or economic loss can be reflected in a rational way by increasing the safety index used in deriving the load and resistance factors. In deriving $\phi$ for brittle materials, $\beta$ has been increased from 3 to 4 . (In order to simplify the design criteria, the load factors have been constrained to be the same as for $\beta=3$ in spite of the fact that, in a strict sense, they are also functions of $\beta$. ) This increase in $\beta$ implies a decrease of over one order of magnitude in design risk, a reflection of the increase in safety desired because of the lack of warning given prior to brittle failure. It should be noted that many structural connections would fall in this category.

The format chosen to evaluate $U$ in criterion 13.2 .4 .1 is similar to one under consideration by CEB (European Concrete Committee) and other organizations in Europe [5]. The maximum total load on a structure or component during its life (herein taken as about 60 years) may result from any one of many different possible load combinations. It has been found that since the probability of a joint occurrence of two or more 


\subsection{STRUCTURE}

\section{.4 STRENGTH AND STIFFNESS}

\subsubsection{1 (Continued)}

extreme loads is negligible, the maximum total load effect results when one variable load assumes its maximum lifetime value $Q$ while others are at their instantaneous values $\Psi_{i} F_{i}[5,6]$. Thus, the individual loads under consideration must be rotated in the load equation, each load taking the position of the maximum mean variable load $\bar{Q}$, while the remaining loads are assigned the value $\Psi_{i} \bar{F}_{i}$, representing the likely value of short-term load $i . \Psi_{i}$ is less than unity because the mean instantaneous load is less than the maximum load. Furthermore, the probability of a joint occurrence of some of the loads is essentially zero, and in these cases the appropriate $\Psi$ value is also zero. For example, wind load is not combined with maximum snow load, since the presence of structurally significant wind prevents development of the maximum snow load. The appropriate wind-snow load combination would be maximum wind + instantaneous snow, as indicated by the $\Psi$ factors given in Method of Evaluation for 13.2.4.1(a). While the $\Psi$ factors have a reliability basis, they also rely in part on subjective judgment.

The criteria are given simply in terms of maximum mean loads to eliminate the need to also specify instantaneous load values. While these mean values will become directly available as additional load data are gathered and thoroughly analyzed [8,9], for the present they must be related to the usual loads specified in ANSI A58.1-1972 [7], MPS [10], and other standards. The conversion factors in 13.2.4.1(a) establish this relation utilizing recent live load survey data and wind engineering 


\subsection{STRUCTURE}

\section{.4 STRENGTH AND STIFFNESS}

\subsubsection{1 (Continued)}

research. Where data are not available, the mean and nominal loads may be assumed to be identical.

It should be noted that combining effects from several loads is not always a simple task, and the formula given for combinations in this document must be used with some judgment. For example, it may be possible for some materials to relieve the effect of constraint loads through creep or by yeilding. Thus for some ductile materials, it would not be necessary to consider constraint loads acting sumultaneously with earthquake loads because the structure would be expected to yield during the earthquake.

\section{References}

1. Hasofer, A., Lind, N., "Exact and Invariant Second-Moment Code Format," J. Eng. Mech. Div., ASCE, Vol. 100 No. ST1, Feb. 1974, pp. 111-121.

2. Galambos, T.V., Ravindra, M., "Tentative Load and

Resistance Factor Design Criteria for Steel Buildings," Structural

Division Research Report No. 18, Washington University, St. Louis, Mo., Sept. 1973.

3. Ellingwood, B., "Reliability Basis for Load and Resistance Factors for Reịnforced Concrete Design," paper in preparation.

4. Ang, A.H. -S., Corne11, C.A., "Reliability Bases of Structural Safety and Design," J.Str. Div., ASCE, Vo1. 100, No. ST9, Sept. 1974.

5. Comite Eurointernational du Beton, "Bulletin D'Information No. 116," Paris, November 1976. 


\subsection{STRUCTURE}

\section{.4 STRENGTH AND STIFFNESS}

\subsubsection{1 (Continued)}

6. Turkstra, C., "Theory of Structural Design Decisions," Solid Mech. Study No. 2, University of Waterloo, 1970.

7. American National Standards Institute, "Building Code Requirements for Minimum Design Loads in Buildings and Other Structures (ANSI A58.1-1972)."

8. Culver, C., "Survey Results for Fire Loads and Live Loads in Office Buildings," National Bureau of Standards, Building Science Series 85, Washington, D.C., May 1976.

9. Marsha11, R.D., Crist, R.A., "Measurements of Wind Loads and TieDown Forces on Mobile Homes," Proc. Eighth Joint Mtg., U.S.-Japan Panel on Wind and Seismic Effects, Washington, D.C., May 1976.

10. "Minimum Property Standards for One and Two Family Dwellings (1973 Ed.)," U.S. Department of Housing and Urban Development, Washington, D.C. 


\subsection{STRUCTURE}

\section{.4 STRENGTH AND STIFFNESS}

\subsubsection{Criterion: Resistance to Repeated Loads}

Structural elements shall be capable to resisting repeated loads which are anticipated in service without failure or visible cracking, but in no case shall these repeated loads be taken as less than 500 cycles from $\bar{D}$ to $\overline{\mathrm{D}}+1 / 2 \overline{\mathrm{Q}}$ where $\bar{Q}$ is defined in Criterion 13.2 .4 .1 .

Method of Evaluation for 13.2.4.2

When evaluated by means of physical simulation, cyclic loading shall be applied after reducing system "slack" by prior application of one preloading cycle of $\overline{\mathrm{D}}+\overline{\mathrm{Q}}$. Cyclic loading shall commence only after deflection recovery from the pre-loading cycle is complete.

\section{Commentary for 13.2 .4 .2}

The behavior of structural elements subjected to repeated loading depends on the fatigue response characteristics of the particular material used and the cyclic load history. There is a roughly linear logarithmic relation between applied stress range and the number of cycles required to initiate damage or failure, with the number of cycles increasing as the stress range decreases. Sources of low-amplitude cycling arise primarily from wind loads, but may also be caused by variation in other loads. Unfortunately, this loading history is generally unknown for residential buildings, making the direct application of fatigue analysis methods difficult.

In order to write a material-independent criterion, it has thus been necessary to assume that any material suitable for structural applications 


\subsection{STRUCTURE}

\section{.4 STRENGTH AND STIFFNESS}

\section{2 .4 .2 (Continued)}

be capable of at least resisting a constant amplitude cycling stress range of 10 percent of its ultimate strength without initiating visible damage within 1 million $\left(10^{6}\right.$ ) cycles. (If it can be later demonstrated that this corresponds to too severe a load spectrum, the criterion can be relaxed accordingly.) The full loading history obviously cannot be simulated economically; however, utilizing the (logarithmically) linear relation between stress range and cycles, the 500 cycles from $\bar{D}$ to $\bar{D}+1 / 2 \bar{Q}$ is an equivalent requirement. 


\subsection{STRUCTURE}

\section{.4 STRENGTH AND STIFFNESS}

\subsubsection{Criterion: Structural Serviceability -- Deflections}

Transverse deflections of structural members, including floors, roofs, partitions, and exterior walls, shall not exceed the following limits:

(1) The total short term deflection due to the service load U, shall not exceed $\ell / 240$ where $\ell$ is the member length;

(2) The total long term deflection due to the service load U, and the effects of creep under sustained load and accumulated inelastic deflections shall not exceed $\ell / 180$;

(3) For members attached to brittle materials such as plaster, that portion of the long term deflection that occurs after the attachment sha11 not exceed $\ell / 360$;

where the service load $U$ is the mean value of the maximum load which acts on the structure during its lifetime (to be distinguished from the factored ultimate design load, U*).

Method of Evaluation for 13.2.4.3

a) Service Load

The service load shall be:

$$
\mathrm{U}=\overline{\mathrm{D}}+\overline{\mathrm{Q}}+\sum \Psi_{i} \overline{\mathrm{F}}_{i}
$$

where $\bar{D}, \bar{Q}$, and $\bar{F}_{i}$ are as defined in Criterion 13.2.4.1 except that earthquake load need not be considered. $\Psi_{i}$ shall be determined from the following table: 


\subsection{STRUCTURE}

\section{.4 STRENGTH AND STIFFNESS}

\subsubsection{3 (Continued)}

\begin{tabular}{|c||c|c|c|c|c|c|}
\hline$F_{i}$ & L & $S$ & $H$ & $W$ & $E$ & $T$ \\
\hline$\Psi_{i}$ & 0.40 & 0.25 & 1.0 & 0 & 0 & 1.0 \\
\hline
\end{tabular}

\section{b) Deflection and Length}

The transverse deflection is the movement of a point on a member in

a direction perpendicular to the member. The length, $\ell$ of a member is defined as the center-to-center spacing of supports or the clear span plus the depth of the member, whichever is shorter. When a member acts as a two-way panel, the shorter direction shall be used for $\ell$. For systems that consist of joists supported by beams, the total deflection at the center of a bay shall also be checked by considering the diagonal distance across the bay as the member length.

\section{c) Deflection Test}

In lieu of analysis based on actual performance data, compliance with the Criterion may be demonstrated by testing representative members with the following procedure: The superimposed load (U less the self weight) is applied for 24 hours and then removed, and the associated deflections are measured immediately after the load is applied $\left(d_{1}\right)$ and immediately before it is removed $\left(d_{2}\right)$. Then, the residual deflection $\left(d_{3}\right)$ is measured at least 24 hours after the load is removed. These deflections shall meet the following conditions:

(1) $\mathrm{d}_{2} \leqq 1.25 \mathrm{~d}_{1}$

(2) $\mathrm{d}_{2} \leqq \ell / 360$ if the member is to be attached to brittle material or $\ell / 240$ otherwise. 


\subsection{STRUCTURE}

\section{.4 STRENGTH AND STIFFNESS}

\subsubsection{3 (Continued)}

(3) $\mathrm{d}_{3} \leqq 0.25 \mathrm{~d}_{2}$ or $\ell / 4000$, whichever is greater.

One preloading cycle is permissible, provided that the deflection recovery from the preloading cycle is substantially complete before the test load is applied.

\section{Commentary for $13 \cdot 2 \cdot 4 \cdot 3$}

The deflection limitations are empirically formulated to fulfill the requirement for structural serviceability [1]. Excessive deflections have been known to have the following effects:

(1) Damage to elements that permanently impair their performance or lead to deterioration.

(2) Damaging transfer of load to nonload-supporting elements.

(3) Ponding of water that the structure is not designed to support.

(4) Interference with or disruption of the operation of service subsystems.

(5) Unacceptable changes in the appearance of any part of the building.

(6) Visually objectionable deflections unless the design provides for these deflections.

If it can be demonstrated that proper performance is obtained and none of the negative effects occur, the empirical limit may be modified.

It should be emphasized that $d_{1}, d_{2}$, and $d_{3}$ refer to net deflections 


\subsection{STRUCTURE}

\section{.4 STRENGTH AND STIFFNESS}

\subsubsection{3 (Continued)}

which are measured from a position at which some deflection due to the selfweight of the structure may have already occurred. The deflection limits apply to structural elements as a whole, and not to components of built up elements, such as skins supported by ribs.

The requirement of 75 percent recovery of deflection stated in Method of Evaluation 13.2.4.3(c) guards against special or innovative structural systems having significant residual deflection increases in each cycle of loading that may lead to incremental collapse. By permitting residual deflections of 25 percent of initial deflection, reasonable tolerance is provided for creep. The 75 percent recovery requirement is relaxed for very stiff structural systems $(\underset{v}{d} \leqq \ell / 4000)$, since there are invariably some small irrecoverable deformations in all structures.

\section{Feference:}

1. Galambos, T.V., et. a1., "Structural Deflections: A Literature and State-of-the-Art Survey," National Bureau of Standards, Building Science Series 47, Washington, D.C. October 1973. 


\subsection{STRUCTURE}

\section{.4 STRENGTH AND STIFFNESS}

\subsubsection{Criterion: Structrual Serviceability -- Lateral Drift}

Lateral drift of structures under the influence of service loads, $U$, as stated in 13.2.4.3(a) shall not cause collision with adjacent structures nor exceed the following limits:

(1) Total drift due to wind ( $\bar{W}$ used as $\bar{Q})$ shall not exceed $h / 500$ and the maximum drift in any single story sha11 not exceed $\ell / 240$ where $\mathrm{h}$ is building height and $\ell$ is story height.

(2) Total drift due to earthquake ( $\overline{\mathrm{E}}$ used as $\bar{Q}$ ) sha1l not exceed $\mathrm{h} / 200$.

Method of Evaluation for 13.2.4.4

Drift due to wind or earthquake shall be calculated by standard analytical means or demonstrated by physical tests. Second order effects ("P-delta) shal1 be included when they increase the first order deflections by $10 \%$ or more.

Commentary for 13.2 .4 .4

In applying the provisions the stiffening effect of non-load supporting elements such as partitions and in-filled walls may be included if substantiating information regarding their effect on the response is available.

In addition to preventing collisions between adjacent structures, the empirical limitation on drift due to wind [1] is intended to fulfill the structural serviceability requirement by preventing:

(1) Separation of cladding or loss of weathertightness [3].

(2) Local damage to building elements such as breakage of glass, damage to partitions, etc. [2]. 


\subsection{STRUCTURE}

\section{.4 STRENGTH AND STIFFNESS}

\subsubsection{4 (Continued)}

(3) Disruption in the operation of elevators and other service systems.

(4) Damaging transfer of load to non-load support elements.

(5) Discomfort to occupants.

The empirical limitation on drift due to earthquake is intended to fulfill the structural serviceability requirement by preventing:

(1) Collapse or failure of non-load supporting elements that could endanger occupants.

(2) Permanent discuption of service systems.

If it can be demonstrated that proper performance is obtained and none of the negative effects occur, the empirical limits may be modified.

It should be noted that in certain instances [1], the laterial drift limitation of $\mathrm{h} / 500$ has been found to result in structures that do not have sufficient stiffness to prevent discomfort to occupants during high winds. However, since such structures tend to be vary tall and slender, with a long period of vibration, it is not likely that a similar situation would arise involving innovative materials.

\section{References:}

[1] Galambos, T.V., et. al., "Structural Deflections: A Literature and State-of-the-Art Survey," National Bureau of Standards, Building Science Series 47, Washington, D.C., October 1973. 


\subsection{STRUCTURE}

\section{.4 STRENGTH AND STIFFNESS}

13.2.4.4 (Continued)

[2] Yoke1, F.Y., et. al., "Investigation of Wind Damage in the Metropolitan Washington, D.C. Area, April 3-4, 1975," National Bureau of Standards, Technica1 Note 909, Washington, D.C., May 1976.

[3] Marshal1, R.D., "Engineering Aspects of Cyclone Tracy, Darwin, Australia, 1974," National Bureau of Standards, Building Science Series 86, Washington, D.C., June 1976. 


\subsection{STRUCTURE}

\section{.4 STRENGTH AND STIFFNESS}

\subsubsection{Criterion: Structural Serviceability -- Vibrations}

Floor systems shall be designed to control vibrations by conforming with the following measures:

\section{a) Transient Vibrations}

Floor stiffness, with all partitions in place, shall be such that the maximum deflection under a $150-1 b$ static line load, distributed over a floor width not greater than the span or 10 times the spacing of repetitive supporting structural elements, whichever is smaller, and applied at a location producing the greatest deflection, is within the following limit:

$$
\mathrm{d} v \leqq \frac{2}{3 f}
$$

where $d_{v}$ is deflection in inches and $f$ is the lowest natural frequency in units of $\mathrm{Hz}$ (cycles/sec.).

b) Damping

The floor with surface coverings, partitions, furniture, and any other items representative of normal occupancy in place shall be adequately damped so that when subjected to load of duration less than $1 / f$, there will be a reduction in the deflection amplitude in the 10th cycle of vibration to less than $1 / 4$ of the amplitude in the 2 nd cycle of vibration.

c) Steady-state Vibration

Under the effect of steady state vibrations and irregular vibrations exceeding $10 / f$ seconds in duration or regularly repeated transient vibrations caused by service conditions: 


\subsection{STRUCTURE}

\section{.4 STRENGTH AND STIFFNESS}

\subsubsection{5 (Continued)}

(1) Any floor with surface coverings, partitions, furnishing and other items representative of normal occupancy in place shall not experience a root mean square acceleration of more than $0.004 \mathrm{~g}$, in which $\mathrm{g}=$ acceleration of gravity, and

(2) The natural frequency of any structural elements or assembly shall be less than 0.7 times or greater than 2.0 times the frequency of any steady state dynamic excitations to which it is exposed unless vibration isolation is provided.

Method of Evaluation for 13.2.4.5

This criterion may be satisfied by a dynmaic analysis, physical simulation, or an impact test conforming to ASTM E72 [1]. paragraphs 12.2.2, 12.2.2.1, 12.2.2.2, 12.2.2.3, and 12.2.3. The test shall be conducted on a floor as installed and normally finished, or a reasonable simulation thereof, using conditions likely to produce the least permanent load from furnishing. Alternatively, records of steady state motion for evaluation of the magnitude of acceleration obtained in a prototype building under normal use conditions, or a reasonable simulation thereof, may be submitted to demonstrate compliance.

\section{Commentary for $13 \cdot 2 \cdot 4 \cdot 5$}

The increasing use of high-strength or low modulus materials leads to longer flexural spans and more flexible floor systems. Under these conditions, vibrations which are disturbing to the building occupants may occur, even for certain floor systems which comply with the static deflection 


\subsection{STRUCTURE}

\section{.4 STRENGTH AND STIFFNESS}

\section{2 .4 .5 (Continued)}

criterion given in Criterion 13.2.4.7. While in the past, the use of a deflection limit related to span length (e.g., $\ell / 360)$ generally precluded such problems, the use of new materials and/or floor systems may require explicit consideration of the dynamic as well as the static characteristics of the floor system.

The provisions contained under the vibration criterion attempt to control the transient and steady-state vibrations of floor systems, as well as their damping and resonance characteristics. They are based, in part, on results presented in the International Organization of Standardization document ISO 2531 [2] and on National Bureau of Standards research $[3,4]$. Their object is basically to limit the velocity and acceleration of the floor during vibration to levels that would perhaps be perceptible but not disturbing to the building occupants.

The measure of damping in paragraph $13.2 .4 .5(\mathrm{~b})$ is equivalent to requiring that the damping be more than $2.75 \%$ of critical damping.

\section{References:}

[1] ASTM E-72, "Standard Methods of Conducting Strength Tests of Panel for Building Construction," American Society for Testing and Materials, Philadelphia, Pennsylvania.

[2] "Guide for the Evaluation of Human Exposure to Whole-Body Vibration," International Organization for Standardization, ISO 2361, September 1974. 


\subsection{STRUCTURE}

\section{.4 STRENGTH AND STIFFNESS}

13.2.4.5 (Continued)

[3] Crist, R.A., Shaver, J., "Deflection Performance Criteria for Floors", NBS Technical Note 900, April, 1976.

[4] Shaver, J.R., "Correlation of Floor Vibration to Human Response," National Bureau of Standards, Technical Note 904, Washington, D.C., May, 1976. 


\subsection{STRUCTURE}

.4 STRENGTH AND STIFFNESS

\subsubsection{Criterion: Structural Serviceability -- Service Environment}

Structural components shall respond to the service environment over the life of the building in accordance with the following measures:

\section{a) Dimensional Changes in Structural Elements}

The most severe changes in dimensions of structural elements due to any cause expected during the life of the structure, together with the most adverse combination of design loads, shall not cause violation of any of the strength and serviceability criteria for structures.

b) Joints

A building joint which is to be filled with a joint sealant and which is intended to relieve restraint forces shall be so designed that:

(1) The maximum movement expected in any joint between structural components does not exceed 50 percent of the design joint width.

(2) The minimum joint width is not less than 1/4-inch except that 1/8inch may be used between glass and surround.

c) Corrosion

Structural components shall not suffer a loss in their cross section of more than 5 percent due to corrosion or other environmental effects during their service life.

d) Material Changes

Structural materials shall either be selected to resist, or be protected against, adverse environments expected in service.

Methods of Evaluation for 13.2.4.6

Review of plans and specifications, particularly data on the behavior 


\subsection{STRUCTURE}

\section{.4 STRENGTH AND STIFFNESS}

\subsubsection{6 (Continued)}

of the material used for the structural component in environments representative of service conditions.

\section{Commentary for 13.2.4.6}

Structural members and systems may be distorted as a result of swelling or shrinkage, and such dimensional changes may affect the integrity or function of the building. Furthermore, certain materials may deteriorate in particular service environments to the point where they may be unable to carry the service loads. This deterioration may manifest itself either in external corrosion, decay or delamination, which would be visible upon inspection, or in undetected changes in the internal structure of the material itself which would reduce its strength. With the present state of knowledge regarding material behavior in various environments, there is no substitute in design evaluation for experimental data using samples of the materials with loads and an environment typical of what would be expected in service. The intent of this criterion is that the designer working with innovative or unproven materials be forced to recognize these problems; he should either factor a specific amount of damage tolerance into his design, or should provide adequate protection through coating systems and/or planned maintenance programs so that such problems are unlikely to occur. 


\subsection{STRUCTURE}

\section{.4 STRENGTH AND STIFFNESS}

\subsubsection{Criterion: Serviceability of Floor Surfaces}

Floors shall withstand the concentrated load defined in Method of Evaluation 13.2.4.7(a) without causing a residual deflection in excess of 0.05 inch and the impact defined in Method of Evaluation 13.2.4.7(b) without causing a residual deflection in excess of $10 \%$ of the maximum net deflection due to the impact or 0.05 inch, whichever is greater.

Method of Evaluation for 13.2.4.7

a) Concentrated Load

The concentrated load shall be 400 lb applied over a 5/8-inch diameter circle and maintained for a one hour period. The residual deflection shall be measured relative to any opposite points on the perimeter of a 16-inch diameter circle concentric with the load. The measurement shall be made one hour after the removal of the load. Where physical testing is necessary to establish conformance, the test procedures shall be those stated in ASTM E-72 [1] except as modified herein.

\section{b) Impact Load}

The impact load shall be $300 \mathrm{ft}-1 \mathrm{bs}$. applied at any point on the floor. The deflection shall be measured one hour after the impact occurs. Where physical testing is necessary to establish conformance, the test procedures shall be those stated in ASTM E-72 [1].

Commentary for $13 \cdot 2 \cdot 4.7$

The concentrated load specified is intended to correspond to heavy items of furniture [3] and the impact load roughly corresponds to the 


\subsection{STRUCTURE}

\section{.4 STRENGTH AND STIFFNESS}

\subsubsection{7 (Continued)}

energy imparted to the floor by a man falling off a ladder [4].

If there is a possibliity that the wearing surface may be removed during the useful life of the building, the floor shall satisfy the Criterion with the wearing surface removed.

A discussion of the state-of-the-art of the test methods for floors can be found in reference [2].

\section{References:}

[1] "Standard Methods of Conducting Strength Tests of Panels for Building Construction, (ASTM E72-74)" American Society for Testing Materials, Philadelphia, Pennsylvania.

[2] Yancy, C., Cattaneo, L.C., "State-of-the-Art of Structural Test Methods for Walls, Floors, Roofs and Complete Buildings," National Bureau of Standards Building Science Series 58, 1974.

[3] Yokel, F., "Study of the Local Resistance of Conventional Plywood Subflooring to Concentrated Load," National Bureau of Standards, NBSIR 73-116, Washington, D.C., March 1973.

[4] Lew, H.S., "The Effect of Impact Loadings on the Performance of Wood Joist Subflooring Systems," National Bureau of Standards NBSIR 73-187, Washington, D.C., May 1973. 


\subsection{STRUCTURE}

\section{.4 STRENGTH AND STIFFNESS}

\subsubsection{Criterion: Serviceability of Walls}

Walls and partitions shall withstand the loads described in Method of Evaluation 13.2.4.8(a) below without causing a residual deflection in excess of $10 \%$ of the maximum net deflection due to the load or $\ell / 4000$, whichever is greater; $l$ is the height between wall supports.

\section{Method of Evaluation for 13.2.4.8}

a) Loads

Walls shall resist the following loads:

(1) A concentrated horizontal load of 150 1b applied at any location over a bearing area not to exceed five square inches and maintained for one minute.

(2) A concentrated horizontal load of $200 \mathrm{lb}$ applied to a bearing area not to exceed five square inches, centered three inches above the finished floor and maintained for one minute.

(3) A uniformly distributed horizontal load of 10 psf applied over the entire vertical surface on one side of the wall and maintained for one minute.

(4) An impact of $25 \mathrm{ft}-1 \mathrm{~b}$ applied horizontally at any location and repeated five times. In cases where damage to surfaces caused by this impact may be repaired using readily available materials and methods that do not require specialized skills, the impact energy may be reduced to $7.5 \mathrm{ft} .-1 \mathrm{bs}$. 


\subsection{STRUCTURE}

\section{.4 STRENGTH AND STIFFNESS}

\subsubsection{8 (Continued)}

(5) A line load of 40 plf*applied vertically with a horizontal eccentricity of six inches plus half the width of the wall, or 1.5 times the maximum load likely to be expected to attached shelves, furniture, etc., whichever is greater. Load bearing walls shall resist this load while simultaneously carrying their service load U, defined in Method of Evaluation 13.2.4.3(a).

b) Test Procedure

Deflections are to be measured 1 hour after removal of the superimposed load. One preloading cycle may be applied before the test load. The impact load (4) shall be done as described in ASTM E-72 [1].

Commentary for $13 \cdot 2 \cdot 4.8$

The specified loads correspond to the following kinds of occupancy activities [2]: (1) is related to human activity (bearing, butting, etc.) (2) is related to impact by furniture, kicking, etc., (3) is related to the minimum ovexall strength desirable for walls, (4) is related to human impact from falls and (5) is related to,attachments to walls, as stated.

${ }^{*}$ plf (pounds per linear foot) 
13.2 STRUCTURE

.4 STRENGTH AND STIFFNESS

13.2.4.8 (Continued)

\section{References}

[1] "Standard Methods of Conducting Strength Tests of Panels for Building Construction (ASTM E72-74)," American Society for Testing and Materials Philadelphia, Pennsylvania.

[2] "Yancey, C., Cattaneo, L., "The Development of an Improved Compression Test Method for Wal1 Panels," National Bureau of Standards NBSIR 75-779, Washington, D.C., December 1975. 


\subsection{EXTERIOR ENCLOSURE}

\section{.2 FIRE (PROTECTION AND SAFETY)}

\subsubsection{Criterion: Balconies and Porches}

To be classed as limited-combustible, the potential heat of any part of a balcony or porch shall not exceed $3500 \mathrm{Btu} / 1 \mathrm{~b}$.

Method of Evaluation for 13.3.2.1

The potential heat test method described in NFPA 259 "Standard Test Method for Potential Heat of Building Materials $1976^{\prime \prime}$ will be used. These components shall also meet the requirements of NFPA 220-1975, for materials defined as limited-combustible.

\subsubsection{Criterion: Linited-Combustible Exterior Enclosures}

To be classed as limited-combustible, exterior walls, exterior stairways, exterior corridors or public exit balcony separations, and structural parts of the roof/ceiling assembly shall consist of materials which have a potential heat no greater than $3500 \mathrm{Btu} / \mathrm{lb}$. and may, in addition, include a material up to 1/32-inch thickness having a potential heat not exceeding $500 \mathrm{Btu} / \mathrm{square}$ foot.

\section{Method of Evaluation for 13.3.2.2}

The potential heat test: method described in NFPA 259 "Standard Test Method for Potential Heat of Building Materials $1976^{\prime \prime}$ will be used. These components shall also meet the requirements of NFPA 220-1975, for materials defined as limited-combustible. 


\subsection{EXTERIOR ENCLOSURE}

\section{.5 ATMOSPHERIC ENVIRONMENT}

13.3.5.1 Criterion: Condensation In or On Walls, Roofs, Floors, Windows and Doors

Protection shall be provided against condensation of moisture within or on walls, floors and ceilings.

Method of Evaluation for 13.3.5.1

The rate of water vapor transmission of material in sheet form sha11 be measured in accordance with ASTM E 96, "Water Vapor Transmission of Materials in Sheet Form." Thick materials will be evaluated using ASTM C355, "Standard Methods of Test for Water Vapor Transmission of Thick Materials."

Commentary for 13.3.5.1

In areas where cold weather condensation is probable and the exterior wall construction is of very low permeability ( 1 perm or less), buildup of moisture can be prevented by, in addition to the use of a vapor barrier, arranging if possible for ventilation of the air space between the permeable wall material with outdoor air.

Increased density of occupancy, tighter constructions, increased humidification and increased use of thermal insulation to conserve energy all contribute to the necessity for more stringent requirements for vapor barrier selection and installation. Experience with conventional construction is of minimal use for special and innovative construction where exterior wall surfaces have a permeance of one perm or less and are not vented. 


\subsection{EXTERIOR ENCLOSURE}

\section{.5 ATMOSPHERIC ENVIRONMENT}

\subsubsection{Criterion: Vapor Barrier Roof Decks}

Flat-roof deck construction shall be protected from entrapment of moisture (excessive condensation from below) and, if wetted from leakage through the roofing membrane, shall allow drying by venting.

Commentary for $13.3 \cdot 5.2$

A methodology for allowing drying is described in "The Effect of Moisture on Heat Transfer Performance of Insulated Flat-Roof Constructions," NBS Building Science Series No. 37, Washington, D.C., October 1971. 


\subsection{EXTERIOR ENCLOSURE}

\section{.6 DURABILITY/MAINTAINABILITY}

\section{JOINT SEALANTS}

Joint sealants used to prevent the passage of air, water, and dust particles through building joints shall withstand the effects of the exterior environment for which the building is designed. The life of the sealant shall be a function of the design life of the building. Sealants shall be tested in accordance with appropriate Federal, ASTM, or trade specifications by qualified commercial, institutional or governmental testing laboratories.

For the application of sealants where a specified performance is required, evaluation of the sealant material will be accomplished through examination of the characteristics set forth in Criteria 13.3.6.1 through $13.3 \cdot 6.14$

\subsubsection{Criterion: Hardness}

Where hardness of a sealant is required, the joint sealant shall exhibit a Shore Hardness value (instantaneous) within the range of 15 to 50 when tested on laboratory cured sealants of $74^{\circ} \mathrm{F}\left(23.3^{\circ} \mathrm{C}\right)$.

Method of Evaluation for 13.3.6.1

$$
\begin{aligned}
& \text { *FS-TT-S-00227E (Par. 3.5.4) } \\
& \text { FS-TT-S-00230C (Par. 4.3.4) } \\
& \text { FS-TT-S-001543A (Par. 4.3.4) }
\end{aligned}
$$

*Federal Specification 


\subsection{EXTERIOR ENCLOSURE}

.6 DURABILITY/MAINTAINABILITY

\subsubsection{Criterion: Color Change}

Where color change is critical, joint sealants shall not fade or change color to an extent that change is noticeable relative to the adjacent features of the building.

Method of Evaluation for 13.3.6.2

$$
\begin{aligned}
& \text { FS-TT-S-00227E (Par. 3.5.7) } \\
& \text { FS-TT-S-00230C (Par. 4.3.7) } \\
& \text { FS-TT-S-001543A (Par. 4.3.8) }
\end{aligned}
$$

\subsubsection{Criterion: Rheological Properties}

Where the flow of uncured sealant is important, the fresh, uncured joint sealant at $122^{\circ} \mathrm{F}\left(50^{\circ} \mathrm{C}\right)$ and $40^{\circ} \mathrm{F}\left(4.4^{\circ} \mathrm{C}\right)$ respectively, shall not flow more than $3 / 16$ inch $(4.76 \mathrm{~mm})$ from specified devices held in a vertical position or in a horizontal position on its side. The joint sealant, when at $122^{\circ} \mathrm{F}\left(50^{\circ} \mathrm{C}\right)$ and $40^{\circ} \mathrm{F}\left(4.4^{\circ} \mathrm{C}\right)$ shall exhibit a smooth level surface when placed in a horizontal position.

Method of Evaluation for 13.3.6.3

$$
\begin{aligned}
& \text { FS-TT-S-00227E (Par. 4.3.2) } \\
& \text { FS-TT-S-00230C (Par. 3.5.2) } \\
& \text { FS-TT-S-001543A (Par. 4.3.2) } \\
& \text { FS-TT-S-001657 (Par. 4.3.5) } \\
& \text { FS-TT-S-00598C (Par 4.3.7) }
\end{aligned}
$$




\subsection{EXTERIOR ENCLOSURE}

\section{.6 DURABILITY/MAINTAINABILITY}

\subsubsection{Criterion: Hardness After Heat Aging}

Where long term sealant hardness is undesirable, the joint sealant hardness value, after 21 days curing at $150^{\circ} \mathrm{F}\left(70^{\circ} \mathrm{C}\right)$, shall not be higher than 50 for flow type or non-sag type.

Method of Evaluation for 13.3 .6 .4

FS-TT-S-00227E (Par. 4.3.4.2)

\subsubsection{Criterion: Application Life}

A multi-component sealant, when mixed, shall have an application life of sufficient duration to insure effective handling and placement.

Method of Evaluation for 13.3.6.5

$$
\text { FS-TT-S-00227E (Par. 4.3.3.1 and 4.3.3.2) }
$$

13.3.6.6 Criterion: Weight Loss, Cracking and Chalking Due to Heat Aging After heating an uncured sealant sample for 21 days at $158^{\circ} \mathrm{F}\left(70^{\circ} \mathrm{C}\right)$, the sample shall not lose more than $10 \%$ of its original weight, nor show surface cracking or chalking.

Method of Evaluation for 13.3.6.6

$$
\begin{aligned}
& \text { FS-TT-S-00227E (Par. 4.3.5) } \\
& \text { FS-TT-S-00230C (Par. 4.3.5) } \\
& \text { FS-TT-S-001543A (Par. 4.3.5) }
\end{aligned}
$$




\subsubsection{Criterion: Tack Free Time}

A Joint sealant shall cure to a tack free condition in not more than 72 hours, at $74^{\circ} \mathrm{F}\left(23.3^{\circ} \mathrm{C}\right)$ from the time it is taken out of its container.

Methods of Evaluation for 13.3.6.7

$$
\begin{aligned}
& \text { FS-TT-S-00227E (Par. 4.3.3.1) } \\
& \text { FS-TT-S-00230C (Par. 4.3.6) } \\
& \text { FS-TT-S-001543A (Par. 4.3.8) } \\
& \text { FS-TT-S-001657 (Par. 3.4.8) } \\
& \text { FS-TT-S-00598C (Par. 3.9) }
\end{aligned}
$$

\subsubsection{Criterion: Staining of Substrate by Sealant}

A sealant in direct contact with the substrate shall not cause any visible stain on the substrate during the period of 100 hours exposure in a weatherometer with UV radiation and intermittent water spray.

Method of Evaluation for 13.3.6.8

$$
\begin{aligned}
& \text { TS-TT-S-00227E (Par. 4.3.7) } \\
& \text { FS-TT-S-00230C (Par. 4.3.7) } \\
& \text { FS-TT-S-001543A (Par. 4.3.7) } \\
& \text { FS-TT-S-001657 (Par. 3.4.8) } \\
& \text { FS-TT-S-00598C (Par. 4.3.8) }
\end{aligned}
$$




\subsection{EXTERIOR ENCLOSURE}

\section{.6 DURABILITY/MAINTAINABILITY}

13.3.6.9 Criterion: Joint Sealant Back-Up Material Stain and Discoloration Joint sealant back-up or packing materials shall not cause discoloration or staining of the sealant on the substrate during its service life.

Method of Evaluation for 13.3.6.9

$$
\begin{aligned}
& \text { FS-TT-S-00230C (Par. 4.3.8) } \\
& \text { FS-TT-S-00227E (Par. 4.3.8) }
\end{aligned}
$$

\subsubsection{Criterion: Feel Adhesion Strength}

Where adhesion is critical, the peel strength of a sealant shall not be less than 5 pounds $(2.27 \mathrm{~kg}$.) after seven days in water, nor shall the specimen show more than $25 \%$ adhesion loss.

Method of Evaluation for 13.3.6.10

$$
\begin{aligned}
& \text { FS-TT-S-00227E } \quad(\text { Par. 4.3.10) } \\
& \text { FS-TT-S-00230C (Par. 4.3.10) } \\
& \text { FS-TT-S-001543A (Par. 4.3.10) }
\end{aligned}
$$




\subsection{EXTERIOR ENCLOSURE}

\section{.6 DURABILITY/MAINTAINABILITY.}

\subsubsection{Criterion: Bond and Cohesion Properties}

A sealant shall not lose more than a specified amount of bond and cohesion after seven days' water immersion followed by seven days of continuous compression beyond the nominal width at $158^{\circ} \mathrm{F}\left(70^{\circ} \mathrm{C}\right)$, followed by 10 cyclic movements of compression and extension at $74^{\circ} \mathrm{F}\left(23.3^{\circ} \mathrm{C}\right)$, followed by 10 additional cycles of compression-extension at $158^{\circ} \mathrm{F}\left(70^{\circ} \mathrm{C}\right)$ and $-15^{\circ} \mathrm{F}\left(-26.1^{\circ} \mathrm{C}\right)$ when tested as described in the Method of Evaluation below.

Method of Evaluation for 13.3.6.11

$$
\begin{aligned}
& \text { FS-TT-S-00227E (Par. 4.3.9) } \\
& \text { FS-TT-S-00230C (Par. 4.3.9) } \\
& \text { FS-TT-S-001543A (Par. 4.3.9) }
\end{aligned}
$$

Primers are to be used only when specified by the sealant producer. The substrate used in the methods of test must be of the material intended for use.

\subsubsection{Criterion: Bubble Formation}

When the sealant is applied to representative substrates at $122^{\circ} \mathrm{F}\left(50^{\circ} \mathrm{C}\right)$ not more than $25 \%$ of the total test surface on either of the substrates to which the sealant is applied shall be covered with bubbles. Method of Evaluation for 13.3.6.12

$$
\text { FS-TT-S-001657 (Par. 4.3.2) }
$$




\subsection{EXTERIOR ENCLOSURE}

.6 DURABILITY/MAINTAINABILITY

\subsubsection{Criterion: Tenacity}

Where cohesiveness or toughness is critical to the performance of the sealant to achieve its function, the sealant compound when bent over a $1 / 4$ inch $(6.35 \mathrm{~mm})$ diameter mandrel after three 24 hour cycles (15 hours at $158^{\circ} \mathrm{F}\left(70^{\circ} \mathrm{C}\right)$, and 8 hours at $-10^{\circ} \mathrm{F}\left(-23.3^{\circ} \mathrm{C}\right)$, shall show no cracking or adhesion loss.

Method of Evaluation for 13.3.6.13

$$
\begin{aligned}
& \text { FS-TT-S-001657 (Par. 4.3.3) } \\
& \text { FS-TT-C-00598C (Par. 3.5) }
\end{aligned}
$$

\subsubsection{Criterion: Shrinkage}

The sealant shall not exceed $25 \%$ shrinkage by volume after 14 days.

\section{Method of Evaluation for 13.3.6.14}

$$
\begin{aligned}
& \text { FS-TT-S-001657 (Par. 3.4.4) } \\
& \text { FS-TT-S-00598C (Par. 3.4) }
\end{aligned}
$$




\subsection{EXTERIOR ENCLOSURE}

.6 DURABILITY/MAINTAINABILITY

ROOFING SYSTEMS

Roofing systems shall protect the structure, j.ts occupants and contents from the deleterious effects of natural weathering for the stipulated functional life of the membrane.

The following listing of tests and evaluation procedures of roofing systems is not all inclusive, nor is it intended that all characteristics identified be met for all given systems or circumstances. The application of the roofing system will be analyzed and those characteristics which are identified as essential will be evaluated using the following procedures.

Built-Up Roofing Membranes:

\subsubsection{Criterion: Tensile Strength}

The tensile breaking strength shall not be less than $200 \mathrm{lb}$./in. $(36.7 \mathrm{~kg} / \mathrm{cm})$ width when tested at $0^{\circ} \mathrm{F}\left(-17.8^{\circ} \mathrm{C}\right)$.

Method of Evaluation for 13.3.6.15

ASTM D2523, "Testing Load-Strain Properties of Roof Membranes."

\section{Commentary for 13.3 .6 .15}

The criterion on tensile strength is based on performance in service. Certain membranes exhibit anisotropic behavior; therefore, the results of tests on specimens taken in the weakest direction (usually "across machine" direction) shall apply. 


\subsection{EXTERIOR ENCLOSURE}

6 DURABILITY/MAINTAINAB ILITY

\subsubsection{Criterion: Thermal Expansion}

The linear thermal expansion coefficient shall not exceed $40 \times 10^{-6}$ per ${ }^{\circ} \mathrm{F}\left(72 \times 10^{-6}\right.$ per $\left.{ }^{\circ} \mathrm{C}\right)$ for temperature range, $0^{\circ}$ to $-30^{\circ} \mathrm{F}(-17.8$ to $-34.4^{\circ} \mathrm{C}$ ). Length measurements shall be determined at equilibrium temperatures within these ranges. Specimens shall be selected to reflect the greatest dimensional changes.

Method of Evaluation for 13.3.6.16

"ASTM Proposed Method of Test for Coefficient of Linear Thermal Expansion of Roofing and Waterproofing Membranes" ASTM Annual Book of Standards, Vol. 15, 1974.

\section{Commentary for $13 \cdot 3.6 .16$}

Certain roof membranes exhibit anisotropic properties regarding temperature change. Tests shall be performed on samples or specimens which exhibit the most movement. Generally, the "across machine" direction will be used since greater movement is expected in this direction. 


\subsection{EXTERIOR ENCLOSURE}

.6 DURABILITY/MAINTAINABILITY

\subsubsection{Criterion: Thermal Movement (Shock Resistance)}

The thermal shock resistance factor shall not be less than $100^{\circ} \mathrm{F}$ $\left(37.5^{\circ} \mathrm{C}\right)$

Method of Evaluation for 13.3.6.17

Test procedure given in NBS Building Science Series No. 55, "Preliminary Performance Criteria for Bituminous Membrane Roofing."

Commentary for $13.3 \cdot 6.17$

For areas which are not subject to large and sudden temperature changes, lower limits for the Thermal Shock Resistance Factor will be established by the accepting authority.

\subsubsection{Criterion: Impact Resistance}

The membrane sha11 remain continuous after an impact of or equivalent to a $11 / 2$ inch $(38.1 \mathrm{~mm})$ diameter hailstone at a speed of $112 \mathrm{ft} . / \mathrm{sec}$. $(34.1 \mathrm{~m} / \mathrm{sec})$ for built-up roofing.

Method of Evaluation for 13.3.6.18

Test procedure in NBS Building Science Series No. 23, "Hail Resistance of Roofing Products."

Commentary for 13.3.6.18

For area which are not subject to hail storm or falling icicles lower limits for impact resistance will be set by the accepting authority. 


\subsection{EXTERIOR ENCLOSURE}

.6 DURABILITY/MAINTAINABILITY

13.3.6.19 Criterion: Wind Resistance

Shall meet the requirements of class 30,60 , or 90 as appropriate to its specific use and local wind conditions (basic wind speeds) appearing in Figures $I$ and 2, ANSI A58.1 - 1972.

Method of Evaluation for 13.3.6.19

Procedure in U. L. Bulletin of Research No. 52 (1962)

Commentary for 13.3 .6 .19

The established requirements for wind resistance should be adequate for most USA locations. However, in high wind areas, i.e., those having basic wind speeds in excess of $60 \mathrm{miles} / \mathrm{hr} .(96.5 \mathrm{~km} / \mathrm{hr}$. ) (as shown in Figures 1 and 2, ANSI A58.1 - 1972) a more stringent criterion will be needed. Other types of tests than the U.I. method, such as those of Factory Mutual, Johns-Manville and Owens Corning Fiberglass will be acceptable. 
13.3. EXTERIOR ENCLOSURE

.6 DURABILITY/MAINTAINABILITY

13.3.6.20 Criterion: Punching Shear Strength

Shall be not less than 250 psi $\left(1.724 \times 10^{6}\right.$ newton/meter ${ }^{2}$ ) (force/ probe area) when tested at $73^{\circ} \mathrm{F}\left(22.8^{\circ} \mathrm{C}\right)$.

Method of Evaluation for 13.3.6.20

Described in NBS, BSS 55 (1974); $3 / 4$ inch (19.05 mm) diameter probe used.

Commentary for $13 \cdot 3 \cdot 6.20$

The roofing membranes sample is placed over representative composition insulation board samples such as foam glass, wood fiber, perlite board, fiberglass and plastic form for testing. 


\subsection{EXTERIOR ENCLOSURE}

.6 DURABILITY/MAINTAINABILITY

\subsubsection{Criterion: Flexural Strength}

The roofing membrane when tested at $73^{\circ} \mathrm{F}\left(22.8^{\circ} \mathrm{C}\right)$ and $0^{\circ} \mathrm{F}\left(-17.8^{\circ} \mathrm{C}\right)$ shall not rupture under a static load of $171 \mathrm{bs} .(7.7 \mathrm{~kg})$.

Method of Evaluation for 13.3.6.21

Test coupons shall conform to ASTM D2523. Length of span and load application given in NBS BSS 55.

Commentary for 13.3 .6 .21

Certain membranes exhibit anisotropic behavior. Consequently, the results of the tests performed in the weakest direction (usually transverse or "across machine") shall apply.

\subsubsection{Criterion: Permeability}

The maximum allowable permeabllity of water and water vapor shall be 0.5 perms.

Method of Evaluation for 13.3.6.22

ASTM E96 "Water Vapor Transmission of Materials in Sheet Form." 


\subsection{EXTERIOR ENCLOSURE}

\section{.6 DURABILITY/MAINTAINABILITY}

\subsubsection{Criterion: Tensile Fatigue Strength}

The roofing membrane shall withstand without rupture a minimum of 10,000 cycles of repeated force under a tension of 20 Ibs. when tested at $73^{\circ} \mathrm{F}\left(9.1 \mathrm{~kg}\right.$ at $\left.22.8^{\circ} \mathrm{C}\right)$ and under a tension of $100 \mathrm{lbs}$. when tested at $0^{\circ} \mathrm{F}$ $\left(45.4 \mathrm{~kg}\right.$ at $\left.-17.8^{\circ} \mathrm{C}\right)$.

Method of Evaluation for 13.3.6.23

Described in NBS BSS No. 55 (1974) and NBS Tech Note 863, (1975).

Commentary for 13.3.6.23

Certain membranes exhibit anisotropic behavior. Consequently the results of the tests performed in the weakest direction (usually transverse or "across machine") shall apply. Reasoning behind the test method and assistance in interpretations of results appear in NBS Tech Note 863 , (1975).

\subsubsection{Criterion: Flexural Strength}

The roofing membrane shall withstand without rupture a minimum of 10,000 cycles of force causing a deflection of $0.125 \mathrm{in}$. (3.175 mm) at midspan in a 1 in. $(25.4, \mathrm{~mm})$ wide strip at $73^{\circ} \mathrm{F}\left(22.8^{\circ} \mathrm{C}\right)$.

Method of Evaluation for 13.3.6.24

Described in NBS BSS No. 55, (1974) and NBS Tech Note 863 (1975).

Commentary for $13 \cdot 3 \cdot 6.24$

Identical to that for $13 \cdot 3 \cdot 6 \cdot 23$ 


\subsection{EXTERIOR ENCLOSURE}

.6 DURABILITY/MAINTAINABILITY

\subsubsection{Criterion: Load Strain Modulus}

The load strain modulus at $-30^{\circ} \mathrm{F}\left(-34.4^{\circ} \mathrm{C}\right)$ shall be at least $70 \%$ of that at $73^{\circ} \mathrm{F}\left(22.8^{\circ} \mathrm{C}\right)$

Method of Evaluation for 13.3.6.25

ASTM D2523 "Testing Load Strain Properties of Roof Membranes."

Commentary for 13.3 .6 .25

Bituminous membranes tend to be brittle at temperatures lower than $30^{\circ} \mathrm{F}\left(-1.1^{\circ} \mathrm{C}\right)$ but their terisile strength tends to be higher.

Roofing systems of mechanically fastened units (e.g. shingles and roll roofing):

\subsubsection{Criterion: Impact Resistance}

The shingle, or roll roofing membrane shall remain continuous after an impact of an $11 / 4 \mathrm{inch}(31.7 \mathrm{~mm}$ ) diameter hailstone at a speed of $82 \mathrm{ft} / \mathrm{sec} .(25.0 \mathrm{~m} / \mathrm{sec})$.

Method of Evaluation for 13.3.6.26

Test procedure in NBS Building Secience Series No. 23 "Hail Resistance of Roofing Products."

Commentary for $13 \cdot 3 \cdot 6.26$

For areas which are not subject to hail storms or falling icicles, lower limits for impact resistance will be set by the accepting authority. 


\subsection{EXTERIOR ENCLOSURE}

.6 DURABILITY/MAINTAINABILITY

\subsubsection{Criterion: Wind Resistance}

The roof system shall remain in contact with the substrate with no uplift of tabs or plies under a windload of $60 \mathrm{mph}(96.5 \mathrm{~km} / \mathrm{hr})$ for 2 hours.

Method of Evaluation for 13.3.6.27

UL 997, Underwriters' Laboratories l'And Resistance of Prepared Roof Covering Materials.

Commentary for 13.3 .6 .27

The Ifmits established for the Criteria are believed to be adequate for most locations in the United States. However, in high wind areas more stringent criterla will be needed such as those in ANSI A58.1. 


\subsection{EXTERIOR ENCLOSURE}

\section{.6 DURABILITY/MAINTAINABILITY}

\section{Elastomeric Roofing Membranes}

Although the generic types of elastomeric roofing products manufactured in the United States are fairly numerous, the total amount produced, when compared with that for asphaltic roofing, is very small. Consequently, criteria have not yet been established by the roofing industry for predicting the performance of elastomeric roofing in service.

In recent years, however, the use of elastomeric roofing in the United States has been increasing. Consequently, it appears that the need is increasing for the development of performance criteria for this type of product. This is discussed by Rossiter and Mathey* who also list the principal types of elastomeric roofing commercially available. In addition, they discuss guidelines for selecting the best types of elastomeric roofing for specific purposes, and suggested performance characteristics as a first step towards the development of performance criteria for this type of roofing.

\subsubsection{Criterion: Tensile Strength}

The tensile strength of elastomeric roofing shall be at least $15 \mathrm{lb} . / \mathrm{in}$. of width $(26.7 \mathrm{gm} / \mathrm{mm})$ in the cured state.

Method of Evaluation for 13.3.6.28

ASTM D2523, "Standard Recommendated Practices for Testing Load Strain Properties of Roof Membranes."

*Rossiter, W.J., and Mathey, R.G., NBS Report in preparation - September 1977. 


\subsection{EXTERIOR ENCLOSURE}

\section{.6 DURABILITY/MAINTAINABILITY}

\subsubsection{Criterion: Resistance to Impact}

The protective coating or roofing membrane over the substrate shall not be ruptured by the impact of a $11 / 4$ inch $(31.8 \mathrm{~mm})$ diam hailstone traveling at a speed of $82 \mathrm{ft.} / \mathrm{sec} .(25 \mathrm{~m} / \mathrm{sec}$.$) .$

Method of Evaluation for 13.3.6.29

Procedure described in NBS BSS 23, "Hail Resistance of Roofing Products."

Commentary for $13 \cdot 3.6 .29$

Common roofing systems such as asphalt shingles and built-up membranes meet the Criterion for the impact of ice spheres (hailstones) and have performed satisfactorily under field conditions involving hail. From limited tests of elastomeric roofing membranes it is believed that similar criteria are reasonable for elastomeric coating and systems used with these coatings.

\subsubsection{Criterion: Wind Resistance}

The criterion, method of evaluation, and commentary for 13.3.6.30 are identical to those for Built-up Roofing Membranes (see 13.3.6.19). 


\subsection{EXTERIOR ENCLOSURE}

\section{.6 DURABILITY/MAINTAINABILITY}

\subsubsection{Criterion: Deformation Recovery}

Complete recovery in the elastomeric roofing membrane shall occur within 1 hour after 100 percent elongation.

Method of Evaluation for 13.3.6.31

ASTM D412, "Tension Testing of Vulcanized Rubber", Die C, Crosshead speed 12 to $20 \mathrm{in} / \mathrm{min}$. (30.5 to $50.8 \mathrm{~cm} / \mathrm{min})$ at $73^{\circ} \mathrm{F}\left(22.8^{\circ} \mathrm{C}\right)$.

\section{Commentary for $13 \cdot 3 \cdot 6 \cdot 31$}

The criterion of $100 \%$ elongation was established on the basis that many commercial elastomeric roofing membrane products which meet this requirement have performed satisfactorily for many years. Many roofing membranes of this type have the ability to recover after much greater elongation. 


\subsection{EXTERIOR ENCLOSURE}

\section{.6 DURABILITY/MAINTAINABILITY}

\subsubsection{Criterion: Adhesion Durability}

The elastomeric roofing material should still be firmly adhered to the substrate after 1,000 hours of test exposure. This applies to products applied in sheet form, fastened to the substrate with adhesive and to products applied in liquid form. It does not apply to "loose laid" products which are fastened mechanically to roof edges and other appropriate places.

Method of Evaluation for 13.3.6.32

Procedure for adhesion durability given in ASTM G23, Operating Light and Water Exposed Aparatus (Carbon Arc Type) for Expsoure of Nonmetallic Materials, Type D Apparatus 18 - 10E cycle (Continuous 1ight18 minute spray per 2 hour cycle). 


\subsection{EXTERIOR EXPOSURE}

\section{.6 DURABILITY/MAINTAINABILITY}

\subsubsection{Criterion: Appearance Change}

The maximum allowable change shall not exceed four color difference units, the degree of chalking shall not exceed No. 7 (See Method (3) below) and there shall be no evidence of checking after 1,000 hours of exposure to artificial weathering.

Method of Evaluation for 13.3.6.33

(1) The artificial weathering procedure used should be the same as that used in 13.3 .6 .32 .

(2) FTMA (Federal Test Method) No. 141a Method 6123, Color Differences of Opaque Materials Instrumental Measurements and

(3) ASTM D659, Evaluating Degree of Resistance of Chalking of Exterior Paint.

\section{Commentary for 13.3.6.33}

The effects of 1,000 hours of artificial weathering as compared to natural weathering are not known. However, accelerated laboratory weathering can be used to compare materials within a class to provide a basis for comparing them to materials that are known to have performed satisfactorily in service. 


\subsection{EXTERIOR EXPOSURE}

\section{.6 DURABILITY/MAINTAINABILITY}

13.3.6.34 Criterion: Curing Time for Liquid Applied Membranes

The maximum "set of touch" drying time shall be 4 hours. The minimum "hard dry" time shall be 24 hours.

Method of Evaluation for 13.3.6.34

ASTM D1640, "Drying, Curing or Film Formation of Organic Coatings at Room Temperature". 


\subsection{EXTERIOR ENCLOSURE}

\section{.6 DURABILITY/MAINTAINABILITY}

\section{Protective and Decorative Exterior Coatings}

Exterior coatings are intended to provide decorative qualities and protection for the surface to which they are applied for a sultable period of time. During, and at the end of this time period, the surface/substrate must be in such condition as to be readily recoated.

The following listing of evaluation procedures for exterior coating systems is not all inclusive, nor is it intended for all given systems or circumstances. The application of the exterior system will be analyzed and those characteristics which are identified as essential w11l be evaluated using the following procedures.

\subsubsection{Criterion: Color Change}

The color change shall not exceed three NBS color difference units after 500 hours of exposure.

Method of Evaluation for 13.3.6.35

ASTM D822 Test Method "Operating Light and Water-Exposure Apparatus" (Carbon Arc Type): exposure of samples to 500 hours of the artificial weathering. Sample colors should be measured before and after exposure to ASTM G23 as described in Federal Test Method Standards No. 14la Method 6123 "Color Differences of Opaque Materials Instrumental Measurements." 


\subsection{EXTERIOR ENCLOSURE}

\section{.6 DURABILITY/MAINTAINABILITY}

\subsubsection{Criterion: Gloss Change}

After exposure to 500 hours of accelerated weathering, the $60^{\circ}$ specular gloss shall be no less than $80 \%$ of the original value.

Method of Evaluation for 13.3.6.36

(1) Initial gloss determined by test method 6101 of Federal Test Method Standard No. 14la "60 Degree Specular Gloss" followed by (2) ASTM D822 "Operating Light and Water-Exposure Apparatus (Carbon Arc Type) for Exposure of Nonmetallic Materials," followed by gloss measurements as in (1) above.

\subsubsection{Criterion: Washability}

(1) Gloss retention sha11 be at least $\pm 20 \%$ of initial gloss and

(2) $45^{\circ}$ reflection shall be not less than $90 \%$ of initial reflectance.

Method of Evaluation for 13.3.6.37

(1) Federal Test Method Standards No. 141a, Method 6101, $60^{\circ}$ Specular Gloss of Method $6121,45^{\circ}, 0^{\circ}$ Directional Reflectance; followed by:

(2) Method 6141, Washability of Paints, and

(3) Specular Gloss and Directional Reflectance as in (1) above. 
13.3 EXTERIOR ENCLOSURE

.6 DURABILITY/MAINTAINABILITY

13.3.6.38 Criterion: Abrasion Resistance

The weight loss of the sample shall not exceed $80 \mathrm{mg}$ after abrasion for a total of 500 cycles.

Method of Evaluation for 13.3.6.38

Federal Test Method Standard No. 141a Method 6192 - Abrasion Resistance. Abrasive wheels GS-17 shall be used. The wheel pressure shall be $1000 \mathrm{gm}$. Completion of test shall be the number of cycles required to expose the substrate, to a maximum of 500 cycles. Following this procedure, the weight loss of the sample shall be determined.

\subsubsection{Criterion: Adhesion}

Loss of adhesion between coating and substrate shall not occur at a beam loading of $4 \mathrm{~kg}$ or lower.

Method of Evaluation for 13.3.6.39

Federal Test Method Standard No. 14la Method 6303.1, "Adhesion of Coatings with Scrape-Adhesion Apparatus." 


\subsection{EXTERIOR ENCLOSURE}

.6 DURABILITY/MAINTAINABILITY

\subsubsection{Criterion: Salt Spray Resistance}

Any area in which peeling, blistering or flaking occurs shall not exceed $5.0 \%$ of the exposed area of the sample.

Nethod of Evaluation for $13 \cdot 3 \cdot 6 \cdot 40$

ASTM B117, "Standard Method of Salt Spray (Fog) Testing," (a concentration of 5 parts of sodium chloride in 95 parts of distilled water should be used) followed by ASTM D174, "Evaluating Degree of Blistering of Paints."

\subsubsection{Criterion: Moisture Resistance}

No peeling, blistering, flaking, nor checking shall have occurred after 1,000 cycles of wetting and drying.

Method of Evaluation for 13.3.6.41

ASTM D2247, "Tentative Method for Testing Coated Metal Specimens at 100 Percent Relative Humidity," will be used but modified so that the specimens are subjected to a 1 -hour cycle of $100 \%$ relative humidity followed by a 1-hour drying cycle. The temperature in the exposure cabinet shall be adjusted to produce condensation on the test panels during the 1-hour humidity cycle. 


\subsection{EXTERIOR ENCLOSURE}

\section{.6 DURABILITY/MAINTAINABILITY}

\subsubsection{Criterion: Impact Resistance}

No chlpping, cracking or flaking shall occur when subjected to Impact by a $0.9070 \mathrm{~kg}$ cylindrical weight.

\section{Method of Evaluation for 13.3 .6 .42}

ASTM D2794, Resistance of Organic Coatings to the Effects of Rapid Deformation (Impact). The test shall be performed with coated side up. 


\subsection{INTERIOR ENCLOSURE}

.2 FIRE (PROTECTION AND SAFETY)

13.4.2.1 Criterion: Limited-Combustible Components of the Interior Enclosure

Interior walls and floor/ceiling assemblies, classed as limitedcombustible, (except the floor covering) shall consist of materials which have a potential heat not greater than $3500 \mathrm{Btu} / \mathrm{lb}$.

Method of Evaluation for 13.4.2.1

The potential heat test method described in NFPA 259 "Standard Test Method for Potential Heat of Building Materials 1976" will be used. Components shal1 also meet the requirements of NFPA 220-1975 for materials defined as limited-combustible. 


\subsection{INTERIOR ENCLOSURE}

.3 ACOUSTIC ENVIRONMENT

\subsubsection{Criterion: Acoust1c Properties of Interdwelling Wa1ls and}

\section{$\underline{\text { Partitions }}$}

Components and assemblies shall meet NIC ratings as determined by tests of field units. NIC values may be five units less than the STC values given in the MPS.

Method of Evaluation for 13.4.3.1

Appendix A1 of ASTM E 336, "Standard Recommended Practice for Measurement of Alrborne Sound Insulation in Bufldings" (see Normalization Procedure below) shall be used.

ASTM C 432, "Standard Method of Test for Sound Absorption of Acoustical Materials in Reverberation Rooms," Section 9.1, shall be used for measurement of decay rate procedure.

Normalization Procedure for NIC Ahsorption Correction: Field performance measurements for determination of NIC shall be conducted between enclosed unfurnished spaces. In the event that the unfurnished space has absorption values less than the reference absorption value $A_{0}=10 \mathrm{~m}^{2}\left(108 \mathrm{ft}^{2}\right)$, the measured noise reduction is to be normalized to the reference absorption value, $A_{0}$, at each of the 16 test frequencies according to the procedure for normalization stated herein. If the unfurnished space has absorption values greater than the referenced absorption, $A_{0}$, normalization need not be made.

The procedure for normalization is as follows:

$$
D_{N}=L_{1}-L_{2}-\left(10 \log _{10} \frac{A}{A_{0}}\right) \text {, }
$$


13.4 INTERIOR ENCLOSURE

.3 ACOUSTIC ENVIRONMENT

\subsubsection{1 (Continued)}

where: $\quad D_{N}=$ Normalized Level Difference

$\mathrm{L}_{1}=$ space-time averaged sound pressure level measured in the source space

$\mathrm{L}_{2}=$ space-time averaged sound pressure level measured in the receiving space

$A=$ total sound absorption of the receiving space calculated by $A=\frac{0.921 \mathrm{Vd}}{\mathrm{c}}$

where: $V=$ total volume

$\mathrm{d}=$ average rate of decay in decibels per second

c $=$ speed of sound

$A_{0}=$ reference equivalent absorption $10 \mathrm{~m}^{2}\left(108 \mathrm{ft}^{2}\right)$

SI or English units may be used, but all quantities must be measured in the same system of units.

\section{Commentary on $13 \cdot 4 \cdot 3.1$}

The NIC rating is based upon noise reduction which is a measure of the sound isolation between two enclosed spaces, the source space and the receiving space, and is not necessarily a function of the dividing partition alone. It may or may not include the effects of flanking paths. The concept of noise reduction is generally based upon a furnished space as a receiving room. Normalization of the noise reduction data is necessary to compensate for furnishing. It is assumed that a furnished space would have absorption of each test 
13.4 INTERIOR ENCLOSURE

.3 ACOUSTIC ENVIRONMENT

13.4.3.1 (Continued)

frequency equal to or greater than a reference absorption value of $A_{0}=10 \mathrm{~m}^{2}\left(108 \mathrm{ft}^{2}\right)$.

When the STC value is used as a design guide and cannot be justified by published data for similar partitions or by computation using appropriate analysis, laboratory measurements shall be made.

\subsubsection{Criterion: Acoust1c Properties of Interdwelling Floor-Ceiling}

Unless compliance with noise level within interior spaces

is determined by Criterion 13.1.3.1, the STC and IIC values shall comply with the MPS.

Method of Evaluation for 13.4.3.2

If required, NIC and field IIC ratings may be determined by tests of field units using Appendix A1 of ASTM E 336, "Standard Recommended Practice for Measurement of Airborne Sound Insulation in Buildings." The normalization procedure for absorption correction given in the Method of Evaluation for 13.4.3.1 shall be used.

Laboratory and field measurement of floor/ceiling assembly impact sound transmission shall be determined by ASTM RM 14-4, 1971, "Proposed Tapping Machine Method for Laboratory Measurement of Impact Sound Transmission through Floor-Ceiling Assemblies."

Since ASTM has not yet proposed a Field measurement method of Impact Sound Transmission, ASTM RM 14-4, 1971 will be used for field IIC with the following modification in the procedure for 
.3 ACOUSTIC ENVIRONMENT

\subsubsection{2 (Continued)}

normalization of the impact sound pressure level:

Prototype field performance measurements for determining IIC shall be conducted between enclosed unfurnished spaces as intended for delivery to the occupant. In the event that the "unfurnished" space has absorptions less than the reference absorption, $A_{0}=10 \mathrm{~m}^{2}$ (108 $\left.\mathrm{ft}^{2}\right)$, the procedure for normalization of the impact sound pressure level to the reference absorption shall be that of ASTM RM 14-4 for laboratory measurements.

\subsubsection{Criterion: Acoustic Properties of Wa1ls and Partitions}

\section{Within a Living Unit}

Unless compllance with noise level within interfor spaces is determined by Criterion 13.1.3.1, walls and partitions within living units where noise isolation between living spaces is desired shall have an STC of 28 minimum.

\subsubsection{Criterion: Acoustic Properties of Floor-Ceiling Assemblies} Within a Living Unit

Unless compliance with noise level within interior spaces is determined by Criterion 13.1.3.1, floor-celling assemblies within a living unit shall provide a noise reduction of NIC 28 and IIC 28.

\section{Commentary for $13 \cdot 4 \cdot 3 \cdot 4$}

As a design guide the STC and IIC rating of intradwelling floorceiling assemblies determined by analysis or laboratory measurements should be from 5 to 7 units greater than the NIC and IIC required. 


\subsection{PLUMBING}

\section{.2 FIRE (PROTECTION AND SAFETY)}

\subsubsection{Criterion: Fire Spread}

The DWV system, as designed and installed, including exposed piping and piping within walls and chases, shall not compromise the fire endurance ratings of such walls and chases, as set forth in Table 13.6.2.1. [1]

TABLE 13.6.2.1

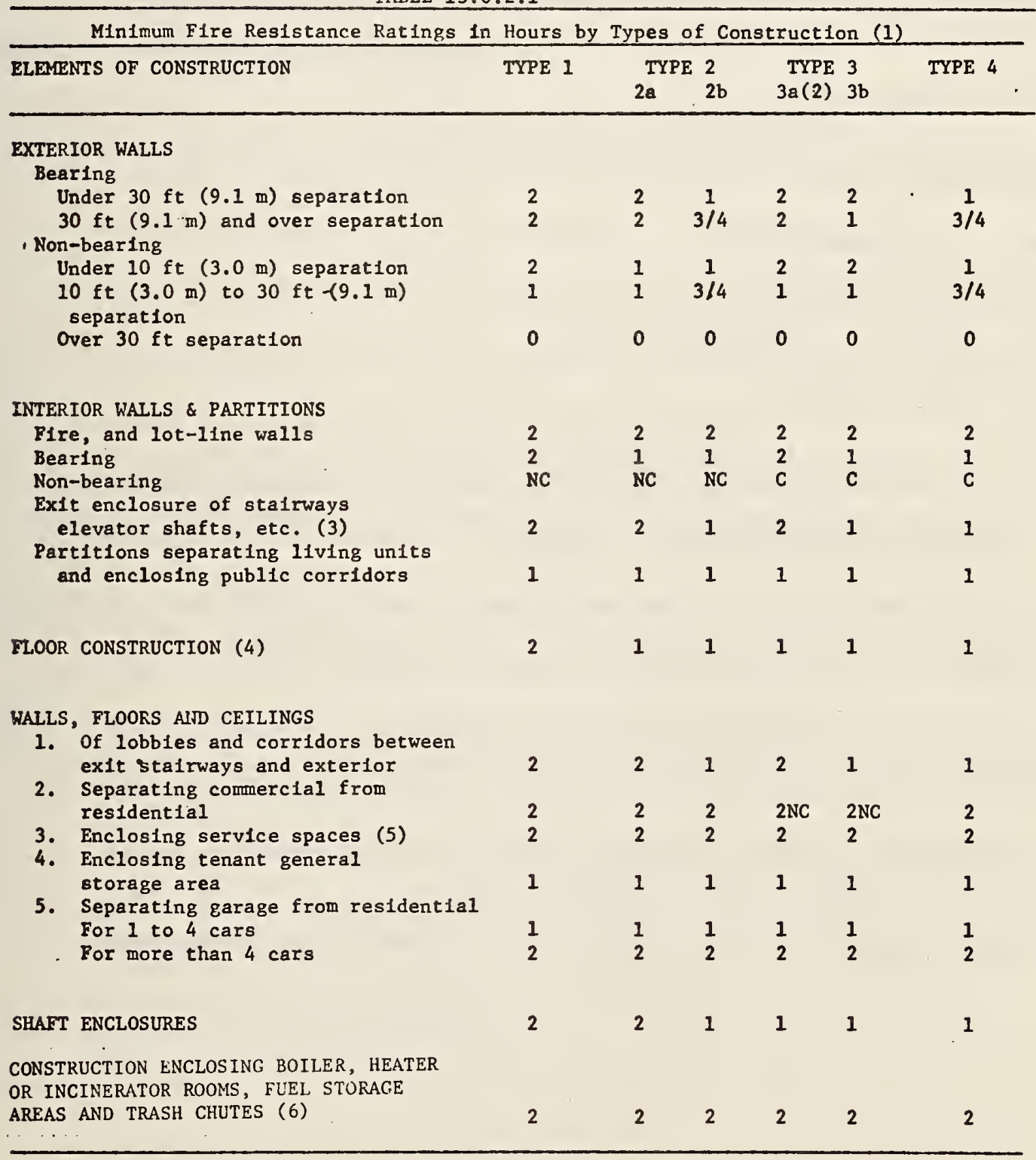




\subsubsection{PLUMBING}

\section{.2 FIRE (PROTFCTION AND SAFFTY)}

\subsubsection{1 (Continued)}

Notes for Table 13.6.2.1

(1) Abbreviations:

0 designates that no specific fire resistance rating is required.

NC designates noncombustible construction, but no specific fire resistance rating is required.

$C$ designates that the structural members of the construction mav he of combustible materials, but no specific fire resistance rating is required.

Types of Construction:

All residential buildings shall be classiffed into one of the following construction types:

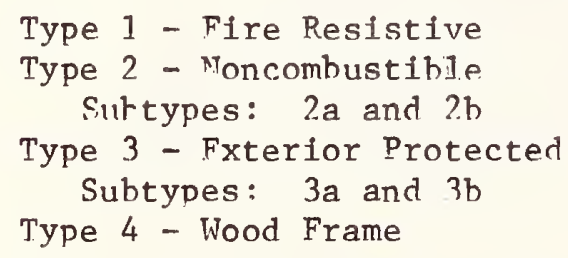

(2) In Type $3 a$ construction the corridor walls, floors and ceflings, partitions enclosing, vertical openings, stairways, columns and heams shall be 2-hr. noncombustible for structures of 3 or more stories, and 1-hr. noncombustible for 1 or 2 stories.

(3) In buildings of Types $1,2 \mathrm{a}$ and $3 a$ construction, not more than 2 stories in height, and having not more than 12 living units within a fire division, exit enclosures may have fire resistance rating of one hour.

(4) Floor construction within a two story living unit may have a $1 / 3 \mathrm{hr}$. fire resistance rating, where limited to one living unit in huiling height, and walls separating units are at least $11 / 2 \mathrm{hr}$. rating.

(5) Service spaces are paint, carpentry or maintenance shons arid other spaces where flammahle materials are stored.

(6) Individual living unit heater rooms not included in this requirement. 


\subsection{PLUMBING}

\section{.2 FIRE (PROTECTION AND SAFETY)}

\subsubsection{1 (Continued)}

Method of Evaluation for 13.6.2.1

The basic wall or chase must be capable of passing the standard ASTM E119 Fire Endurance Test.

If the walls or chases are penetrated by DWV piping the following additional test procedure is required:

a) A mock-up of the actual installation preserving all of the essential features such as pipe material, pipe size, piping configuration, chase and wall dimensions, inlet pressure, etc., shall be constructed. Two thermocouples shall be placed under felted asbestos pads on the unexposed surface in line with the laterals, one located 2 foot $(0.6 \mathrm{~m})$ above the lateral and the second 1 foot $(0.3 \mathrm{~m})$ below the simulated ceiling level.

b) The side of the assembly for which the fire rating is required shall be fire exposed to the prescribed ASTM E119 time-temperature condition in a standard wall test furnace. The lateral shall enter the furnace, and the furnace pressure relative to the adjacent test area at the inlet shall be positive and equal to the product of 0.001 inches $(0.0254 \mathrm{~mm})$ water column times the intended height of the lateral above the floor of the room in inches. (This pressure is applicable to cases where stack effect is not appreciable.) 


\subsection{PLUMBING}

\section{.2 FIRE (PROTECTION AND SAFETY)}

\subsubsection{1 (Continued)}

c) Acceptable performance shall be indicated if neither of the two ASTM thermocouples located on the unexposed surface of the chase or wall exceed $181^{\circ} \mathrm{F}\left(325^{\circ} \mathrm{C}\right)$ temperature rise during the fire rating period, and if flaming or hot gases sufficient to ignite a cotton pad do not come through at any point on the unexposed surface of the chase or wall within the fire-rating period.

\section{Commentary for 13.6 .2 .1}

The fire resistance of rated walls and chases which are to have plumbing systems within or penetrating their construction should be subjected to the same testing criterion as the rated assembly without plumbing. ASTM E119 is a generally accepted test for rating the fire resistance of structural components. Therefore, a test of the assembly with the plumbing system installed as intended for the field application is recommended to assure compliance with the fire resistance requirements of Criterion 13.6.2.1. Traps extending from the wall should be filled with water as representative of a field installation. The ASTM E119 fire endurance test puts limits on the temperature rise of the unexposed side of the wall $\left(139^{\circ} \mathrm{C}\right.$ average temperature rise over the surface and $181^{\circ} \mathrm{C}$ rise at any point), and prohibits the passage of flames and hot gases sufficient to ignite cotton padding. Trap arms, traps and pipes penetrating the wall are excluded from the temperature rise limitation since they are not part of the wall surface specified in ASTM E119. 


\subsection{PLUMBING}

\section{.2 FIRE (PROTECTION AND SAFETY)}

\subsubsection{1 (Continued)}

It is intended that the fire resistance of a DWV plumbing chase or wall shall be sufficient to prevent the spread of fire into the chase or from one dwelling to another for the designated test time period.

Research results [2] have shown that metal and thermoplastic DWV systems would not be expected to reduce the generally specified fire resistance of conventionally constructed walls and chases for housing, provided that the annular ring in the wall around the lateral is sealed and the stud space depth is at least $5-1 / 2$ inches $(14 \mathrm{~cm})$ and sufficient to prevent any tee or wye fittings in the vertical stacks or vertical waste pipes from penetrating the wall.

The specific test condition involving positive pressure is applicable to situations where stack effect is not appreciable, e.g., low rise buildings. At present, there is no standard or established method for quantitative measurement of the smoke passing out through any lateral, through an annular area around the lateral, or through the hole left by a lateral consumed by fire or pulled out or collapsed as a result of exposure to fire.

\section{References}

[1] HUD Minimum Property Standards, 1973 Edition Multifamily Housing, 4910.1, Superintendent of Documents, U.S. Government Printing Office Washington, D.C. 20402.

[2] "Fire Endurance of Gypsum Board Walls and Chases Containing Plastic and Metallic Drain, Waste and Vent Plumbing Systems," NBS BSS 72, September 1975. 


\subsection{PLUMBING}

\section{.6 DURABILITY/MAINTAINABILITY}

\subsubsection{Criterion: Life Expectancy Design}

A reasonable, planned life expectancy shall be incorporated in the design of the various plumbing subsystems, based on the relative ease of removal or replacement of the components as shown in Table 13.6.6.1.

Table 13.6.6.1

Rating Scheme for Life-Expectancy

Design of Plumbing Subsystems

\begin{tabular}{|c|c|c|c|}
\hline Element: & Characteristics & $\begin{array}{l}\text { : Minimum Years: } \\
\text { : to Replacement: }\end{array}$ & $\begin{array}{l}\text { Life } \\
\text { Class }\end{array}$ \\
\hline $\begin{array}{l}\text { Traps, trap arms, } \\
\text { fixture drains, } \\
\text { fixture branches, } \\
\text { receptors, sumps, } \\
\text { equipment } 1 / \text {, } \\
\text { devices } 1 / \text {, } \\
\text { appurtenances } 1 /\end{array}$ & $\begin{array}{l}\text { Replacement not facilitated } \\
\text { (concealed, access only by } \\
\text { destroying or damaging } \\
\text { plumbing or building element } \\
\text { and/or by excavation); } \\
\text { (a) Encased in concrete or } \\
\text { enclosed in concrete } \\
\text { structure w/o access } \\
\text { (b) Enclosed in light-weight } \\
\text { structure w/o access } \\
\text { (i) replacement- } \\
\text { (ii) not replacement- } \\
\text { (c) Buried in soil (not } \\
\text { under concrete) } \\
\text { (i) under building } \\
\text { (ii) not under building }\end{array}$ & $\begin{array}{l}20 \\
30\end{array}$ & $\begin{array}{l}3 \\
2\end{array}$ \\
\hline
\end{tabular}

(Continued) 


\title{
13.6 PLUMBING
}

\section{.6 DURABILITY/MAINTAINABILITY}

\subsubsection{1 (Continued)}

Table 13.6.6.1 (Continued)

\begin{tabular}{rll}
\hline$:$ & & $:$ Minimum Years: Life \\
Element $:$ & Characteristics & $:$ to Replacement: Class \\
\hline
\end{tabular}

\section{Drainage and vent piping, water service piping}

\begin{abstract}
Replacement facilitated (exposed or provided with ready access):
\end{abstract}
(1) replacement-designed 2 /
(i1) not replacement- deslgned 3 /

Replacement not facilitated (concealed, access only by destroying or damaging and/ or by excavation);

(a) Encased in or under concrete or enclosed w/o access

(b) Enclosed in 1ightweight structure w/o access
(i) replacement- designed2/
(ii) not replacement- designed $3 /$

(c) Buried in soil (not under concrete)
(i) under building
(ii) not under building

This refers to equipment, devices, and appurtenances connected to a line of piping, but does not refer to plumbing fixtures and appliances.

Provided with means designed to facilitate removal/replacement of the element without cutting, chipping, or breaking plumbing elements or 3/ other building elements.

Requires cutting or heating plumbing element for its removal. 


\subsection{PLUMBING}

. 6 DURABILITY/MAINTAINABILITY

\subsubsection{1 (Continued)}

Method of Evaluation for 13.6.6.1

Review of plans and specifications.

Review of test data, calculations, and/or documentation on service history and functional reliability/sufficiency.

Inspection of prototype systems.

Commentary for $13 \cdot 6 \cdot 6.1$

This Criterion can be beneficial in the systematic and orderly presentation of specification briefs prepared by innovators.

Innovative materials and new physical designs will require judgement and improved methods for quantitative evaluation to determine absolute compliance with this Criterion. Where other Criteria determine the acceptability of an element of a particular design or material, for either general or restricted use, this Criterion provides a conceptual means of rating the relative life expectancy of such elements as a function of the type of service, and the features of the overall design that facilitate maintainability, repairability, and replaceability.

Much of the piping, equipment, devices and appurtenances associated with plumbing subsystems can be readily serviced or replaced if suitable access and/or easy means of removal are provided in the overall design 
of the subsystems and the building system as a whole. Such design methods would tend to make the use of relatively short-life elements feasible in some applications. 


\subsection{PLUMBING}

\section{.6 DURABILITY/MAINTAINABILITY}

\subsubsection{Criterion: Maintenance of Hydraulic Function by Design}

Pipe, fittings and plumbing elements shall facilitate hydraulic efficiency and continuity of functional operation of the plumbing system, as follows:

1. The interior surfaces of assembled traps, pipes, fittings, receptors, and other devices and equipment intended to convey potable water, clear-water wastes, or sewage shall be acceptably smooth and essentially free of burrs, ledges, shoulders or other surface discontinuities.

2. Pipe reaches shall be routed in straight lines, and nominally horizontal reaches shall be installed with uniform grade in the direction required to facilitate drainability, as detailed In the model plumbing codes.

3. Changes in direction shall be accomplished by the use of appropriate, standard fittings, as detailed in the model plumbing codes.

4. Materials and techniques for making joints shall not effectively reduce the internal cross-sectional area of the piping nor introduce significant discontinuities in the interior surface.

5. Drainage piping shall not be reduced in cross-sectional area in the normal direction flow. Exception: standard methods for connecting 4-inch water closet branches to 3-inch soll stacks are acceptable. 
13.6 PLUMBING

.6 DURABILITY/MAINTAINABILITY

\subsubsection{2 (Continued)}

6. Conditions likely to contribute to gradual fouling and clogging of vents in the DWV subsystem should be avolded through appropriate design.

7. The DWV and rainwater drainage subsystem designs shall provide for water velocities of at least $2 \mathrm{fps}(0.6 \mathrm{~m} / \mathrm{s})$ in all active traps and drainage pipes during typical loading cycles in peak-load periods.

8. Design velocities in water piping shall not exceed values consistent with the chemical composition and temperature of the water, with the properties of the piping material and with generally recognized acoustic requirements including Criteria 13.6.7.7. Design velocities determined according to current generally recognized good practice shall be acceptable [1], but sha11 not exceed $8 \mathrm{fps}(2.4 \mathrm{~m} / \mathrm{s})$ in any event 1 !

\section{Method of Evaluation for 13.6.6.2}

Evaluation shall be based on analysis of the data provided, and on inspection where appropriate.

1/ This limitation need not be applied to individual fixture supply branches and water supply fitting connectors. 


\subsection{PLUMBING}

\section{.6 DURABILITY/MAINTAINABILITY}

\subsubsection{2 (Continued)}

Standard test methods do not exist (except, to a degree, for some of the acoustic criteria). However, evaluation will be facilitated by the systematic utilization of information given in selected references $[2,3,4$,

\section{Commentary for 13.6.6.2}

Excessive roughness causes energy loss and reduction of hydraulic capacity in piping and may contribute to the buildup of deposits in either water supply piping or drainage piping. Changes in direction of piping should be accomplished by the use of hydraulically efficient fittings to avold stoppage. Drainage piping should not be reduced in cross-sectional area in the normal direction of flow (certain standard methods for connecting 4 in, water closet branches to 3 in. soil stacks excepted).

Restrictions, abrupt enlargements or discontinuities at pipe joints, and sharp changes in direction can reduce hydraulic capacity, contribute to fouling and stoppage, adversely affect cleanability, and contribute to corrosion.

Useful guidance for designers and installers in providing minimum hydraulic resistance and in maintaining surface continuity has been given in a number of publications.

Flow velocity, water composition and service temperature should be considered in the selection of piping materials and in the estimation 


\subsection{PLUMBING}

\section{.6 DURABILITY/MAINTAINABILITY}

\subsubsection{2 (Continued)}

of hydraulic resistance in the service enviornment. Further data are needed on the interdependence of these parameters, to facilitate rational and realistic decisions concerning design and specification where innovative piping materials are being considered.

Standard test methods for hydraulic resistance or for surface discontinuity and relief are needed, that would address the parameters indicated above. Laboratory test procedures should provide for a reproducible, representative fluid load, applied to a representative assembly of pipe and fittings. The measure of overall resistance to fluid flow might be a roughness factor or a head loss as determined by a procedure that is consistent with the generally accepted "rational" pipe flow formula [5]. The measure of surface relief and discontinuity might be based further on the adaptation of a method that has been used for determining the surface profiles of abraded surfaces or porcelain enameled and fiberglass-reinforced polyester sanitary plumbing fixtures [6]. 


\subsection{PLUMBING}

\section{. 6 DURABILITY/MAINTAINABILITY}

\subsubsection{2 (Continued)}

\section{References:}

[1] Chapter 10 and Appendix B, National Standard Plumbing Code. National Association of Plumbing-Heating-Cooling Contractors and National Society of Plumbing Engineers, Washington.

[2] Recommended Minimum Requirements for Plumbing. Report on SubCommittee on Plumbing of the Building Code Committee. National Bureau of Standards, BH13, 1931.

[3] Standard Plumbing Engineering Design, John Wiley and Sons, 1963. L.S. Nie1sen.

[4] National Plumbing Code Handbook. McGraw-Hill, 1957. V.T. Manas and H. N. Eaton.

[5] Handbook of Hydraulics, H.W. King, 5th Edition., McGraw-Hill, 1963.

[6] Investigation of Performance Characteristics for Sanitary Plumbing Fixtures, National Bureau of Standards BSS 22 (1970). 


\subsection{PLUMBING}

\section{.6 DURABILITY/MAINTAINABILITY}

13.6.6.3 Criterion: Long-Term Stability of Dimensions and Strength of Piping

The planned life expectancy of the piping system as installed shall be attainable without compromise of the essential functional performance of the system. Important dimensional and structural properties of the piping materials shall not be compromised when exposed to conditions of expected extremes of hot water and agressive wastes, and to the expected maximum pressures and other structural loads. The following criteria are applicable:

(a) Dimensional Change

Exposure to 100,000 cycles of a suitable hot-water exposure test $1 /$ shall not cause the maximum angular deflection of pipes to exceed arctan 0.01 , the diametral difference to exceed $10 \%$, and the creep or permanent lineal dimensional change to exceed $0.5 \%$.

(b) Strength Reduction

Exposure of 100,000 cycles of a suitable hot-water exposure test* shall not cause the impact resistance, the ring-deflection strength and the beam strength to decrease by more than 25\%. Further, the exposure shall not cause the burst strength and leak resistance to be reduced below the levels required by Criteria 13.6.6.4 and $13.6 \cdot 6.5$

$1 /$ See Reference 5 for publication identifying some hot-water exposure tests that have been used for thermoplastic piping. 


\subsection{PLUMBING}

.6 DURABILITY/MAINTAINABILITY

\subsubsection{3 (Continued)}

Method of Evaluation for 13.6.6.3

Although no standard all-inclusive performance evaluation methodology has yet been established (see Commentary), the following test methods should be used for determination of important individual performance characteristics or related properties.

(a) Glass Transition Temperature $\stackrel{?}{=}$

See Table 13.6.6.3

(b) Hardness Temperature Coefficient

See Table 13.6.6.3

(c) Heat Deformation and Permanent Set

See Table 13.6.6.3

(d) Burst Strength Under Cyclic Pressure

See Table 13.6.6.3

(e) Lateral Deflection

See Table 13.6.6.3

A discussion of the applicable test methods is provided in the Commentary .

Commentary for $13 \cdot 6 \cdot 6.3$

Evaluations of innovative piping materials should take into account the possible adverse effects of extreme thermal and structural loads, 2. This and other terms are defined in Standard Definitions of Terms Relating to Plastics, ASTM D883. 


\subsection{PLUMBING}

\section{.6 DURABILITY/MAINTAINABILITY}

\subsubsection{3 (Continued)}

piping system installation details, and representative conditions of use. Dimensional changes which may occur and the probable extremes of thermal and structural loads should not cause significant degradation of any essential aspect of functional performance including self-scouring capability, drainability, hydraulic capacity, freedom from leaks, and structural reliability of supports and attachments. Examples of environmental factors which should be considered are hot water, wood shrinkage and settlement of soil or building. Permanent dimensional changes and changes in stress distributions resulting from such factors should not be sufficient to produce damaging stresses on joints, supports and attachments; excessive distortion of cross-section or excessive laterial deflection; separation of joints and expansion fittings, etc.

Depending on the duration and frequency of intermittent exposure to hot water, pipe diameter and wall thickness, distance from the source, and other factors, the temperatures within the piping materials in the service environment are likely to be appreciably less than those at the source (water heater). Recent measurements [1,2] of glass transition temperatures for $\mathrm{PVC}, \mathrm{ABS}, \mathrm{CPVC}$, and $\mathrm{PB}$ yielded values ranging from a low of $79^{\circ} \mathrm{C}\left(174^{\circ} \mathrm{F}\right)$ for PVC to a high of $123^{\circ} \mathrm{C}\left(253^{\circ} \mathrm{F}\right)$ for CPVC. Temperatures in excess of $65^{\circ} \mathrm{C}$ $\left(140^{\circ} \mathrm{F}\right)$ are rarely reached in residential plumbing applications. Where higher temperatures are anticipated, CPVC, PB or other heat-resistance materials should be used. Thus, there should be little concern about using $A B S, P V C, C P V C$ or $P B$ (having formulations identical to those examined in this study) in residential plumbing insofar as glass transition 


\subsection{PLUMBING}

\section{.6 DURABILITY/MAINTAINABILITY}

\subsubsection{3 (Continued)}

is concerned, when installed and used in accordance with generally accepted good practice. However, for future materials, this measure should be considered for evaluation purposes.

A number of ASTM tests of properties which may relate to functional performance capability are identified in a current report [3]. These should be evaluated for usefulness in completing the development of the performance tests needed in 13.6.6.3.

There are several tests of individual properties which can be used to indicate possible deficiencies in the ability of a piping system to provide essential long-term functional performance as required by Criteria 13.6.6.1, 13.6.7.1, 13.6.7.4, 13.6.7.5 and 13.6.7.6. Comments on some of these recommended evaluation tests are given below:

Glass transition. For a thermoplastic pipe, the glass transition temperature must be above the maximum service temperature (actual temperature in the piping material) if possible excessive permanent dimensional changes due to relaxation of internal stresses in the plastic piping components produced in the manufacture of pipe and fittings are to be prevented. The recommended test involves the measurement of the displacement of a loaded probe resting on a specimen, as a function of temperature, time and load (see Table 13.6.6.3).

Heat deformation and permanent set. A short, simple test is needed to indicate the magnitude of the permanent deformation (dimensional change) that may be expected from exposure to heat at temperatures near 


\subsection{PLUMBING}

\section{.6 DURABILITY/MAINTAINABILITY}

\subsubsection{3 (Continued)}

the expected maximum pipe temperature in service. It appears that a simple oven test made with relatively short lengths of pipe or with fittings, not structurally loaded, provides a realistic measure of the possible deformation. Recent measurements[2] in 120 hour oven tests (see Table 13.6 .6 .3 ) with $\mathrm{PVC}$ and $\mathrm{ABS}$ at $77^{\circ} \mathrm{C}\left(171^{\circ} \mathrm{F}\right.$ ) produced essentially no length change in $A B S$, and about $-1 \%$ length change in PVC. In residential plumbing applications, a temperature as high as $77^{\circ} \mathrm{C}$ within the piping material seems highly unlikely because of the typical intermittent, shortduration exposure pattern and because of the cooling of the hot water in the distributing pipes and drain lines. Since typical maximum pipe temperatures in drainage systems in residential use are likely to be appreciably less than $77^{\circ} \mathrm{C}$, heat deformation of PVC or ABS should not be a problem in residential usage.

Creep. . Small dimensional changes in piping materials can be accomodated by design and installation, but excessive changes, whether intermittent or permanent, can lead to rupture and leaking, drainability problems, acoustical problems, etc. Under some conditions, permanent dimensional changes can occur through long-term creep under forces of structural or thermal origin. The BRAB tests S-3 Concentrated Load Test [4] measures creep under externally imposed structural loads, but the length of this test $(10,000$ hours $)$ is a disadvantage. Tests recent1y made for heat deformation [2] and hot water effects [5] of PVC, ABS and CPVC showed no cause for concern about dimensional changes in properly installed 


\subsection{PLUMBING}

\section{.6 DURABILITY/MAINTAINABILITY}

\subsubsection{3 (Continued)}

piping under conditions of use. No tests specifically for creep were made in this study; however the tests of assemblies with intermittent hot water exposure involved some structurally and thermally induced stress. The dimensional changes observed in this test were within the limitation of Criterion 13.6.6.3.

Hardness as a function of temperature. The evaluation of piping materials for resistance to impact (e.g., shock pressure) would be facilitated if a simple relationship could be established between the temperature coefficient of hardness and the effect of temperature on the resistance of the material to failure under impact. Recent measurements. indicate there may be a correlation between these quantities. Summary of Tests. Table 13.6.6.3 provides a summary of the tests referred to in Section 13.6.6.3 and relates them to specific performance criteria.

Correlation needs. Before full reliance can be placed on the tests suggested above for evaluating the stability of dimensions and strength of piping materials, it will be necessary to establish correlations, under selected conditions, between the performance measured in these tests and that in full-scale tests in representative assemblies exposed to intermittent hot and/or cold water, and to shock pressure and sustained pressure. 


\begin{tabular}{|c|c|c|c|c|}
\hline & 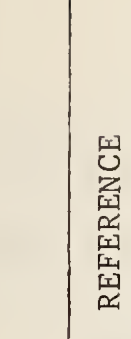 & 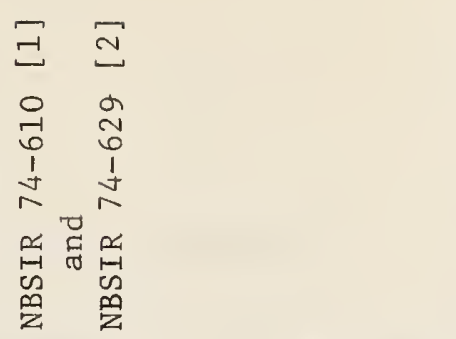 & 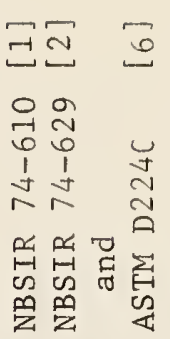 & 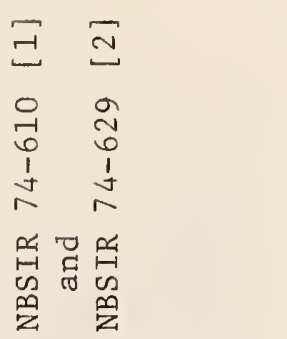 \\
\hline 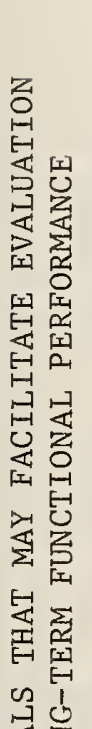 & 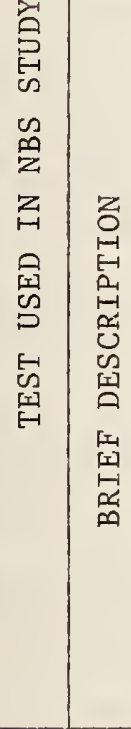 & 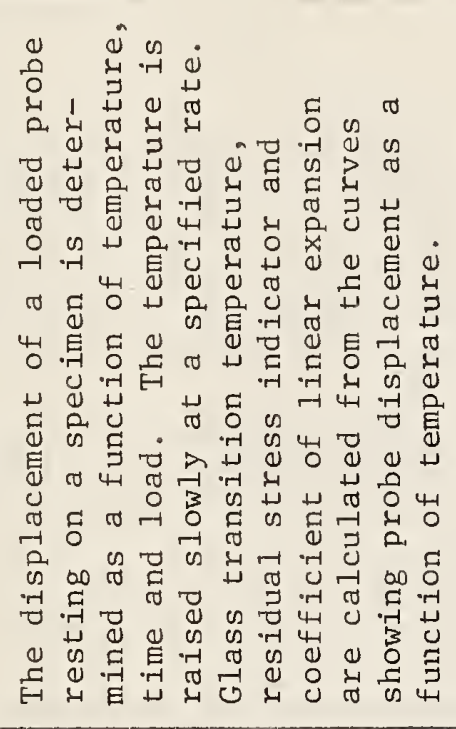 & 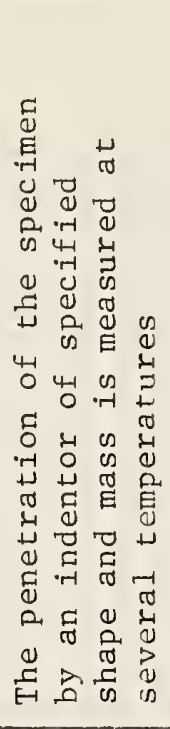 & 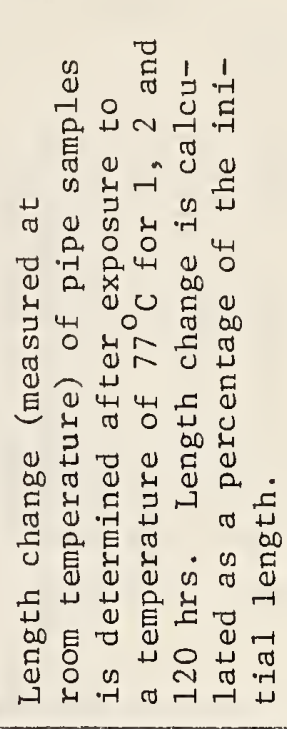 \\
\hline 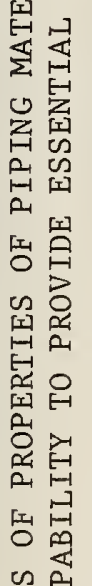 & 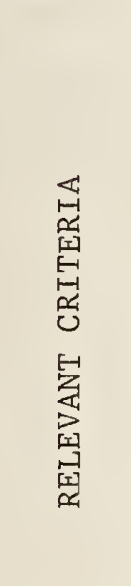 & 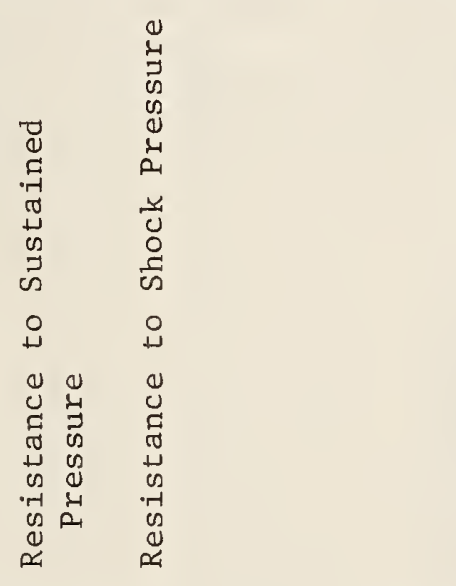 & 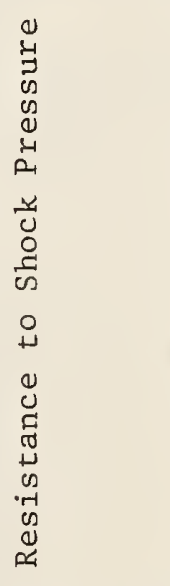 & 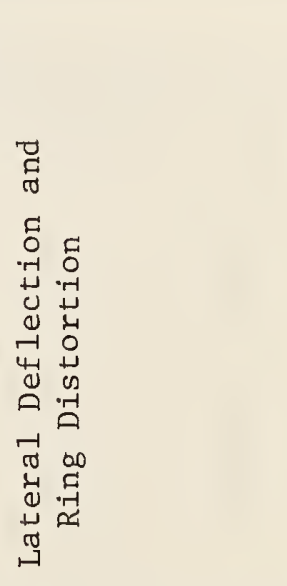 \\
\hline 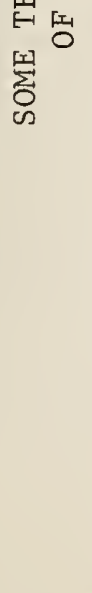 & 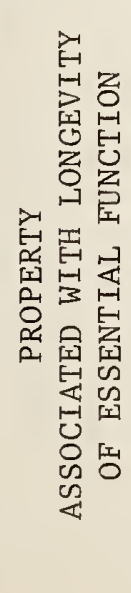 & 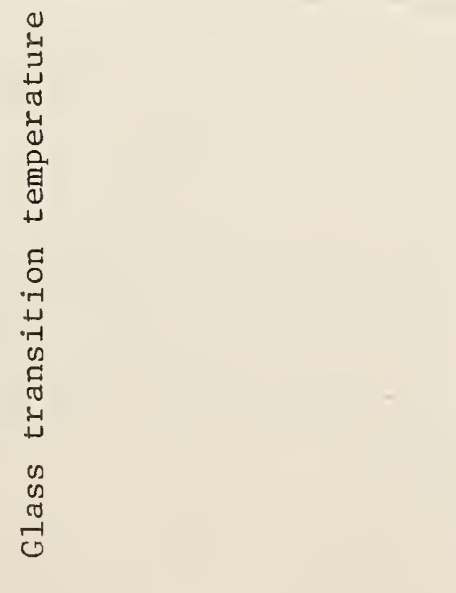 & 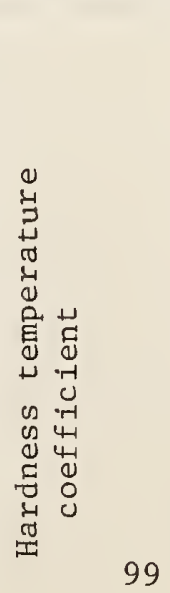 & 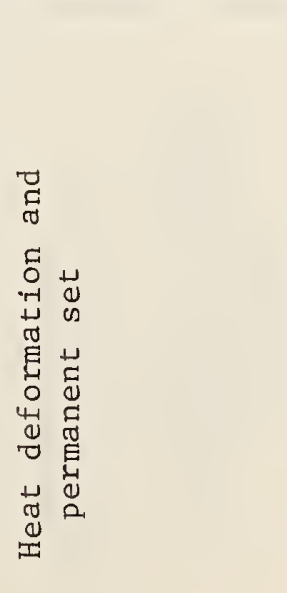 \\
\hline
\end{tabular}




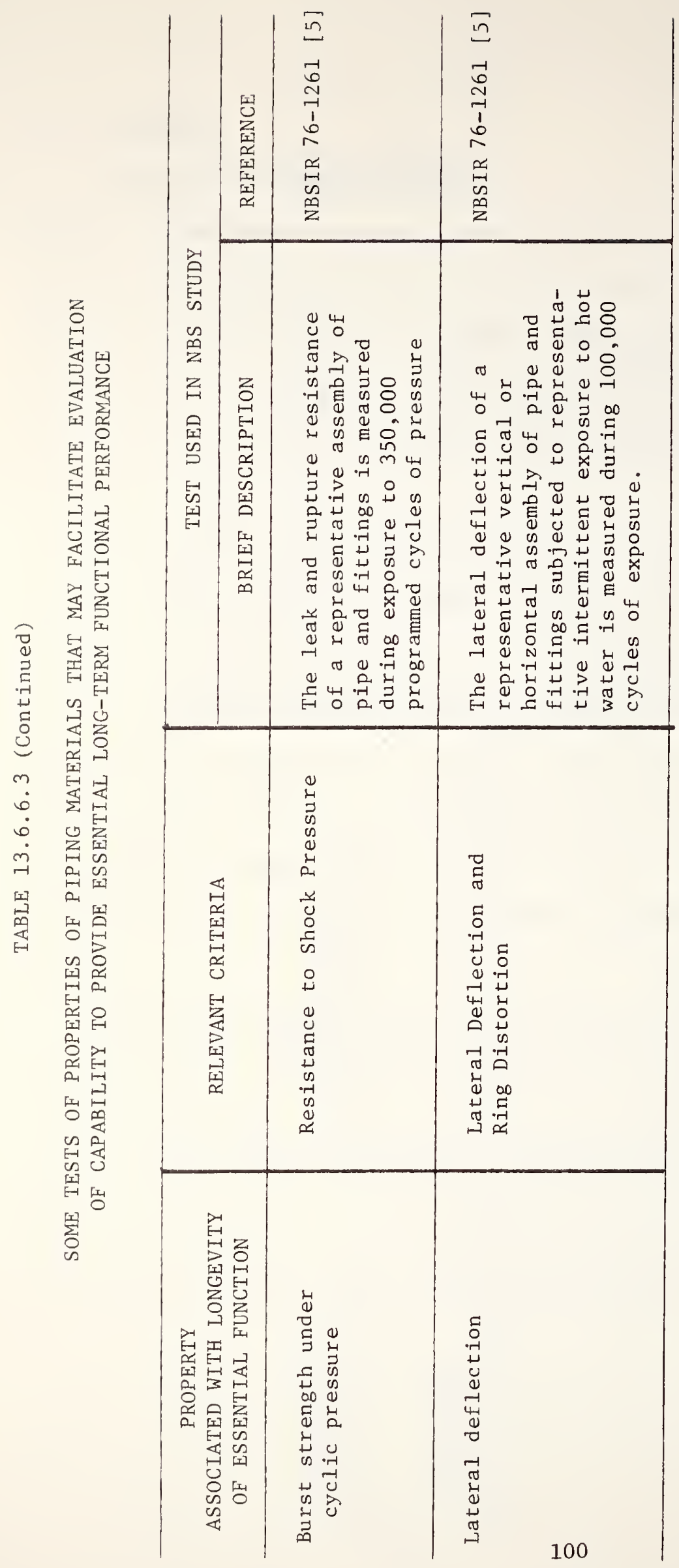




\subsection{PLUMBING}

\section{.6 DURABILITY/MAINTAINABILITY}

\subsubsection{3 (Continued)}

\section{References:}

[1] "Investigation of Procedures for Determination of Thermal Performance Characteristics of Plastic Piping Used in Housing." National Bureau of Standards, NBSIR 74-610.

[2] "Thermal Properties of Selected Plastic Piping Used in Housing," National Bureau of Standards, NBSIR 74-629.

[3] "Investigation of Standards, Performance Characteristics and Evaluation Criteria for Thermoplastic Piping in Residential Plumbing Systems." National Bureau of Standards, BSS (in publication).

[4] "Thermoplastic Piping for Potable Water Distribution Systems," F.C.C. Technical Report No. 61, NAS-NRC (1971).

[5] "Laboratory Tests of Selected Thermoplastic Piping Assemblies Subjected to Water Hammer or Intermittent Hot Water Flow," National Bureau of Standards, NBSIR 77-1261.

[6] "Indentation Hardness of Rubber and Plastics by Means of a Durometer," ASTM D2240, 1916 Race Street, Philadelphia, PA 19103. 


\subsection{PLUMBING}

.6 DURABILITY/MAINTAINABILITY

\subsubsection{Criterion: Resistance to Sustained Pressure}

Assemblages of pipe and fittings shall withstand sustained system design pressures at anticipated service temperatures in tests up to 100,000 hours with extrapolation to 50 years without rupture or leakage of fluids from the system, based on a safety factor of 2.0. Applicable temperatures are:

Cold-water (only) systems: $73.4^{\circ} \mathrm{F}\left(23^{\circ} \mathrm{C}\right)$

Domestic hot-water (or hot/cold water) systems: $180^{\circ} \mathrm{F}\left(82^{\circ} \mathrm{C}\right)$

Method of Evaluation for 13.6.6.4

The present ASTM D1598 $1 /$ and D1599 $2 /$ tests for long-term and short-time pressure testing used together appear sufficient for this requirement.

The apparatus and procedure for long-term testing are as specified in ASTM D2837 3 / except that the test specimen sha11 consist of two equal lengths of pipe joined with a fitting in accordance with the recommendations of the pipe manufacturer. The evaluation shall be performed with each type of fitting that might be used to join the pipe for the application considered.

I/ Time-to-Failure of Plastic Pipe Under Constant Internal Pressure, ASTM D1598 (ANSI B72.6).

2/ Short-Time Rupture Strength of Plastic Pipe, Tubing, and Fittings, ASTM D1599 (ANSI K65.53).

3/Obtaining Hydrostatic Design Basis for Thermoplastic Pipe Materials, ASTM D2837 (ANSI K65.153). 


\subsection{PLUMBING}

\section{.6 DURABILITY/MAINTAINABILITY}

\subsubsection{4 (Continued)}

The temperature of the water within the test specimen during the test shall be as stated in the Criterion, for the application considered. The short-time burst strength of the pipe and fitting assemblage shall be as recommended by the manufacturer based on documented data correlating results from short-time and long-term destructive tests.

\section{Commentary for 13.6 .6 .4}

Piping joining solvents, cements or other joining materials must be compatible with the pipe so that made-up joints are adequately tight and strong to preclude leakage under service conditions or representative hydrostatic/pneunatic tests. Chemical or physical compatibility must exist to preclude joint leakage due to poor bond, or to chemical or aging changes in the joining material or in the attached pipe, fitting, or device. The means provided for joining pipe and fittings to dissimilar materials should be such as to facilitate the maintenance of lead-free connections under conditions of variable temperature and pressure, and to facilitate making repairs in the future, where required. The joint system should be appropriate to the particular piping material and the procedures for preparing and making the joints should be based on the manufacturer's recommendations. Product Standards and industry publications provide guidance in these matters.

The important feature of the suggested performance test is that an assembly of pipes and joints is tested together. The investigation of 
13.6 PLUMBING

.6 DURABILITY/MAINTAINABILITY

13.6.6.4 (Continued)

ASTM D2837 as the test method to statistically and mathematically analyze failure test data for such systems has not been carried out. 


\subsection{PLUMBING}

\section{.6 DURABILITY/MAITAINABILITY}

13.6.6.5 Criterion: Resistance to shock pressure (water hammer)

Pipe, fittings, and joints intended for use in water-distributing systems within residential buildings shall withstand a repetitive shock pressure of 150 psi (1.03M Pa) (static plus dynamic pressure) for 350,000 cycles at temperatures specified in Table 13.6.6.5 without rupture or leakage of fluids from the system.

TABLE 13.6 .6 .5

SHOCK PRESSURE TEST TEMPERATURES

\begin{tabular}{lr}
\hline Intended Application & Test Temperature \\
\hline Cold Water Only & $50^{\circ} \mathrm{F}\left(10^{\circ} \mathrm{C}\right)$ \\
\hline Hot Water On1y & $180^{\circ} \mathrm{F}\left(82^{\circ} \mathrm{C}\right)$ \\
\hline Hot or Cold Water & $50^{\circ} \mathrm{F}\left(10^{\circ} \mathrm{C}\right)$ \\
$180^{\circ} \mathrm{F}\left(82^{\circ} \mathrm{C}\right)$
\end{tabular}

If water hammer arrestors are provided they sha11 conform to the requirements of ANSI A112.26.1 [1].

Method of Evaluation for 13.6.6.5

Evaluation shall be based on analysis of the data provided and on inspection where appropriate. No standard test method exists, however, evaluation will be facilitated by the systematic utilization of information given in references $[1,2,3]$ 


\subsection{PLUMBING}

\section{.6 DURABILITY/MAITAINABILITY}

\subsubsection{5 (continued)}

Commentary for $13 \cdot 6 \cdot 6.5$

An important basic criterion by which the ability of piping systems to withstand the impact producted by water hammer may be judged is the number of cycles of shock pressure that may occur before fallure.

However, the result may be dependent on the form of the pressure wave as well as on the properties of the piping material. A suitable test procedure should utilize a reproducible, representative pressure cycle with respect to amplitude and frequency. These parameters might be related to the properties of a piping material that determine its ability to absorb the energy at the rate produced.

Some methods that have been used in shock pressure tests of piping have been summarized [2]. Based on this work, a frequency of $2 \mathrm{~Hz}$ with a pulse width of $0.16 \mathrm{sec}$. is suggested for test purposes.

A method for shock pressure testing for acceptance of water-hammer arrestor devices has been described in ANSI A112.26.1[1]. The recommendation for resistance to a repetitive 150 pse (shock p.lus static) pressure stems from that standards. REFERENCES

[1] Water Hammer Arrestors, ANSI A112.26.1, American Society of Mechanical Engineers and American Society of Sanitary Engineering.

[2] Laboratory tests of Selected Thermoplastic Piping Assemblies Subjected to Water Hammer and Intermittent Hot Water Flow D.E. Rorrer, J.R. Shaver and R.W. Wyly, National Bureau of Standards - NBSIR 77-1261, August, 1977.

[3] Performance of PVC Pipe in Water Distribution Systems., R.T. Hucks, Jr., Modern Plastics, September 1972. 


\subsection{PLUMBING}

\section{.6 DURABILITY/MAINTAINABILITY}

\subsubsection{Criterion: Evaporation Protection in Seldom-Used Traps}

Suitable provisions shall be made to maintain at least one-half of the full trap seals during anticipated idle periods, in all seldom-used traps in sanitary DWV and rainwater drainage subsystems that provide a primary barrier against entry of sewer gases and vermin into the buildings. A period of protection adequate to account for anticipated evaporation during non-use periods sha11 be provided, in no case less than 60 days.

\section{Method of Evaluation for 13.6.6.6}

Evaluation will take into account the following considerations:

(1) Maintainance of an adequate depth of trap seal sha11 be accomplished without waste of water.

(2) If a device is used that is connected to the potable water supply, it shall be so designed and/or installed as to prevent backflow from the trap into the potable water supply upon a reduction of supply pressure to subatmospheric. Backflow protection shall be assured in accordance with generally accepted standards $[1,2]$.

(3) If protection is to be provided through element design to reduce evaporation rate or otherwise increase the time required for $50 \%$ trap-seal depletion rather than by replenishment of the trap seal, calculations sha]1 be submitted showing the predicted period to reach a $50 \%$ reduction in idle trap seal based on 


\subsection{PLUMBING}

.6 DURABILITY/MAINTAINABILITY

\subsubsection{6 (Continued)}

anticipated temperature/humidity conditions during the most critical season. Calculations may be made according to HHFA HRP 31 [3] or comparable methods.

\section{REFERENCES}

[1] Backflow protection requirements of the Model Codes:

Basic Plumbing Code (BPC) 1975. (Basic Principle No. 16; Article No. 1203.6, 1217.3, 1605.1, 1605.8, and 1605.11). Building Officials and Code Administrators International, Inc. (BOCA), 1313 E. 60 Street, Chjcago, Illinois 60637.

National Standard Plumbing Code (NSPC) 1975. (Basic Principle Paragraphs No. 7.5, 7.16.1, 10.4 and 10.5). American Society of Plumbing-Heating-Cooling Contractors (NAPHCC) and Americal Society of Plumbing Engineers (ASPE), 1016 20th Street, NW, Washington, DC 20036

Standard Plumbing Code (SPC) 1975. (Basic Principle No. 61; sections No. 905.1, 1204, and 1205). Southern Bullding Code Congress International, Inc. (SBCC), 3617 8th Avenue, Sough Birmingham, Alabama 35222 .

Uniform Plumbing Code (UFC) 1976. (Sections No. 707, 1002, and 1003). International Association of Plumbing and Mechanical Officials (IAPMO), 5032 Alhambra Avenue, Los Angeles, California 90032.

[2] Trap Seal Primer Valves. Standard No. 1018. American Society of Sanitary Engineers, 960 Illuminating Ruilding, Cleveland, Ohio 44113.

[3] Performance of Plumbing Fixtures and Drainage Stacks. Housing and Home Finance Agency HRP31, 1954. 


\subsection{PLUMBING}

.6 DURABILITY/MAINTAINABILITY

\subsubsection{Criterion: Freeze Protection}

Essential functions of plumbing systems sha11 not be compromised by extremes in cold weather that could cause rupture, leaking or interruption of flow from freezing during the period of the design life expectancy of the buildings (See Criterion 13.6.6.1).

\section{Method of Evaluation for 13.6.6.7}

Review of Plans, specifications and calculations. Inspection of build elements.

\section{Commentary for $13 \cdot 6 \cdot 6.7$}

Freezing of water supply piping and fixture traps can cause critical damage to the plumbing system, or at the least cause interruption of service. Freezing of vent terminals (roof vents) can temporarily interrupt the function of these vents, but this is less critical than freezing of water piping and fixtures.

The freeze-protection requirements of the applicable plumbing and building codes should be observed. Calculations should be based on pertinent National Weather Service data and applicable thermal relationships of the ASHRAE GUIDE[1] and NBS BMS 142[2]' Research organizations or manufacturers of piping materials should provide data showing the 


\subsection{PLUMBING \\ .6 DURABILITY/MAINTAINABILITY}

\subsubsection{7 (Continued)}

results of repetitive freezing of pressure pipes and fixture traps under representative service conditions.

Generally accepted good practice in insulation placement and thickness, and in the distribution of warm air should be followed, especially as it might affect the ambient air temperature around pipes and traps near or within outside walls or other spaces that might be exposed to subfreezing temperatures in extremely cold weather. In areas subject to freeze damage, water pipes and fixture traps should not be placed within or adjacent to uninsulated outside walls, nor on the cold side of the insulation when within or adjacent to insulated outside walls. Vent terminals should not extent more than 6 inches $(15 \mathrm{~cm})$ through the roof on the high side, and size increasers below the roof line may be required under extreme conditions.

\section{References}

[1] ASHRAE Handbook of Fundamentals (1972). Amer. Soc. of Heating, Refrigeration and Air Conditioning Engineers.

[2] Frost Closure of Roof Vents. National Bureau of Standards BMS 142 (1954) H.N. Eaton and R.S. Wyly. 


\subsection{PLUMBING}

\section{$.7 \quad$ FUNCTIONAL OPERATION}

\subsubsection{Criterion: Leak Resistance}

The piping of plumbing subsystems shall not leak when subjected to simulated service pressures for 15 minutes.

\section{Method of Evaluation for 13.6.7.1}

1. The water service and distribution subsystem shall be tested with :

a. Water pressure equal to the maximum anticipated hydrostatic service pressure, but not less than 100 psi (690 kPa) imposed on each element, or

b. Air pressure of $50 \mathrm{psi}(345 \mathrm{kPa})$ imposed on each element.

2. The sanitary DWV subsystem shall be tested as follows:

a. Rough piping shall be tested with either water or air pressure equivalent to the maximum anticipated hydrostatic pressure caused by a typical critical stoppage for the design being evaluated, but in no case less than that equivalent to a 10 foot head $(3.0 \mathrm{~m})$ of water imposed on each critical element.

b. Finished plumbing $1 /$ shall be tested with the maximum air pressure differential anticipated from typical critical pneumatic pressure differentials within the DWV piping but in no case less than that equivalent to a 2-inch (50 mm) head of water.

1 With all fixtures, appliances and traps installed and the traps filled with water before the test. 


\subsection{PLUMBING}

\section{.7 FUNCTIONAL OPERATION}

\subsubsection{1 (Continued)}

3. The rainwater drainage subsystem shall be tested $2 /$ using either water or air pressure equivalent to the maximum anticipated hydrostatic pressure caused by a typical critical stoppage for the design being evaluated, but in no case less than that equivalent to a 10 foot $(3.0 \mathrm{~m})$ head of water imposed on each critical element.

\section{Commentary for $13 \cdot 6.7 .1$}

It is desirable that leak tests be made on the entire subsystem after field assembly/erection. The application of tests to the individual components may be useful at critical stages during the manufacturing, distribution, and/or construction process, but for factory made assemblies subject to possible joint damage in handling and transport, as well as assemblies requiring field joints, appropriate tests of the complete, finished subsystem should be made before acceptance. The model plumbing codes and industry literature provide further detail on leak testing procedures.

\footnotetext{
2 'Rainwater gutters and leaders, external to the building and properly installed so as to avoid wetting the building walkways or causing building damage on leaking, may be excepted from this test.
} 


\subsection{PLUMBING}

.7 FUNCTIONAL OPERATION

\subsubsection{Criterion: Adequacy of Flow Rates at Water Outlets}

Water service and distribution subsystem shall be designed to provide adequate, but not excessive, flow rates at all water outlets under design peak demand conditions as shown in Table 13.6.7.2. 
13.6 PLUMBING

.7 FUNCIITONAL OPERATION

13.6.7.2 (Continued)

Table 13.6.7.2

1. Maximum and Minimum Flow Rates and Minimum Flow Pressures 1 at Water Outlets

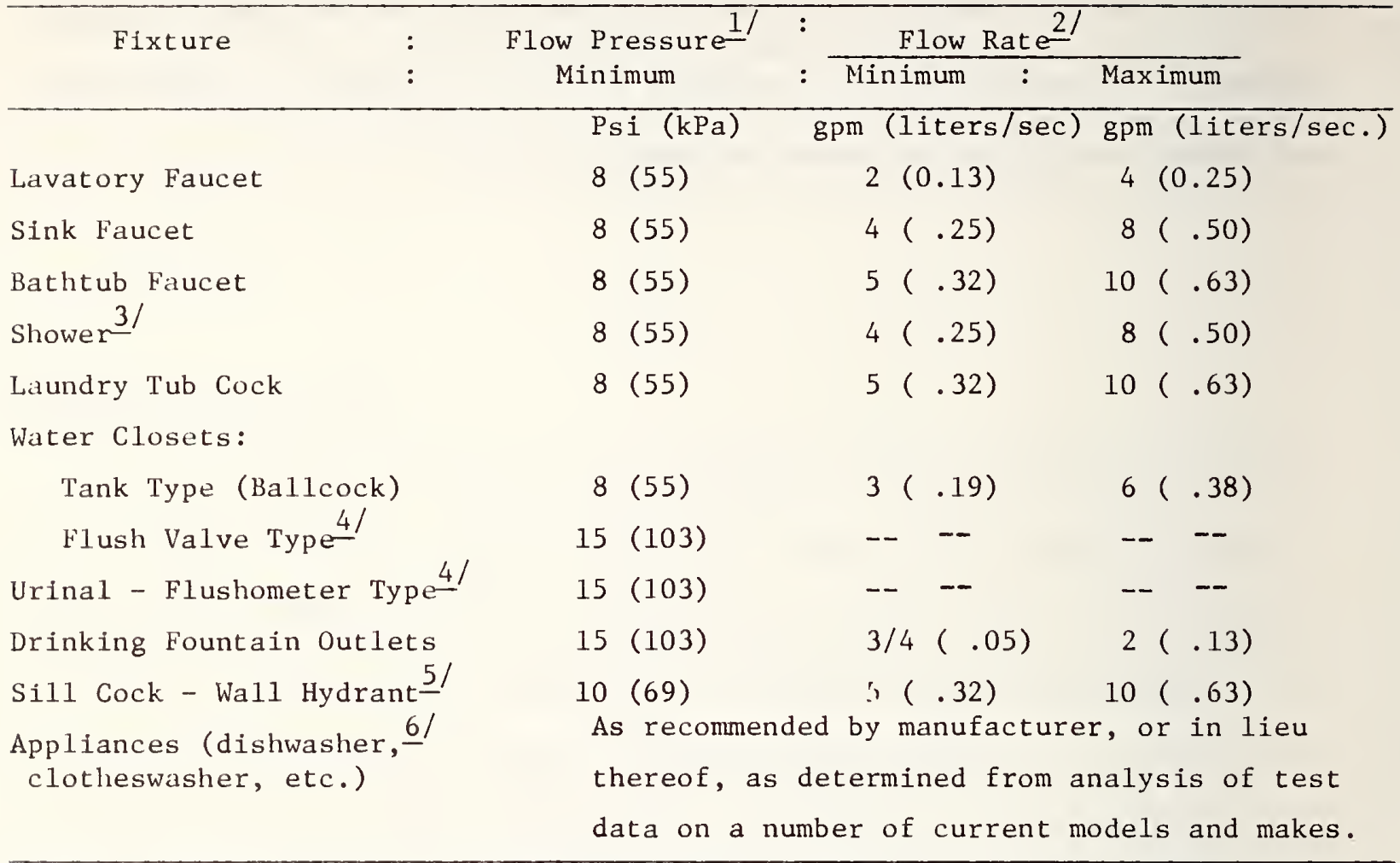

I/The minimum pressure in the fixture supply pipe at the point of connection to the water supply fitting assembly, while the water is flowing at design load conditions. Design flow pressures may have to be greater than indicated minimum values to produce required flow rates in some circumstances.

2/Flow rates are applicable to cold water only for outlets not supplied with hot water; and to hot, cold, and all degrees of mix for outlets equipped with mixing faucets or devices.

3 /These rate limits may be reduced as much as $50 \%$ by flow restrictors for purposes of water conservation.

4/Wide range in flow rates due to variation in design and type of flush valves and fixture bowls, and in flow pressure. A range of $20-40 \mathrm{gpm}$ (1.3-2.5 liters/ sec.) may be typical of $1^{\prime \prime}$ WC flushometers, and 10-20 (0.6-1.3 1iters/sec.) gpm for 3/4" urinal flushometers

5/With 50 feet $(15.2 \mathrm{~m})$ of $3 / 4^{\prime \prime}$ garden hose attached, without nozzle. 6/A range of 4-8 (0.25-0.50 liters/sec.) gpm may be typical. 


\subsection{PLUMBING}

\section{$.7 \quad$ FUNCTIONAL OPERATION}

\subsubsection{2 (Continued)}

\section{Method of Evaluation for 13.6.7.2}

By calculation in accordance with generally accepted practice, [1, 2, 3] by test of full-scale simulation or prototype installation subjected to representative hydraulic loads.

\section{Commentary for $13 \cdot 6 \cdot 7.2$}

Not only is it essential to have specified minimum flow rates at outlets to satisfy functional requirements, but in the interest of water conservation and acoustical control, and of improving the precision of peak load estimates for design purposes, control of the maximum flow rate is also desirable. This may be accomplished through appropriate hydraulic design of the water supply fittings, or by the use of flow-limiting devices such as variable area orifices, etc. Application of this criterion would be facilitated if manufacturers would furnish the necessary hydraulic data for their water supply fittings obtained by a standard procedure and presented in a standard format, and if new data on peak water demand in buildings were provided.

In determining conformance to this criterion, it is important also to determine conformance to the criteria relating to maximum flow velocities and general hydraulic design $(13 \cdot 6 \cdot 6 \cdot 2)$.

Test methods for determining hydraulic characteristics at water outlets under representative loading conditions are needed. Perhaps the loadselection criteria for such tests could be patterned after those suggested for $13 \cdot 6 \cdot 7 \cdot 4$ and $13 \cdot 6 \cdot 7 \cdot 5$ 


\subsection{PLUMBING}

.7 FUNCTIONAL OPERATION

13.6.7.2 (Continued)

\section{References}

[1] Standard Plumbing Engineering Design, John Wiley and Sons, 1963, L. S. Nielsen.

[2] National Standard Plumbing Code (Appendix B) - Sizing the Building Water Supply System. National Association of Plumbing-HeatingCooling Contractors and American Society of Plumbing Engineers, 1975.

[3] Water-Distributing Systems for Buildings, National Bureau of Standards BSM 79, 1941, R.B. Hunter 


\subsection{PLUMBING}

\section{.7 FUNCTIONAL OPERATION}

\subsubsection{Criterion: Hydraulic Capacity of Rainwater Drainage Subsystems}

Rainwater drainage subsystem designs shall demonstrate carrying capacities sufficient to accomodate the following conditions:

1. All anticipated critical combinations of duration and intensity of rainfall at any time during the design return period shall be taken into account.

2. With all drains discharging freely, water temporarily impounded shall not produce superimposed structural loads exceeding $15 \mathrm{psf}$ $\left(73.3 \mathrm{~kg} / \mathrm{m}^{2}\right)$ at any point in the catchment areas of controlledflow systems at any time during the design return period unless the structure is designed for the added load.

3. With all drains closed, superimposed structural loads due to impounded water shall be limited to no more than $20 \mathrm{psf}\left(97.7 \mathrm{~kg} / \mathrm{m}^{2}\right)$ at all points on roofs or other above-ground, structurally supported catchment areas served by controlled-flow systems unless the structure is designed for the added load.

4. With all drains discharging freely, systems designed for instantaneous removal of rainwater shall have sufficient hydraulic capacities to avoid over flowing of eaves gutters or creation of backwater conditions on the catchment areas served at any time during the design return period.

5. Leaders and conductors shall be sized to avoid excessive vibration and acoustic nuisance, by limiting the water cross section to a maximum of $30 \%$ of the leader or conductor area at terminal velocity. 


\section{.7 FUNCTIONAL OPERATION}

\subsubsection{3 (Continued)}

6. Building storm drains and building storm sewers may be sized to flow full computed as the limiting condition for open-channel flow, provided no floor drains or other input elements are connected to the building drain within the lowest branch interval; otherwise the building storm drain and building storm sewer shall be sized on the basis of flowing at a depth of $2 / 3$ of the pipe diameter.

7. If a controlled-flow design is used, it shall demonstrate the ability to remove the impounded water in a period of time sufficiently short to preclude freezing of the impounded water. A period of not exceeding 17 hours for removal of water from a 25-year (return period) storm will be acceptable. Other periods may be accepted, if such other periods are either necessary or reasonable based on local weather records published by the National Oceanic and Atmospheric Administration.

8. Design return periods shall not be less than indicated in Table 13.6.7.3. 


\subsection{PLUMBING}

\section{.7 FUNCTIONAL OPERATION}

13.6.7.3 (Continued)

Table 13.6.7.3

Minimum Design Return Periods for Computation of Pipe Sizes in Rainwater Drainage Subsystems

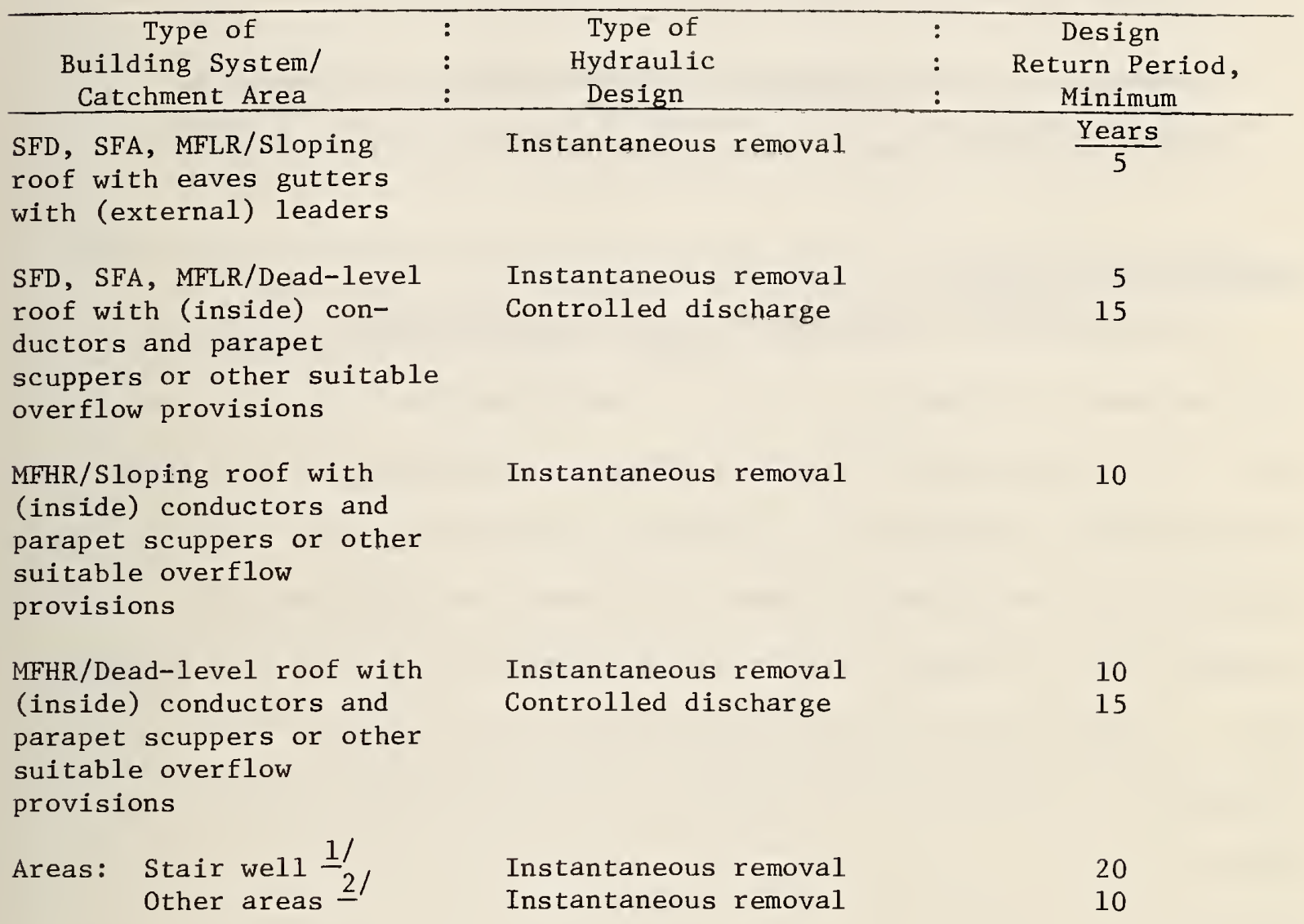

I/ A 20-year return period is given based on the criterion that flooding of a portion of the building due to water rise above threshold level is allowable on the average, no more than once in 20 years.

2/E.g., porches, marquees, etc. A 10-year return period is given based on the premise that a storm exceeding the design storm for the area being drained will not flood the interior of the building, nor cause damage to structures or embankments. If such flooding would occur, a longer return period should be selected for design purposes. 


\subsection{PLUMBING}

\section{.7 FUNCTIONAL OPERATION}

\subsubsection{3 (Continued)}

Method of Evaluation for 13.6.7.3

Review of plans and specifications

Review of Test data and/or sizing calculations.

Evaluation will be facilitated by the systematic utilization of information given in selected references $[1,2,3,4,5,6,7,8]$.

\section{Commentary for $13 \cdot 6 \cdot 7.3$}

Economic benefits, functional adequacy and environmental effects may be advantageously balanced by the use of controlled-flow drainage in some cases. Where appreciable structural allowance is provided for snow load, controlled-flow drainage may be particularly attractive. Also it may be desirable where environmental impact requirements severely limit the allowable rate of rainwater runoff from buildings and adjacent hard-surfaced areas. Publications providing design guidance for controlled flow storm drainage $[3,4,5$,$] should be consulted in reviewing designs based on this$ concept.

\section{References}

[1] Standard Plumbing Engineering Design. Louis S. Nielsen, McGraw-Hil1 (1963).

[2] Design of Plumbing and Drainage Systems, Second Edition (1963). Louis Blendermann, Industrial Press.

[3] Storm Water Roof Drainage Systems. Louis Blendermann, Manual CF, Josam Manufacturing Co., Michigan City, Indiana, 46360 (1969).

[4] Basic Plumbing Code (BPC) 1975, Article 8, Storm Drains. Building Officials and Code Administrators International, Inc. (BOCA), $1313 \mathrm{E} 60$ th Street, Chicago, Illinois 60637. 


\section{REFERENCES CONTINUED}

[5] National Standard Plumbing Code (NSPC) 1975, Chapter 13, Storm Drains, National Association of Plumbing-Heating-Cooling Contractors (NAPHCC) and American Society of Plumbing Engineers (ASPE), 1016 20th Street, N.W., Washington, D.C. 20036

[6] Technical Paper No. 25, "Rainwater Intensity-Duration-Frequency Curves for Selected Stations in the United States, Alaska, Hawaiian Islands, and Puerto Rico." U.S. Department of Commerce, Weather Bureau (1955).

[7] Technical Paper No. 40. "Rainfall Frequency Atlas of the United States for Durations from 30 minutes to 24 hours and Return Periods from 1 to 100 years", U.S. Department of Commerce, Weather Bureau (1963).

[8] Rainfall Data in addition to [6] and [7] may be obtained from the National Oceanic and Atmospheric Administration (NOAA), Department of Commerce, Environmental Data Service, Federal Building, Asheville, North Carolina, 28801. 


\subsection{PLUMBING}

\section{.7 FUNCTIONAL OPERATION}

13.6.7.4 Criterion: Hydraulic and Pneumatic Performance - DWV Branch Assembly

The DWV branch assembly for each branch interval, including all its traps, fixture drains, trap arms, vertical waste pipes, fixture branches, and vent pipes, shall be designed and installed so that during representative peak-loading conditions the following levels of performance will be acheived:

1. Adequate trap-seal retention:

Self-siphonage. Trap-seal retention shall be at 1 east $50 \%$ or

1 in. (25 mm), whichever is greater, in all traps when tested for self-siphonage.

Induced siphonage. Trap-seal retention shall be at least $50 \%$ or

1 in. $(25 \mathrm{~mm})$, whichever is greater, in all traps when tested for cumulative effects of induced siphonage.

2. Limitation of water rise:

Water rise into dry vents shall not occur during the induced siphonage test. Water rise in the fixture-side of idle traps shall not exceed $100 \%$ of the full trap-seal depth, and water rise at the lower ends of idle horizontal branch drains shall not exceed one drain diameter during the induced siphonage test.

Method of Evaluation for 13.6.7.4

See section $13 \cdot 6 \cdot 7.5$ 


\subsection{PLUMBING}

\section{$.7 \quad$ FUNCTIONAL OPERATION}

\subsubsection{Criterion: Hydraulic and Pneumatic Performance - DWV Stack and}

\section{Building Drain Assembly}

The DWV stack and building-drain assembly, including all of its soil, waste, and vent piping, shall be designed and installed so that during representative peak-loading conditions the following levels of performance will be achieved:

\section{Adequate trap-seal retention:}

Trap-seal retention shall be at least $50 \%$ or 1 in. (25mm), whichever is greater, in all traps when tested for cumulative effects of induced siphonage.

2. Absence of blow-back, and limitation of water rise:

Blow-back shall not occur. Water rise in the fixture-side of idle traps shall not exceed $100 \%$ of the full trap-seal depth, and water rise at the lower ends of idle horizontal branch drains shall not exceed one drain diameter during the induced siphonage test. Rise of waste water into dry vents shall not occur during the induced siphonage test.

3. Adequacy of flushability and discharge characteristics of fixtures and appliances:

(a) The characteristic average and peak rates of drainage discharge from active fixtures discharged individually shall not be changed by more than $10 \%$ when discharged in combination during the induced siphonage test. 


\subsection{PLUMBING}

\section{.7 FUNCTIONAL OPERATION}

\subsubsection{5 (Continued)}

(b) The ratio of one second peak-to-average discharge rates of plumbing fixtures shall not exceed 1.5 when tested by a suitable procedure $[1,2,3,4,5,6,7,]^{1 /}$

(c) The flushing performance of water closets shall satisfy the relevant performance requirements derived from manufacturers' quality control standards when determined during the induced siphonage test.

(d) Water closets shall not discharge more than 3.7 gal. (14.0 liters), including afterflow, in a representative operation when tested by a suitable procedure.

\section{Method of Evaluation for 13.6.7.4 and 13.6.7.5}

1. Self siphonage test. Discharge filled individual fixture for four successive times, and observe trap-seal reduction after each run.

2. Induced siphonage test. Discharge predetermined combinations of fixtures obtained from Tables $13 \cdot 6 \cdot 7 \cdot 5-1$ or 13.6.7.5-2, as applicable, for four successive times without refilling idle traps after each run. Additives should be in accordance with Table 13.6.7.5-3. Observe trap-seal reduction in all idle traps after completion of the fourth run.

3. Blowback and water rise tests. During the induced siphonage test (see 2 above) observe for blowback in idle traps, water rise in the fixture sides of idle traps, and water rise at the lower ends of idle horizontal

1/References provide test methods that have been used for evaluating hydraulic characteristics and flushability of plumbing fixtures. 


\subsection{PLUMBING}

\section{.7 FUNCTIONAL OPERATION}

\subsubsection{5 (Continued)}

branch drains and at the lower ends of dry vents.

4. Flushability tests and discharge characteristics. From applicable flushing tests 1 , calculate the flushing performance rating of the lowest water closet connecting to the drainage stack that is involved in the test loads applied in the induced siphonage tests. Make flushability test during the imposition of the induced siphonage test loads. Using suitable test methods ${ }^{1 /}$, measure the average and peak rates of drainage discharge from the fixtures discharged individually, and calculate the ratio of the one second peak to the average rate. Also, determine the total volume discharged (and the amount of afterflow for water closets, appliances or appurtenances that are designed to provide automatic replenishment of trap seals depleted in normal service).

Commentary for $13 \cdot 6 \cdot 7.4$ and $13 \cdot 6 \cdot 7.5$

There is a need for standard test methods for the several performance characteristics addressed by $13 \cdot 6.7 .4$ and 13.6.7.5. This is recognized by all the model code organizations $[8,9,10,11]$, and one of them has provided some detailed guidelines for evaluation of innovative hydraulic systems [10].

Recent research reports $[12,13,14,15,16,17]$ describe some of the test methods that have been used in hydraulic performance testing of plumbing systems by various investigators. 
TABLE $13 \cdot 6 \cdot 7 \cdot 5-1$

Guide for Selecting Test Loads for

Plumbing Systems Comprising Up to 32 Fixtures

(Induced Siphonage Tests)

\begin{tabular}{l|l}
\hline $\begin{array}{l}\text { Number of Fixtures } \\
\text { Served by System or } \\
\text { Component Being } \\
\text { Tested }\end{array}$ & $\begin{array}{l}\text { Number of Concurrently Operating } \\
\text { Fixtures to Comprise Test Load }\end{array}$ \\
\hline 1 & 1 \\
$2-5$ & $2 *$ \\
$6-12$ & 3 \\
$13-32$ & 4 \\
\hline
\end{tabular}

*For a 2-fixture system or component, also discharge each fixture individually. 


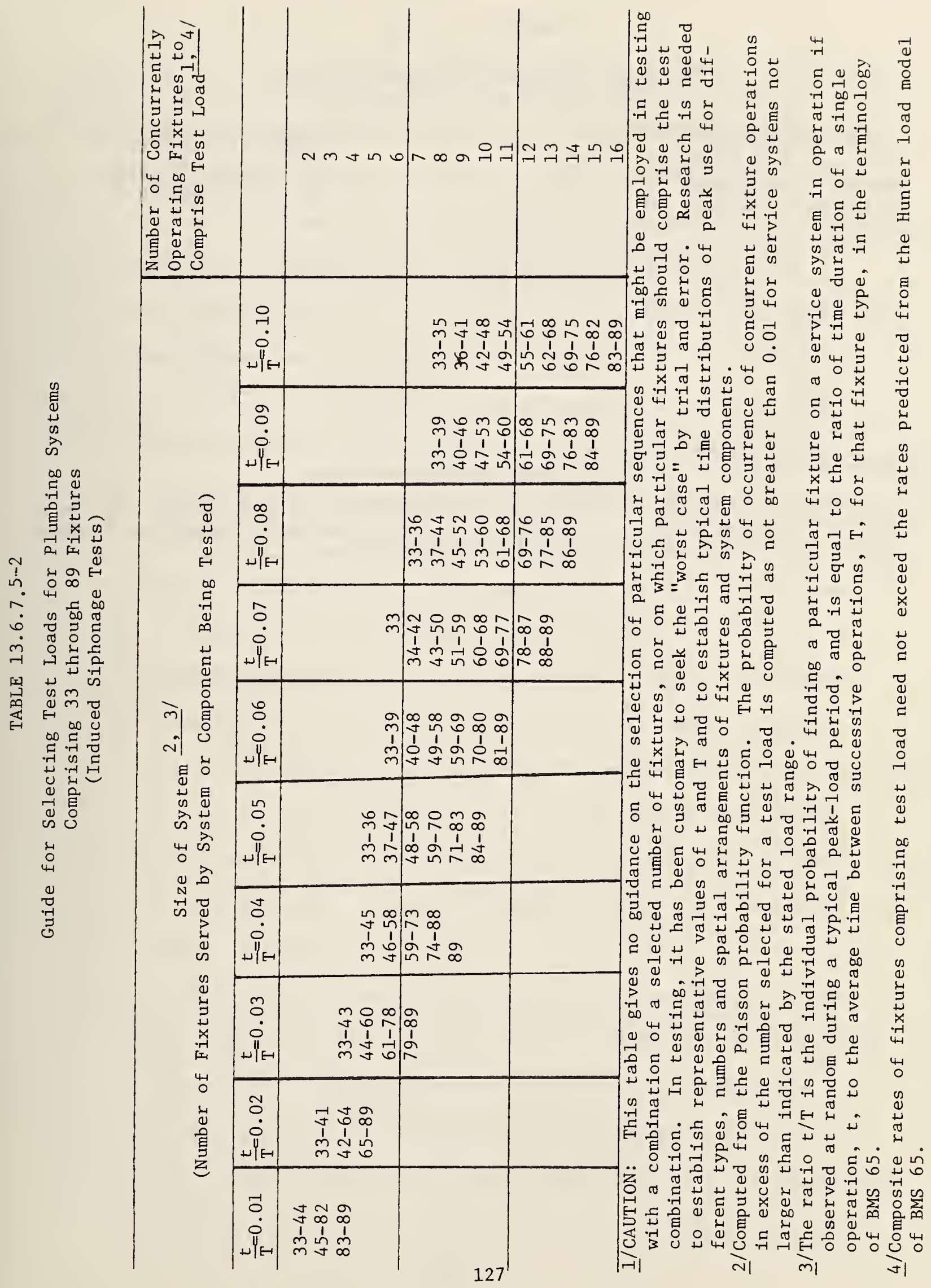


TABLE $13 \cdot 6 \cdot 7 \cdot 5-3$

Guide for Additives in Hydraulic Loads

for Drain-Waste-Vent Systems

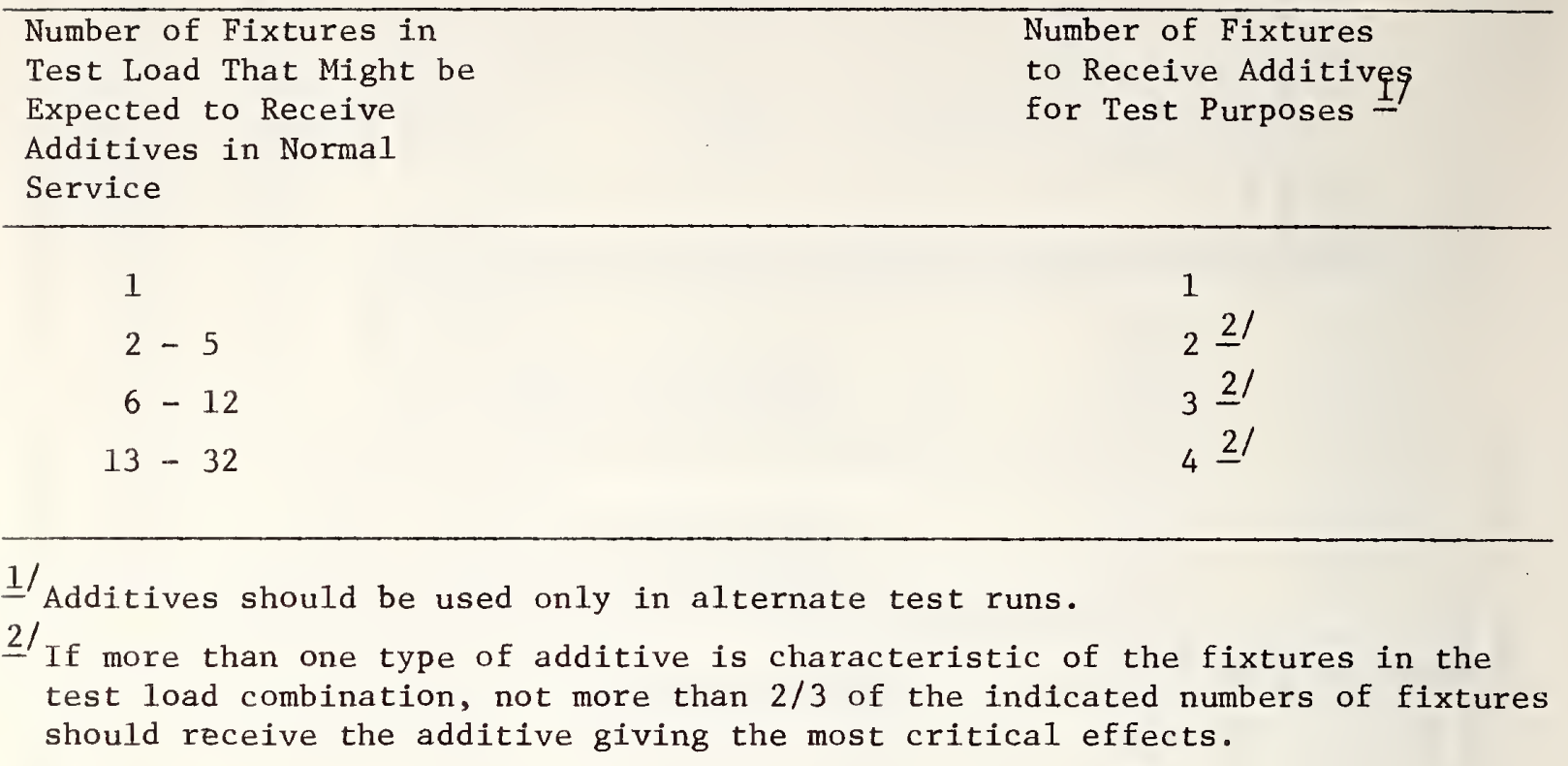


Recommendations for the Use of Tables $13.6 .7 .5-1,13.6 .7 .5-2$ and 13.6.7.5-3

1. For the application of Table 13.6.7.5-2 to the usual system having several different types of fixtures, compute an average value of $t / T$ for all the fixtures served by the system or component being tested.

2. In selecting a distribution of a particular number of test load fixtures determined from Table $13.6 .7 .5-1$ or $13.6 .7 .5-2$, the following recommendations are to be observed:

(a) For any group of fixtures within a particular branch interval, or connected to a particular branch, the number of fixtures in concurrent operation should not exceed that obtained from Table 13.6.7.5-1. Select as active fixtures those with the greatest individual peak discharge rates. Use for test purposes the number of fixtures shown in above table.

(b) Starting at the top of a multistory system, select as active fixtures those having the greatest individual peak discharge rates. The number to be discharged is obtained from Table 13.6.7.5-1 or $13 \cdot 6 \cdot 7 \cdot 5-2$ as applicable. Continue this procedure downward until approximately $50 \%$ of the total test-load discharge rate is accounted for. Observe the limitations of (a) within each branch interval.

(c) Starting at the lowest branch interval of a multistory system and continuing upward, select the active fixtures remaining after completion of the selection procedure in (b). Observe the limitations of (a) within each branch interval.

(d) Additives, such as paper diapers, sanitary napkins and detergents, should be used with the test loads if distributed in accordance 
Recommendations for the Use of Tables (Continued)

with Table 13.6.7.5-3 and if appropriate for the types of fixtures selected for discharge.

(e) If a choice in location of active fixture(s) is possible under the constraints of (a) through (d), the distribution giving the worst effects should be used. Examination of piping schematics may indicate the appropriate choice. 
$\underline{\text { References }}$

[1] Comparative Tests of Hydraulic and Flushing Performance Characteristics of Several Water Closet Tank-and-Bowl Combinations; GEBERIT Manufacturing, Inc., P.0. Box 20008, Michigan City, Indiana 46360. P. Juple and R. Wyly.

[2] Vitreous China Plumbing Fixtures, - American National Standard A112.19.2 -1973, American National Standards Institute.

[3] The Effect of Water Closet Type on Drainage System Capacity, - Plumbing Engineer, July/August and September/October, 1974. Thomas P. Konen.

[4] Discharge Characteristics of Sanitary Appliances, Description of Method for Measuring, -- Proceeding of C1B W62 Symposium on Drainage Services in Buildings, National Swedish Building Research Institute, Stockholm, Sweden, September, 1973. V. Nielsen.

[5] Laboratory Investigation of the Discharge Characteristics of Sanitary Appliances. I bid. B.J. Pink.

[6] Etude des Conditions de Vidange des Appareils Sanitaires, - Proceedings of C1B W62 Symposium on Drainage and Water Supply for Buildings, Danish Building Research Institute, Copenhagen, Denmark, September, 1974. P. Dauphin and G. Pinchon.

[7] Performance of Plumbing Fixtures and Drainage Stacks. - Housing and Home Finance Agency HRP31, 1954. F.McGhan, R. Wyly and 0. Hintz.

[8] Basic Plumbing Code (BPC) 1975. Building Officials and Code Administrators International, Inc. (BOCA), 1313 E. 60 Street, Chicago, I11inois 60637.

[9] National Standard Plumbing Code (NSPC) 1975. National Association of Plumbing-Heating-Cooling Contractors (NAPHCC) and American Society of Plumbing Engineers (ASPE), 1016 20th Street, N.W., Washington, D.C. 20036.

[10] Standard Plumbing Code (SPC) 1975. Southern Building Code Congress International, Inc. (SBCC), 3617 8th Avenue, South, Birmingham, Alabama 35222.

[11] Uniform Plumbing Code (UPC) 1976. International Association of Plumbing and Mechanical Officials (IAPMO), 5032 Alhambra Avenue, Los Angeles, California 90032 .

[12] Performance of a Single-Stack DWV System Utilizing Low-Angle Stack-Branch Confluence and Bottom Shunt Venting. National Bureau of Standards Building Science Series BSS 41 (1972). S.D. Catalog No. C13.29:2/49. R.S. Wyly and G.C. Sherlin.

[13] Demonstration of Performance for a Sovent System Installed at Towensend Tower Near East Side Urban Renewal Project for New York State Urban Development Corp., Syracuse, New York. Barnard and Maybeck, Consulting Engineers, 75 College Avenue, Rochester, N.Y. 14607 (July, 1972). E.M. Maybeck. 


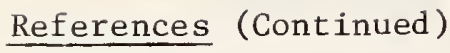

[14] Field Test of Hydraulic Performance of a Single-Stack Drainage System at the Operation BREAKTHROUGH Prototype Site in King County, Washington. National Bureau of Standards NBSIR 73-161 (May, 1973). PB 225310/LK \$4.25. R.S. Wyly and D.E. Rorrer.

[15] An Investigation of the Adequacy of Performance of Reduced-Size Vents Installed on a Ten Story Drain, Waste and Vent System. Davidson Laboratory, Stevens Institute of Technology Report SIT-DL-73-1708. (July, 1973). T. Jackson and T.P. Konen.

[16] A Test Procedure for Evaluating Capacity of Building Drainage Systems. Davidson Laboratory, Stevens Institute of Technology Report SIT-DL-75-1841 (July, 1975). P.M. Brady, Jr.

[17] Hydraulic Performance of a Full-Scale Townhouse System with Reduced-Size Vents. National Bureau of Standards Building Science Series BSS 60 (August, 1975). S.D. Catalog No. C13.29:2/60. M.J. Orloski and R.S. Wyly. 


\subsection{PLUMBING}

\section{.7 FUNCTIONAL OPERATION}

\subsubsection{Criterion: Lateral Deflection and Ring Distortion of Piping}

Essential functions of the piping shall not be compromised by intermittent and temporary changes in design direction or pitch, nor in crosssectional area or shape of the piping, during exposure to representative intermittent hot water loading $\left(140^{\circ} \mathrm{F} / 60^{\circ} \mathrm{C}\right.$ for $\mathrm{DWV}$ piping and $180^{\circ} \mathrm{F} / 82.2^{\circ} \mathrm{C}$ for residential water distribution piping) and associated pressures and thermally induced structural loads. Directional or pitch change shall not exceed arctan 0.01 (equivalent to a grade change of one in 96). The difference between maximum and minimum diameters at any cross section (diametral difference) shall not exceed $10 \%$.

\section{Method of Evaluation for 13.6.7.6}

Evaluation shall be based on analysis of the data provided, and on inspection where appropriate.

No standard test method exists. However, evaluation may be facilitated by utilization of information given in selected references- $[1,2,3]$.

\section{Commentary for $13 \cdot 6.7 .6$}

Adequate hydraulic capacity is essential for the purposes of the basic functional requirements. Satisfaction of this requirement is facilitated by materials and designs that provide for the minimization of, or satisfactory accomodation to, intermittent changes in cross sectional area and shape, and for the minimization of or satisfactory accomodations to, laterial movement or deflection under ordinary service conditions. 
13.6 PLUMBING

.7 FUNCTIONAL OPERATION

\subsubsection{6 (Continued)}

Hydraulic carrying capacities, venting and self-scouring capability are dependent on the continuous maintenance of design pitch in "horizontal" lines and on the maintenance of initial cross-sectional area and shape in both horizontal and vertical lines. Pitch changes of more than arctan 0.01 in horizontal lines can adversely affect self-scouring capability, venting effectiveness and hydraulic capacity. Directional changes of more than arctan 0.01 in either vertical or horizontal lines can adversely affect acoustic performance. Diametral differences greater than $10 \%$ may indicate structural instability of the pipe. A reasonable limit for crosssectional area change needs to be established. A suitable test procedure should provide for a reproducible, representative loading cycle, applied to a representative assembly of pipe, fittings, supports and attachments. The minimum level of performance established should be consistent with the essential requirements for fluid-transport capacity of the piping system, and consistent with the general capability of the trade to provide the corresponding necessary precision in installation detail. Some of the test procedures that have been utilized in experimentation have been summarized in Reference 1.

The test employed should be designed for extended application to serve the needs of 13.6.6.3. Probably the purposes of 13.6.7.6 would be served by measurements made during the first 100 cycles of an extended cyclic hot water exposure test suitable for the purposes of 13.6.6.3.

Satisfactory accomodation to intermittent, relatively small temporary changes in pipe length or lateral deflection can usually be provided through 


\subsection{PLUMBING}

\section{.7 FUNCTIONAL OPERATION}

13.6.7.6 (Continued)

design and installation detail to minimize the effects of these changes.

\section{$\underline{\text { References }}$}

[1] Laboratory Tests of Selected Thermoplastic Piping Assemblies Subjected to Water Hammer and Intermittent Hot-Water Flow. D.E. Rorrer, J.R. Shaver and R.S. Wyly National Bureau of Standards NBSIR 77-1261, August 1977.

[2] The Deflection of Thermoplastic Pipe Resulting from Thermal Cycling. Robert C. Wilging, Engineered Plumbing Exposition, American Society of Plumbing Engineers, Chicago, I11. September 1970.

[3] Elevated Temperature Cycling Test., Appendix G, British Standard 4514:1969, Specification for UPVC Soil and Ventilating Pipe, Fittings and Accessories. British Standards Institution, London. 


\subsection{PLUMBING}

\section{.7 FUNCTIONAL OPERATION}

\subsubsection{Criterion: Noise Reduction Between Spaces Within a Living}

Unit, Through Walls and Partitions Containing Piping

The design and installation of the plumbing systems, taken together with that of the wall, chase, or partition in which the piping is enclosed, sha11 be such that a noise reduction of at least NIC 28 can be attained within a living unit between spaces where noise insulation is intended. As a design guide, the STC rating of the walls, determined by documentation or laboratory measurement, should be at least 7 units greater than the NIC value given.

Method of Evaluation for 13.6.7.7

The NIC ratings shall be determined by tests of prototype or field units.

The following test methods are applicable:

Appendix A1 of ASTM E336, "Standard Recommended Practice for Measurement of Airborne Sound Insulation in Buildings" (for NIC).

ASTM E90, "Standard Recommended Practice for Laboratory Measurement of Airborne Sound Transmission Loss of Building Partitions"(for STC). ASTM E413, "Standard Classification for Determination of Sound Transmission Class." (This is used for both NIC and STC determination).

Commentary for $13 \cdot 6 \cdot 7.7$

The NIC rating is based upon noise reduction, which is a measure of the sound isolation between two enclosed spaces, the source space and 


\subsection{PLUMBING}

\section{.7 FUNCTIONAL OPERATION}

\subsubsection{7 (Continued)}

the receiving space, and is not necessarily a function of the dividing partition alone since it is affected by any flanking paths.

The STC rating is a laboratory measure of the best sound isolation that could be obtained with a given partition design. It specifically excludes the effects of any flanking paths, and is usually somewhat better than field performance. When the STC rating cannot be justified by published data for similar partitions or by computation using appropriate analysis, laboratory measurements shall be made. Results should be obtained prior to construction.

As a design guide, STC-type measurements of completed assemblies (with all plumbing installed) may be made in the laboratory to help predict attainment of the required field performance.

\subsubsection{Criterion: Noise Reduction Between Spaces Within a Living Unit, Through Floor-Ceilings Containing Piping}

The design and installation of the plumbing system, taken together with that of the chase or floor-ceiling in which the piping is enclosed, shall be such that a noise reduction of at least NIC 28 and field IIC 28 can be attained within a living unit between spaces where noise insulation is intended.

As a design guide, the STC and IIC ratings of the floor-ceiling assemblies determined by documentation or laboratory measurements should be at least 7 units greater than the NIC and field IIC values given. 


\subsection{PLUMBING}

.7 EUNCTIONAL OPERATION

\subsubsection{8 (Continued)}

Method of Evaluation for 13.6.7.8

The NIC and field IIC ratings shall be determined by tests of prototype or field units.

The following test methods are applicable:

Appendix Al of ASTM E336, "Standard Recommended Practice for Measurement of Airborne Sound Insulation in Building" (for NIC).

ASTM E90, "Standard Recommended Practice for Laboratory Measurement of Airborne Sound Transmission Loss of Building Partitions" (for STC). ASTM E413, "Standard Classification for Determination of Sound Transmission Class." (This is used for both NIC and STC determination.)

ASTM E492, "Tentative Method of Laboratory Measurement of Impact Sound Transmission Through Floor-Ceiling Assemblies Using the Tapping Machine." This is used for both laboratory and field measurements.

\subsubsection{Criterion: Noise Level in Interior Spaces During Operation of} Plumbing Systems

Noise in interior spaces shall be kept below a level which will cause discomfort or annoyance to the occupants. Each plumbing system element shall perform its intended function without excessive noise generation or compromise of the acoustical performance of other building elements. The design and installation of the plumbing system, taken together with that of the plumbing wall, chase, floor-ceiling or partition 


\subsection{PLUMBING}

\section{.7 FUNCTIONAL OPERATJON}

\subsubsection{9 (Continued)}

in which the piping is enclosed, shall be such that the A-weightedsound levels in interior living spaces shall not exceed $45 \mathrm{~dB}$ during the imposition of typical hydraulic loads (drainage and water supply).

\section{Method of Evaluation for 13.6.7.9}

Measurement of sound pressure levels in living spaces of unoccupied prototypes after completion with all plumbing systems installed and in operation.

The following test method is applicable:

ANSI S1.13, "Standard Methods for the Measurement of Sound Pressure Levels." (Sound levels resulting from interior building sources shall be read on a meter with fast-response characteristic and weighted on the A-scale as defined for Sound Level Meters.)

Commentary for $13 \cdot 6 \cdot 7.9$

Standard Methods of hydraulic loading are needed to simulate representative acoustic effects for measurement under Criterion 13.6.7.9. Possibly hydraulic loads similar to those suggested for $13.6 .7 .2,13.6 .7 .4$ and 13.6.7.5 would suffice for this purpose. Noise levels associated with water flow in supply and drainage piping systems, as well as in fixtures and appliances, should be determined.

Investigation may be needed as to whether this criterion and the indicated hydraulic loading should be applicable between living units as well as inside a particular living unit. 


\subsection{PLUMBING}

\section{.7 FUNCTIONAL OPERATION}

\subsubsection{Criterion: Elution of Toxic Substances}

Materials used for potable water service and distribution systems shall not contribute to a health hazard through contamination of the potable water. The purity of the potable water at the points of use shall meet the levels in the Public Health Service Drinking Water Standards:[1]as amended by the National Interim Primary Drinking Water Regulations [2]. Inorganic chemical contaminants shall not exceed the levels set forth in Table 13.6.7.10.

TABLE $13 \cdot 6 \cdot 7 \cdot 10$

\section{Maximum Contaminant Levels}

Inorganic Chemicals:

\begin{tabular}{|c|c|}
\hline Contaminant & $\begin{array}{l}\text { Level, } \\
\text { milligrams } \\
\text { per liter }\end{array}$ \\
\hline Arsenic $\ldots \ldots \ldots \ldots \ldots \ldots \ldots$ & 0.05 \\
\hline 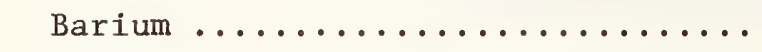 & 1. \\
\hline Cadmium $\ldots \ldots \ldots \ldots \ldots \ldots \ldots$ & 0.010 \\
\hline 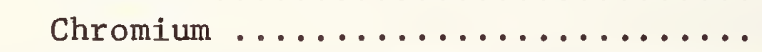 & 0.05 \\
\hline Lead $\ldots \ldots \ldots \ldots \ldots \ldots \ldots \ldots$ & 0.05 \\
\hline Mercury $\ldots \ldots \ldots \ldots \ldots \ldots \ldots$ & 0.002 \\
\hline Nitrate (as $N) \ldots \ldots \ldots \ldots . . . \ldots$ & 10 \\
\hline 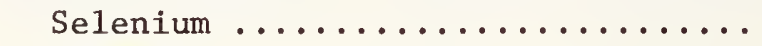 & 0.01 \\
\hline Silver $\ldots \ldots \ldots \ldots \ldots \ldots \ldots \ldots$ & 0.05 \\
\hline
\end{tabular}

Method of Evaluation for 13.6.7.10

The test procedure for extraction of inorganic chemicals shall be as promulgated by the National Sanitation Foundation $[3,4]$ and recommended by a task group of the Federal Construction Council - Building Research Advisory Board [5.]. All innovative piping materials used in the potable 


\subsection{PLUMBING}

\section{.7 FUNCTIONAL OPERATION}

\subsubsection{0 (Continued)}

water service and distribution systems shall be approved as toxicologically suitable for the purpose by a generally recognized testing/evaluating agency. One such agency is the National Sanitation Foundation Testing Laboratory .

\section{Commentary for 13.6.7.10}

The test recommended appears adequate for inorganic chemical contaminants. However, no test has been developed for possible contaminants or other effects from potential organic growth on the interior of the pipe.

Generally, lead pipe and fittings shall not be used to convey potable water, nor shall pipe and fittings be used, in the conveyance of potable water, that are manufactured with a process that leaves a residue of lead compound on the interior surface of the piping, nor shall the materials as installed contribute to deleterious elution of lead compounds into the potable water.

Surveillance of the literature is recommended to determine whether a need exists for the development of new tests for elution or impartation of other contaminants.

In the installation or major repairs of potable water systems, sterilization shall be accomplished in accordance with generally accepted practice, and piping which has previously been used for any purpose other than for conveying potable water shall not be used for conveying potable water $[6,7,8,9,10]$. 
13.6 PLUMBING

.7 FUNCTIONAL OPERATION

\subsubsection{0 (Continued)}

\section{References}

[1] Public Health Service Drinking Water Standards - 1962, PHS Publication No. 956. Superintendent of Documents, U.S. Government Printing Office, Washington, D.C. 20402.

[2] National Interim Primary Drinking Water Regulations, Environmental Protection Agency Water Programs, Subchapter D, Part 141, Federal Register, Volume 40, No. 248, December 24, 1975. Superintendent of Documents, U.S. Government Printing Office, Washington, D.C. 20402.

[3] A Study of Plastic Pipe for Potable Water Supplies, W.D. Tiedman and N.A. Milone, June 1955, National Sanitation Foundation, P.0. Box 1468, 2355 West Stadium Blvd., Ann Arbor, Michigan 48106.

[4] National Sanitation Foundation Standard No. 14. "Thermoplastic MaterialsPipe, Fittings, Valves, Jointing Materials," October 1965. National Sanitation: P.O. Box 1468, 2355 West Stadium Blvd., Ann Arbor, Michigan 48106.

[5] Thermoplastic Piping for Potable Water Distribution Systems, BRAB/FCC Technical Report No. 61, 1971, National Academy of Sciences - National Research Council, 2101 Constitution Avenue, Washington, D.C. 20418.

[6] Basic Plumbing Code (BPC), Building Officials and Code Administrators International, Inc. (BOCA), 1313 E. 60 Street, Chicago, I1linois 60637.

[7] National Standard Plumbing Code (NSPC), American Society of PlumbingHeating-Cooling Contractors (NAPHCC) and American Society of Plumbing Engineers (ASPE), 1016 20th Street, N.W., Washington, D.C. 20036.

[8] Standard Plumbing Code (SPC), Southern Building Code Congress International, Inc. (SBCC), 3617 8th Avenue, South Birmingham, Alabama 35222.

[9] Uniform Plumbing Code (UPC), International Association of Plumbing and Mechanical Officials (IAPMO), 5032 Alhambra Ave., Los Angeies, CA 90032.

[10] AWWA Standard for Disinfecting Water Mains, AWW C101, American Water Works Association, 2 Park Avenue, New York, New York 10016. 


\subsection{ELECTRICAL}

\section{.1 ACCIDENT PROTECTION AND SECURITY}

\subsubsection{Criterion: Safety of Electrical Components, Designs and}

\section{Installation}

When special components or systems are proposed which do not conform to the National Electrical Code (NEC), documentation shall be provided to demonstrate that the intent of the NEC has been satisfied.

Method of Evaluation for 13.7.1.1

Evaluation of features and components deviating from the National Electrical Code; inspection and/or testing of such components; if necessary evaluation, inspection and testing of prototype components or installations. 


\subsection{ELECTRICAL}

6 DURABILITY/MAINTAINABILITY

\subsubsection{Criterion: Resistance to Deterioration}

The properties of electrical wiring and equipment deviating from NEC shall be free from degradating changes with time that can result in excessive deterioration or unsafe conditions.

Method of Evaluation for 13.7.6.1

Accelerated performance tests made on such wiring and equipment, e.g., UL 20, 498, 514 and/or other methods acceptable to HUD should be used to ensure stability of temperature and materials properties. 


\subsection{HARDWARE AND SPECIALITIES}

\section{DURABILITY/MAINTAINABILITY}

\subsubsection{Criterion: Functional Life of Hardware}

Building hardware shall retain its original appearance and operating characteristics for the number of operating cycles appropriate to its grade.

\section{Method of Evaluation for 13.8.6.1}

Performance tests will be approved by the accepting authority from the appropriate standards of BHMA, ANSI, ASTM, Federal and will be for at least the minimum grades of hardware listed.

Examples of standards for performance tests are listed below:

$$
\text { Table } 13.8-1
$$

Components

Cabinet Hardware

Door Controls (closers)

Door Controls (overhead holders)

Sliding and Folding Door Hardware

Auxiliary Locks

Locks and Lock Trim

Exit Devices

Architectural Door Trim

Spring Hinges

Auxiliary Hardware

Materials and Finishes

Butts and Hinges
Standard

BHMA 201

BHMA 301

BHMA 311

BHMA 401

BHMA 501

BHMA 601

BHMA 701

BHMA 1001

BHMA 1101

BHMA 1201

BHMA 1301

ANSI A156.1 


\subsection{HARDWARE AND SPECIALITIES}

.6 DURABILITY/MAINTAINABILITY

13.8.6.1 (Continued)

Table 13.8-1 (Continued)

Components

Salt Spray Test

Hardware, Builder's; Locks and Door Trim

Aluminum Sliding Glass Doors
Standard

ASTM B117-64

(Federal) FF-H-106

ANSI A134.2 


\subsection{HARDWARE AND SPECIALITIES}

\section{.7 FUNCTIONAL OPERATION}

\subsubsection{Criterion: Functional Compatibility}

Individual items of hardware in an assembly shall be compatible.

\section{Method of Evaluation for 13.8.7.1}

The performance tests required (see Table 13.8-1) may be expanded to include a test of the assembly. Operating forces shall be

applied to knobs and pulls and operating cycles shall include engagement of latches or catches with opening stops where appropriate. The force of this contact and/or engagement shall be twice that specified for the latch or catch. 


\subsection{APPLIANCES}

\section{.7 FUNCTIONAL OPERATION}

\subsubsection{Criterion: Performance of Appliances}

Each major appliance shall perform its design function with capacity to meet the design need with minimum practical energy consumption. Major appliances are those items provided with the building such as: ranges, refrigerators, ventilation fans, dishwashers, clothes washers and dryers, garbage disposal units and trash compactors.

\section{Methods of Evaluation for 13.9.7.1}

Tests of appliances will be based on recognized industry standards, or on other tests as required by the accepting authority. The sponsor shall identify the standards used in the selection of the appliances and may recommend means of evaluation/test. Manufacturer's performance data and engineering information, including functional and safety certification shall be provided. 


\section{APPENDIX A}

\section{DEFINITIONS}

Active Fixture: A fixture that is operating for the purpose of creating or contributing to a hydraulic test load, or that is operating under service conditions.

Acoustical Design: A consideration of all factors bearing on the achievement of a desirable acoustical environment, including the selection of sites, orientation of buildings, space arrangements within buildings, and proper selection and installation of wall and floor assemblies, building equipment, and service.

Acoustical Privacy: The provision for sufficient isolation from intruding and disturbing noises.

Acoustical Treatment: The application or use of any sound absorbers, building materials, or construction techniques for purposes of controlling noise and improving the acoustical environment.

Air Chamber: A device containing air or inert gas having greater compressibility than water, design to be installed in a water distribution system for the purpose of controlling water hammer through limitation of pressure rise and shock effect accompanying the closure of valves.

Airborne Sound: Sound that reaches the point of interest by propagation through air.

Applicable Requirement (Criterion): Where a structure or component serves more than one purpose and where differing requirements or criteria apply, the most restrictive shall be applicable.

Background Noise: The sound level present in a room or space at any given time above which speech, music, desired signal, or sound must be raised in order to be heard or made intelligible.

Back Vent: A back vent is a branch vent installed primarily for the purpose of protecting fixture traps from self-siphonage.

Backwater: Excessive hydrostatic head in a building drain caused by an overloaded public sewer, sometimes causing backing up of sewerage into the building through floor drains and plumbing fixtures.

Blow-Back: Ejection of liquids, suds, air, or other gases through the trap seal to the room side of a trap as a result of excessive pneumatic, hydrostatic, or hydrodynamic pressure (back-pressure) on the drain side of the trap.

Branch: Any part of the piping system other than a main, riser, or stack. 
Built-up Roofing Membrane: Composed of alternate layers of materials to form a flexible roof cover with sufficient strength to resist normal expansion and contraction forces. A top surfacing generally composed of mineral aggregate, may be included in the built-up roofing membrane.

Calk: An elastic non-setting material used for sealing cracks, seams and joints to prevent leakage of sound or infiltration of outside air.

Combustible Materials: Materials with a potential heat of more than 3200 $\mathrm{Btu} / 1 \mathrm{~b}$. and complies with NFPA 220.

Common Vent: A vent connecting at the junction of two fixture drains and serving as a vent for both fixtures.

Creep: Time-dependent deformation caused by sustained loads.

Cross Flow: The movement of waste water from the trap of an operating (active) fixture to the trap of a non-operating (idle) fixture, or from an active to an idle drain.

Decibel (Symbol $d B$ ): The unit of measurement for the relative loudness of sounds, equal approximately to the smallest degree of difference ordinarily detectable by the human ear. More technically, the decibel is used as the unit for the logarithmic expression of ratios of power, voltage, or current.

Deflection: The displacement of a point in a structure caused by the application of loads or other actions specifically defined in these criteria.

Gross Deflection: The total deflection at a point.

Inelastic Deflection: Same as Residual Deflection. (See below)

Net Deflection: Deflection attributable solely to the deformation of a structural member of assembly, measured relative to a specified coordinate system.

Residual Deflection: The gross or net deflection at a point which remains after removal of superimposed loads.

\section{Drainage:}

Conventionally-Vented Drainage: The traditional type of sanitary drainage system in which drainage is accomplished through soil and/ or waste stacks, and venting is accomplished by the appropriate use of vent stacks and individual, common, wet, branch, and relief vents.

Single-Stack Drainage: A type of sanitary drainage system in which drainage and venting is accomplished by one means or another in a single stack without the use of a vent stack and individual, wet, 
and branch vents. In "modified single-stack drainage," limited use is made of relief vents.

Controlled Flow Storm-Water Drainage: A type of storm drainage that temporarily stores a significant portion of the precipitation on a roof or other catchment area and permits it to drain off over a period of hours at a relatively low rate of discharge.

Instantaneous Storm-Water Drainage: The conventional type of storm drainage that provides for removal of water as rapidly as it is received, without storage on the roof or other catchment area.

Drift: Horizontal gross deflection measured at a floor level.

Ductility Factor: A factor measuring the ductility of structural assemblies, defined in Section 13.2.4.1.

DWV System: The drain-waste-vent system, including all sanitary drainage and venting piping.

Fixture Drain (also called Trap Arm): The drain from the trap of a fixture to the junction of that drain with any other drain pipe.

Fixture Unit (Drainage): The term fixture unit identifies a measure of the problem peak demand on the water supply system or peak discharge into the drainage system by various types of plumbing fixtures. The fixture unit value for a particular fixture depends on its volume rate of supply demand on drainage discharge, on the time duration of a single supply or drainage operation, and on the average time between excessive operations during peak use periods.

Fixture Unit Load: Is the sum of the numerical values of the fixture unit ratings for all the fixtures connected to a plumbing system or portion thereof.

Flat Roof: A roof whose design incorporates a slope to drain of at least $1 / 4^{\prime \prime}$ or not more than $2^{\prime \prime}$ per foot.

Flexible Coupler: A device to prevent or reduce the transmission of vibration, particularly between vibrating equipment and service distribution systems involving ductwork, piping, and electrical lines.

Flood-Level Rim: The top edge of a receptacle or fixture bowl from which water can overflow in the absence of or malfunction of an overflow device.

F1ow:

Cross Flow: The flow of water in a sanitary drainage system so directed that it enters an idle horizontal drain or trap in a manner contrary to generally accepted good practice in plumbing design. 
Interfixture Flow Retardation: A decrease in normal discharge rate and an accompanying lengthening in normal period of discharge of one or more other fixtures.

Group Vent: A branch vent that performs its functions for two or more traps.

Horizontal Pipe: Any pipe or fitting which makes an angle of less than $35^{\circ}$ with the horizontal.

Hydrodynamic Back Pressure: A significant static head of water in idle drains caused by the discharge of a fixture or fixtures resulting in extreme cases in backing-up of waste water into idle fixtures.

Idle Fixture: A fixture that is not operating during the imposition of a hydraulic load by fixtures in operation.

Impact Sound: The sound produced by the impinging or striking of one object with another, e.g., sound caused by footsteps.

Induced Siphonage: The process whereby a reduction in the surface level of a trap seal of a fixture is caused by the discharge of other fixtures on the system, such discharge resulting in transient local pressure fluctuations that siphon or otherwise remove water from the trap.

Indirect Waste Pipe: A waste pipe which does not connect directly with the drainage system, but which discharges into the drainage system through an air break or air gap into a trap, flxture, receptor, or interceptor.

Load:

Design Load (Plumbing): The volume rate of flow that is predicted to occur in a pipe or piping system with sufficient frequency to warrant its utilization as a design value.

Earthquake Load (E): A load caused by seismic disturbances.

Restraint Load: A load caused by the resistance of structural elements to dimensional changes or to reactive displacements.

Service Load: A maximum load which has a specified mean recurrence interval; e.g., a 50-year load has a mean recurrence interval of 50 years, or a probability of 1 in 50 to be exceeded in any 1-year period.

Soil and Hydrostatic Load - A load resulting from pressure exerted and transmitted by surrounding soil, ground water, and flood water.

Superimposed Load: A load applied to a structure exclusive of dead loads. 
Sustained Load: A load that is sustained over a period of time.

Wind Load (W): A load caused by wind effects, referenced to a basic wind speed of a given mean recurrence interval, where the basic wind speed is the extreme-mile windspeed 30 feet above ground.

Length of Member: Unless otherwise noted, the length of a member is taken as its length between the centerline of its supports, or the clear distance between supports plus the member depth, whichever is smaller. For the determination of vertical and horizontal deflection limits only, the equivalent "length" of cantilever members is taken as twice their actual length from the free end of the support.

Limited Combustible Materials: Unless otherwise stated material with a potential heat of no greater than $3500 \mathrm{Btu}$ per $1 \mathrm{~b}$. and complies with NFPA 220.

Noise: Unwanted sounds

Noise Isolation Class (NIC): A single rating obtained by field measurements which provides an estimate of the noise isolation between two enclosed spaces. It may or may not include flanking naths.

P-Trap: The P-trap, resembling an inverted siphon, is one of several designs of devices used in drains to provide a water seal against passage of sewer gases, odors, vermin, etc., into the building.

Physical Stimulation: A test procedure designed to closely simulate the behavior of the actual structure in order to determine its response to the loads it is likely to receive during its service life.

Pipe: A term applied generally to tubular products and materials commonly used to conduct or transportfluids or gases. As a specific nomenclature, "pipe" usually has greater wall thickness than similar products called "tube" or "tubing."

Piping: A term with broader meaning than "pipe." For example, "cold water piping" includes the pipe, tube, or tubing used to conduct the cold water, the fittings used to change the direction of flow or change the size of pipe, tube, or tubing, and the direction of flow. "Hot water piping" and "drainage piping" have similarly broad meanings.

Potential Heat: The difference between the heat of combustion of a representative specimen of material and the heat of combustion of any residue remaining after exposure to a simulated standard fire, determined by combustion calorimetric.

Pressure Shock: Same as Water Hammer.

Recirculation: Recirculation in a DWV system is the flow of air within the network comprised of interconnected vent piping, to meet the demand for air in critical areas inside the system as water is discharged from the fixture. 
Reduced-Size Venting: A type of venting which utilizes dry vent sizes smaller than permitted by most plumbing codes. Such reduced-size vents are limited to locations not lower than 6 inches above effective flood level for the fixtures involved.

Resonance: The sympathetic vibration, resounding, or ringing of enclosures, room surfaces, panels, etc., when exclted at their natural frequencles.

Reverberation: The persistance of sound within a room or enclosure after a sound source has stopped radiating. This effect is very pronounced in large, relatively empty or partially furnished rooms with hard reflecting walls, celling, or floor surfaces.

Roofing: (See Built-Up Roofing) The top waterproof covering component of the roof system.

Roof System: A covering on top of a building, including roofing, insulation, and deck, employed for the principal purpose of excluding the elements.

Roof-edge Scupper: A suitably sized, shaped and located opening provided in a parapet wall for the prevention of an excessive accumulation of water on a roof in the event of precipitation or clogged drains.

Roughing-In: A term indicating the installation of all parts of the plumbing system which can be completed prior to the installation of the plumbing fixtures and their traps. This includes drainage, water supply, vent piping and the necessary fixture backing/supports, and any fixtures that are built into the structure.

Self-Siphonage: Reduction in trap seal of a fixture caused solely by the discharge of the fixture.

Sound: The sensation of sound or a branch of physics concerned with the propagation of mechanical disturbances in matter and related subjects. In this context, sound is originated by vibrating bodies or aerodynamically, is propagated as an elastic disturbance at least partly in the air, and arrives at the ear or other receiver (microphone, etc.).

Sound Attenuation: The reduction of the energy or intensity of sound.

Sound Frequency: The number of vibrations that a source of sound makes in one second measured in hertz (cycles per second).

Sound Insulation, Isolation: The use of building materials or construction which will reduce or resist the transmission of sound.

Sound Leak: A hole, crack, or opening which permits the passage of sound. 
Sound Pressure: A fluctuation superimposed on the static atmosphere pressure by the passage of sound waves.

Sound Pressure Level (SPL): Expressed in decibels, the SPL is 20 times the logarithm to the base 10 of the ratio of the pressure of sound to the reference pressure 20 micronewtons per square meter ( 0.02 microbar).

Sound Transmission Class (STC): A rating obtained by laboratory measurements providing a convenient method of rating the airborne sound insulation performances of various wall and floor systems partition or floor by its location on the ASTM E 90 contour chart according to criteria set forth in the standard.

Structural Failure: Failure of a structure or any structural components is one of the following:

a. Sudden, locally-increased curvature, major spalling, or structural collapse.

b. Inability to resist a further increase in load.

c. An increase in deflection of no less than the maximum allowable deflection under service load conditions, occurring during any 10-minute period after application of the superimposed load without increase in the applied load.

d. Any deformation or other damage in a load-supporting structural member or assembly (see definition) that would permanently impair the load-supporting function of that member or assembly.

Structureborne Sound: Sound energy imparted directly to and transmitted by solid materials such as building structures.

Trap: A fitting or device constructed so as to provide, when properly vented, a water seal for protection against the emission of noxious or explosive sewer gases, without significantly retarding the flow of sewerage or waste water through it.

Trap-Seal Reduction: A loss of trap-seal depth.

Trap-Seal Retention: The amount of trap-seal retained.

Vent Stack: A vertical vent pipe extending through one or more stories, installed to provide circulation of air between different elements of the DWV system. Usually, the vent stack is the vertical main of the vent system to which branch vents are connected.

Vent Terminal: The portion of a vent pipe that extends through the roof, wall, or gable of a building to the atmosphere. 
NBS. II AA (REV. 7.73)

\begin{tabular}{|c|c|c|c|}
\hline $\begin{array}{l}\text { BIBLIOGRA. OF COMM. } \\
\text { SHEET }\end{array}$ & $\begin{array}{l}\text { 1. PUBLICATION OR REPORT NO. } \\
\text { NBSIR }-77-1316\end{array}$ & $\begin{array}{l}\text { 2. Gov't Accession } \\
\text { No. }\end{array}$ & 3. Recipient's Accession No. \\
\hline \multirow{2}{*}{\multicolumn{3}{|c|}{ Performance Criteria Document for Innovative }} & $\begin{array}{l}\text { 5. Publication Date } \\
\text { November } 1977\end{array}$ \\
\hline & & & 6. Performing Organization Code \\
\hline 7. AUTHOR(S) Thomas 1 & Faison & & 8. Performing Otgan. Report No. \\
\hline \multicolumn{3}{|c|}{ 9. PERFORMING ORGANIZATION NAME AND ADDRESS } & 10. Project/Task/Work Unit No. \\
\hline \multicolumn{3}{|c|}{$\begin{array}{l}\text { 12. Sponsoring Organization Name and Complete Address (Street, City, State, ZIP) } \\
\text { Department of Housing and Urban Development } \\
\text { Division of Energy, Building Technology \& Standards } \\
\text { Office of Policy Development and Research } \\
\text { Washington, D.C. } 20410\end{array}$} & $\begin{array}{l}\text { 13. Type of Report \& Period } \\
\text { Covered }\end{array}$ \\
\hline
\end{tabular}

15. SUPPLEMENTARY NOTES

16. ABSTRACT (A 200-word or less factual summary of most significant information. If document includes a significant bibliography or literature survey, mention it here.)

Performance criteria for innovative construction are presented in this resource report in order to assist in the broad technical acceptance of new building products and materials. The levels of performance stated are intended to be equivalent to the Minimum Property Standards (MPS) which reflects acceptable performance of conventional building materials and designs for programs sponsored by the Department of Housing and Urban Development. The report is structured so that new performance criteria can be added in the future as additional technical data and evaluation methods become available.

17. KEY WORDS (six to twelve entries; alphabetical order; capitalize only the first letter of the first key word unless a proper name; separated by semicolons) acoustics; appliances; atmospheric; environment; durability; electrical; housing technology; HVAC; maintainability; materials; minimum property standards; performance criteria; performance evaluation; plumbing; safety; innovative construction; structures; test methods.

18. AVAILABILITY $\mathrm{XX}$ Unimited

[? For Official Distribution. Do Not Release to NTIS

[] Order From Sup, of Doc., U.S. Government Printing Office Washington, D.C. 20402, SD Cat. No. C13

X Order From National Technical Information Service (NTIS) Springfield, Virginia 22151

\begin{tabular}{|c|c|}
\hline $\begin{array}{l}\text { 19. SECURITY CLASS } \\
\text { (THIS REPURT) }\end{array}$ & $\begin{array}{l}\text { 21. NO. OF PAGES } \\
162\end{array}$ \\
\hline UNCL ASSIF IED & \\
\hline $\begin{array}{l}\text { 20. SECURITY CLASS } \\
\text { (THIS PAGE) } \\
\text { UNCLASSIFIED }\end{array}$ & $\begin{array}{l}\text { 22. Price } \\
\$ 8.00\end{array}$ \\
\hline
\end{tabular}

